ANNOUNCEMENT

Assistance Recipients and Non-M\&O/M\&I Contractors

PART I: STI PRODUCT DESCRIPTION

(To be completed by Recipient/Contractor

A. STI Product Identifiers

1. REPORT/PRODUCT NUMBER(s)

Final Report

2. DOE AWARD/CONTRACT NUMBER(s)

DE-FG36-05G015085

3. OTHER IDENTIFYING NUMBER(s)

B. Recipient/Contractor

UOP LLC

C. STI Product Title

OPPORTUNITIES FOR

BIORENEWABLES IN OIL REFINERIES

FINAL TECHNICAL REPORT

\section{Author(s)}

Marker, T.L.

E-mail Address(es):

Terry.Marker@UOP.COM

\section{E. STI Product Issue Date/Date of Publication}

$12 / 12 / 05$

(mm/dd/yyyy)

F. STI Product Type (Select only one)

$X \quad$ 1. TECHNICAL REPORT

X Final $\square$ Other (specify)

2. CONFERENCE PAPER/PROCEEDINGS

Conference Information (title, location, dates)

\section{JOURNAL ARTICLE}

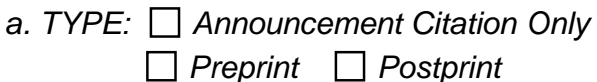

b. JOURNAL NAME

c. VOLUME d. ISSUE

e. SERIAL IDENTIFIER (e.g. ISSN or CODEN)

OTHER, SPECIFY

G. STI Product Reporting Period ( $\mathrm{mm} / \mathrm{dd} / \mathrm{yyyy})$

$06 / 07 / 2005$

Thru

$12 / 12 / 05$
H. Sponsoring DOE Program Office

Office of Biomass

I. Subject Categories (list primary one first)

Biomass, Petroleum, Refining, Co-processing

Keywords

J. Description/Abstract

Attached on page 2

K. Intellectual Property/Distribution Limitations

(must select at least one; if uncertain contact your Contracting Officer (CO))

X 1. UNLIMITED ANNOUNCEMENT (available to

U.S. and non-U.S. public; the Government assumes no liability for disclosure of such data)

2. COPYRIGHTED MATERIAL: Are there any restrictions based on copyright? $\square$ Yes $\square$ No If yes, list the restrictions as retained in your contract

3. PATENTABLE MATERIAL: THERE IS

PATENTABLE MATERIAL IN THE DOCUMENT INVENTION DISLOSURE SUBMITTED TO DOE: DOE Docket Number: S-

(Sections are marked as restricted distribution pursuant to 35 USC 205)

4. PROTECTED DATA: $\square$ CRADA $\square$ other If other, specify

Release date ( $\mathrm{mm} / \mathrm{dd} / \mathrm{yyyy})$

5. SMALL BUSINESS INNOVATION RESEARCH (SBIR) DATA

Release date (Required,

(No more than 4 years from date listed in part 1.E above)

6. SMALL BUSINESS TRANSFER (STTR) DATA

Release date (Required,

No more than 4 years from date listed in part 1.E above)

7. OFFICE OF NUCLEAR ENERGY APPLIED TECHNOLOGY

L. Recipient/Contractor Point of Contact Contact for additional information (contact or organization name to be included in published citations and who would receive any external questions about the content of the STI Product or the research contained therein)

Name and/or Position

Richard Marinangeli, Manager New Directions

E-mail Phone

Richard.Marinangeli@uop.com 8473913327

Organization UOP LLC 


\section{PART II: STI PRODUCT MEDIA/FORMAT and LOCATION/TRANSMISSION}

(To be completed by Recipient/Contractor)

\section{A. Media/Format Information:}

1. MEDIUM OF STI PRODUCT IS:

X Electronic Document $\square$ Computer medium

$\square$ Audiovisual material $\square$ Paper $\square$ No full-text

2. SIZE OF STI PRODUCT $1.2 \mathrm{Mb}$

3. SPECIFY FILE FORMAT OF ELECTRONIC DOCUMENT BEING TRANSMITTED, INDICATE:

$\square$ SGML $\square$ HTML $\square$ XML $\square$ PDF Normal X PDF Image

$\square$ WP-Indicate Version (5.0 or greater)

Platform/operating system

$\square$ MS-Indicate Version (5.0 or greater)

Platform/operating system

$\square$ Postscript

4. IF COMPUTER MEDIUM OR AUDIOVISUAL

a. Quantity/type (specify)

b. Machine compatibility (specify)

c. Other information about product format a user needs to know:

B. Transmission Information:

STI PRODUCT IS BEING TRANSMITTED:

$X$ 1. Electronic via Elink

$\square$ 2. Via mail or shipment to address indicated

in award document (Paper products,

CD-ROM, diskettes, videocassettes, et.)

$\square$ 2a. Information product file name

(of transmitted electronic format)

\section{PART III: STI PRODUCT REVIEW/RELEASE INFORMATION}

(To be completed by DOE)

\section{A. STI Product Reporting Requirement Review: \\ X 1. THIS DELIVERABLE COMPLETES ALL REQUIRED DELIVERABLES FOR THIS AWARD \\ $\square$ 2. THIS DELIVERABLE FULFILLS A TECHNICAL REPORTING REQUIREMENT, BUT SHOULD NOT BE DISSEMINATED BEYOND DOE.}

\section{B. DOE Releasing Official}

$\square$ 1. I VERIFY THAT ALL NECESSARY REVIEWS HAVE BEEN COMPLETED AS DESCRIBED IN DOE G 241.1-1A, PART II, SECTION 3.0 AND THAT THE STI PRODUCT SHOULD BE RELEASED IN ACCORDANCE WITH THE INTELLECTUAL PROPERTY/DISTRIBUTION LIMITATION ABOVE.

Released by (name)

Date (mm/dd/yyyy)

E-mail

Phone

Abstract: The purpose of this study was to evaluate the potential for using biorenewable feedstocks in oil refineries. Economic analyses were conducted, with support from process modeling and proof of principle experiments, to assess a variety of potential processes and configurations. The study considered two primary alternatives: the production of biodiesel and green diesel from vegetable oils and greases and opportunities for utilization of pyrolysis oil. The study identified a number of promising opportunities for biorenewables in existing or new refining operations. 
Purpose: DOE F 241.3 provides the Office of Scientific and Technical Information (OSTI) information required to appropriately identify, process, and/or announce and disseminate the results of work funded by the U.S. Department of Energy (DOE). For general information or assistance with this form, contact OSTI at (865) 241-6435, or at the following e-mail address: 241user@adonis.osti.gov.

When to use: Submit this form with each scientific and technical information (STI) Product. Electronic format is the preferred method for submitting the announcement record and STI Product. When submitting electronically, use the electronic version of the form (http://www.osti.gov/elink; discuss with your DOE Contracting Officer).

Describing the data fields: Descriptions of the various DOE F 241.3 data fields, STI Products, format, etc., can be found in ATTACHMENT 3 and other sections of the DOE G 241.1-1A, Guide to the Management of Scientific and Technical Information. Available online at http://www.osti.gov/stip/

DOE Financial Assistance Recipients/Contractors Recipients and Contractors should complete Parts I and II of the form and forward the form along with the STI product to the DOE Contracting Officer who will complete the rest of the form and submit the package to OSTI.

NOTE: Sensitive, proprietary, or other STI Products for which access is restricted by statute or regulation shall not be transmitted via open systems networks (e.g., the Internet) unless authorization and/or encryption has been coordinated with OSTI in advance. This form, unless it in itself is classified, can be transmitted via open systems networks (.e.g, the Internet).

RECORD STATUS - This is a required field. The record status identifies the announcement record or the STI Product as new, or revised. If the record status is not provided, the record is considered "New."

Part I: STI PRODUCT DESCRIPTION (To be completed by Recipient/Contractor)

\section{A. STI PRODUCT IDENTIFIERS}

1. Report/Product Number(s). This is a required field. The unique primary report or product number assigned to the STI product. If a report number is not provided, the word "NONE" should be entered.

Following are examples of report number formats for multiple volumes, parts, or revisions:

\section{DOE/ID/13734-2}

\section{DOE/NE/01834--1-Pt. 1}

More than one report number may be provided. Multiple numbers are separated with a semicolon and a space. When more than one number is entered, the first number, considered the primary number, should identify the submitting organization. All other numbers are considered secondary numbers.

2. DOE Award/Contract Number(s). This is a required field. Enter the DOE award/contract number under which the work was funded. Additional DOE award/contract numbers related to the product may be entered. Multiple numbers are separated with a semicolon and a space. When more than one number is entered, the first number is considered the primary number.

3. Other Identifying Number(s). An additional unique identifying number assigned to the STI product. (e.g., CRADA numbers, Non-DOE contract numbers). More than one other identifying number may be provided. Multiple numbers are separated with a semicolon and a space.
B. RECIPIENT/CONTRACTOR - This is a required field. Provide the name and location of the organization that performed the research or issued the STI product. More than one organization may be provided; separate multiples with a semicolon and a space.

Example: University of Tennessee, Knoxville, TN

C. STI PRODUCT TITLE - This is a required field. Provide the title exactly as given on the product itself, including part, volume, edition, and similar information.

D. AUTHOR(s) - This is a required field. Provide the name of the author (last name first) of the STI product. More than one author may be provided; separate multiple entries with a semicolon and a space. If an author does not exist, the word "None" should be entered.

Examples: Jones, T.M.; Markay, Arthur R. III Fields, J.M., ed.

Author(s) E-mail Address(es). Provide the e-mail address for each author. Multiples may be provided; they should be listed in the same order as the authors and should be separated by a semicolon and a space.

E. STI PRODUCT ISSUE DATEIDATE OF PUBLICATION - This is a required field. Provide the date when the information product was published or issued.

F. STI PRODUCT TYPE - This is a required field. It should agree with the reporting requirement identifier in the reporting requirements checklist; federal assistance reporting checklist; or in the statement of work if the product is a required deliverable that warrants accountability.

1. Technical Report. Identify the type of technical report provided.

2. Conference Paper. Provide all available conference information. An agenda alone is not sufficient for announcement.

3. Journal Article. Provide all available Journal Article information.

G. STI PRODUCT REPORTING PERIOD. Specify the beginning and ending dates of the period covered by the STI product.

H. SPONSORING DOE PROGRAM OFFICE - Enter the name or acronym of the DOE Program Office (e.g., Office of Science or SC) providing the funding for the work described in the STI product. For projects funded by more than one Program Office, indicate all sources of the DOE funding in descending order of dollar amount of funding appropriated. Separate multiple program offices with a semicolon and a space. If no sponsoring DOE Program Office is provided, "DOE" will be the sponsor.

I. SUBJECT CATEGORIES - Select one or more categories from the list provided. List the primary one first. A list of subject categories is available at (http://www.osti.gov/elink/).

Keywords. Provide terms which describe the content of the publication. More than one term may be entered; separate multiple terms with a semicolon and a space.

J. DESCRIPTIONIABSTRACT - Provide a clear, concise, and publicly releasable English language summary of the information content of the STI product. The abstract length should be no more than 5,000 characters. If you are utilizing paper media, you may provide via attachment. 
K. INTELLECTUAL PROPERTYIDISTRIBUTION LIMITATIONS - This is a required field. STI products should be written for public release; therefore, STI products should not contain proprietary, classified or any information subject to export control. Recipients/Contractors are responsible for notifying their DOE contracting officer if the document contains other than unclassified data before submitting to the DOE address in the award document. Recommendations to restrict access to STI products must have a legal basis or be accompanied by written programmatic guidance. For questions concerning current laws and guidance, refer to Part II or ATTACHMENT 7 of the DOE G 241.1-1A, Guide to the Management of Scientific and Technical Information, or contact your DOE Contracting Officer.

1. Unlimited Announcement. The unrestricted, unlimited distribution of the product (will be made publicly available). The Government assumes no liability for disclosure of such data.

2. Copyrighted Material. A copyright restriction on part or all of the contents of the STI product may affect the reproduction and distribution of the product by OSTI. Any restriction must be specified.

3. Patentable Material. Provide all applicable patent information.

4-6. No special instructions.

7. Office of Nuclear Energy Applied Technology pursuant to 10 CFR 810.

L. RECIPIENT/CONTRACTOR POINT OF CONTACT. Provide the organization or individual(s) name with corresponding contact information who will be included in the published citation as the point of contact and will respond to external questions about the content of the STI product.

Part II. STI PRODUCT MEDIA/FORMAT AND LOCATIONI TRANSMISSION (To be completed by recipient/contractor)

A.

\section{MEDIA/FORMAT INFORMATION}

1. Medium. This is a required field. Select one of the medium options provided. Note: When announcement record only is submitted, select "No full-text."

2. Size of STI Product. Provide the total number of pages or other designation which gives an indication of the size of the information product (e.g., 200 pages; 20 images; 3500 kilobytes; 3-3 1/2 inch diskettes).

3. File Format. This is a required field if the STI product is electronic fulltext. Select one of the options provided.

4. If Computer Medium or Audiovisual Material (do not include software packages). a. Indicate the quantity and type of medium, e.g., 2 videocassettes, 1 magnetic tape.

b. Indicate the machine with which the medium is compatible, i.e., with which it can be used (e.g., VHS; IBM PC compatible, hard disk, 8 Megs.)

c. Enter any other information which would be helpful to the user of the STI product (e.g., programming language, file format, etc.)

\section{B. LOCATION/TRANSMISSION INFORMATION}

\section{STI PRODUCT IS BEING TRANSMITTED}

1. This is a required field. Provide if the full-text STI product is being transmitted electronically. Indicate if product is being transmitted via Internet-accessible system called Elink at https://www.osti.gov/elink/.

2. This is a required field. Provide an electronic copy of the STI product that is being transmitted via other computer-generated medium or other method. Indicate if product is being transmitted via mail or other shipment method (paper products, CD-ROM, diskettes, videocassettes, etc.). Provide information product filename of transmitted electronic format, if applicable.

Part III: STI PRODUCT REVIEW/RELEASE INFORMATION (To be completed by DOE)

\section{A. STI PRODUCT REPORTING REQUIREMENT REVIEW}

1. This is a required field if all other required STI products have been received for this award by OSTI and this STI product is the final deliverable required according to the technical information reporting requirement.

2. Indicated if the STI product is not suitable for dissemination beyond DOE based on report type or content, it is being submitted because it fulfills a technical information reporting requirement.

B. RELEASEING OFFICIAL - This is a required field. Provide the name and additional information of the site's individual(s) responsible for the appropriate review and release of the STI product. Do not forward this form or the STI product until after it has been reviewed and released for announcement.

\section{OMB BURDEN DISCLOSURE STATEMENT}

Public reporting burden for this collection of information is estimated to average 30 minutes per response, including the time for reviewing instructions, searching existing data sources, gathering and maintaining the data needed, and completing and reviewing the collection of information. Send comments regarding this burden estimate or any other aspect of this collection of information, including suggestions for reducing this burden, to the Office of Information, Records and Resource Management, SO-31, FORS, U.S. Department of Energy, Washington, DC 20585 and to the Office of Management and Budget (OMB), Paperwork Reduction Project (1910-1400), Washington, D.C. 20503. 


\title{
OPPORTUNITIES FOR BIORENEWABLES IN OIL REFINERIES
}

\author{
FINAL TECHNICAL REPORT
}

\author{
SUBMITTED TO: \\ U.S. DEPARTMENT OF ENERGY
}

\section{UOP}

25 East Algonquin Road

Des Plaines, Illinois 60017-5017

U.S.A.

DOE Award Number:

Period of Performance:

Technical Point of Contact:
DE-FG36-05G015085

$12 / 01 / 2004$ to $04 / 15 / 2005$

Richard Marinangeli

Manager, New Directions Exploratory and Fundamental Research UOP LLC

(847) 3913327 (phone)

(847) 3913724 (fax)

richard.marinangeli@uop.com

Terry Marker, John Petri, Tom Kalnes, Mike McCall, Dave Mackowiak, Bob Jerosky, Bill Reagan, Lazlo Nemeth, Mark Krawczyk

Stefan Czernik

Doug Elliott

David Shonnard

Michigan Technological University 


\section{TABLE OF CONTENTS}

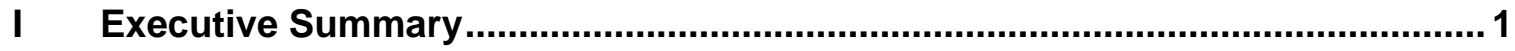

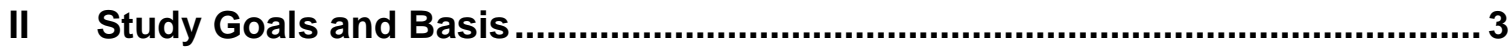

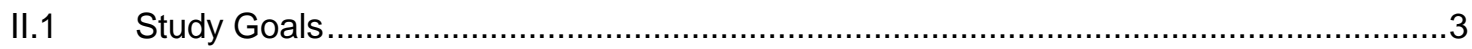

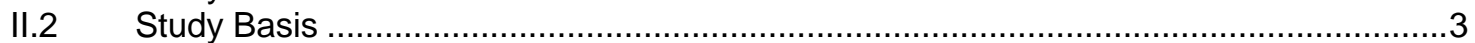

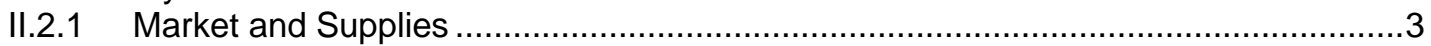

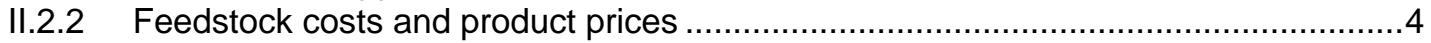

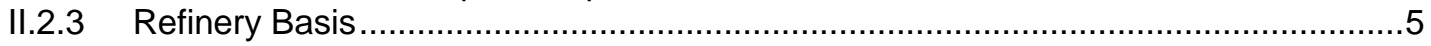

III Refinery Opportunities for Vegetable Oils and Grease ................................... 8

III.1 Biodiesel (Fatty Acid Methyl Ester) Production........................................................

III.1.1 Fatty Acid Methyl Ester Production in Existing Refining Units ............................

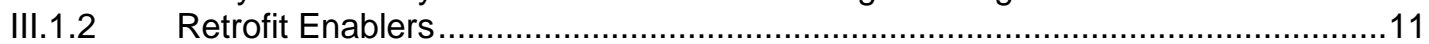

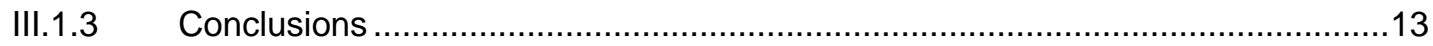

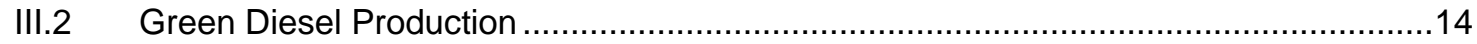

III.2.1 Green Diesel Production Approaches ........................................................14

III.2.2 Green Diesel Production - Co-Processing Biofeedstocks in an Existing Unit .....14

III.2.3 Green Diesel Production - Processing Biofeedstocks in a Stand-Alone Unit......18

III.2.4 Green Diesel Experimental Results ...........................................................20

III.3 Comparison of Biodiesel and Green Diesel Process and Properties ..........................21

III.4 Green Gasoline and Green Olefins Production .....................................................22

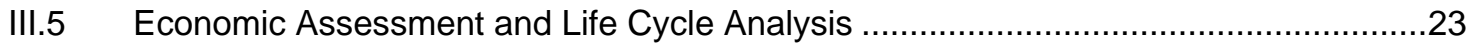

IV Refinery Opportunities for Pyrolysis Oil ......................................................... 25

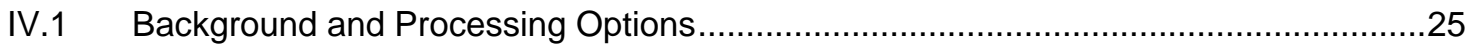

IV.2 Gasoline And Aromatics Production from Pyrolytic Lignin ......................................27

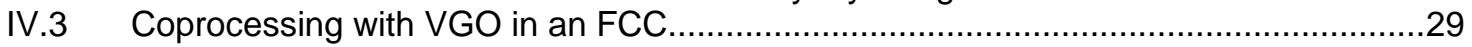

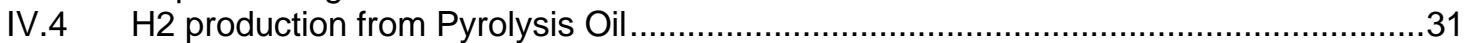

IV.4.1 Integration of Pyrolysis Oil Reforming into Refinery Hydrogen Plants .................31

IV.4.2 Aqueous Phase Reforming (APR) of the Aqueous Phase of Pyrolysis Oil ..........33

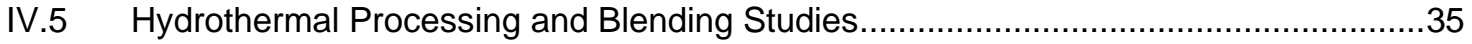

IV.6 Economic Analysis of Pyrolysis Oil Processing Options ............................................

V Opportunities for Fischer Tropsch Liquids ................................................... 39

VI Acronyms and Abbreviations........................................................................ 41

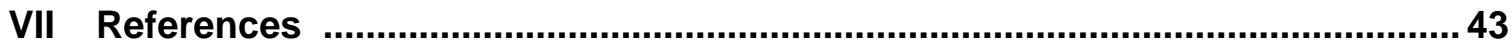




\section{LIST OF FIGURES}

Figure 1. Global feedstock supplies. (a) Availability of oil and grease relative to other fuels.', (b) Potential contribution to chemicals production.'

Figure 2- Average feedstock prices. Note that $\$ 306 /$ ton $=\$ 40 / \mathrm{bbl}$ for WTI crude (2nd quarter 2004)

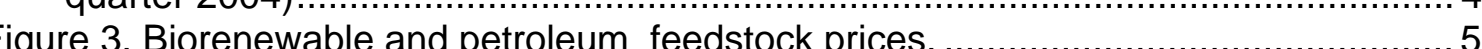

Figure 4. Typical U.S. refin petroleum feedstock prices. ..........................................5

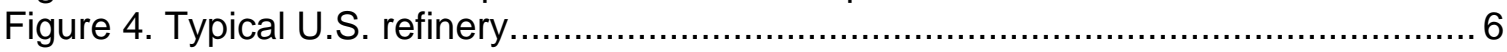

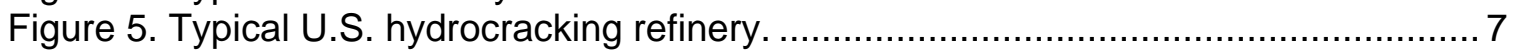

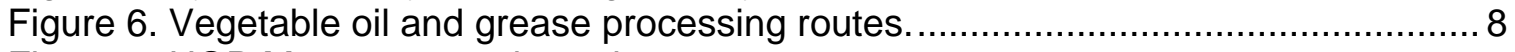

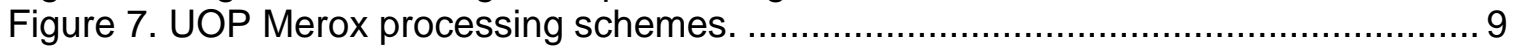

Figure 8. Possible Merox unit retrofit to FAME service............................................. 10

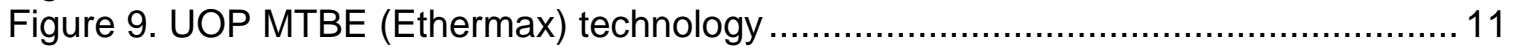

Figure 10. Alternatives for green diesel production............................................... 14

Figure 11. Effect of co-processing brown grease on catalyst temperature cycle............ 16

Figure 12. Effect of co-processing brown grease on catalyst deactivation rate.............. 16

Figure 13. Effect of co-processing brown grease on catalyst cycle length. .................. 17

Figure 14. Proposed flow scheme for standalone production of green diesel. ............... 18

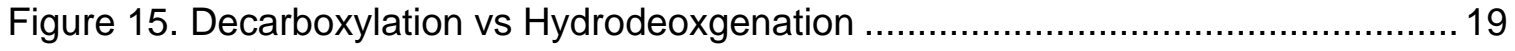

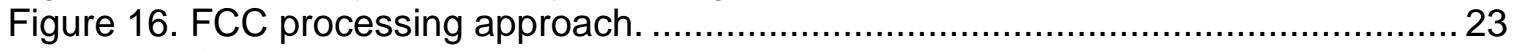

Figure 17. Capital costs of biofuels production from oils and greases.........................23

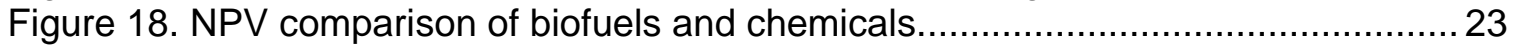

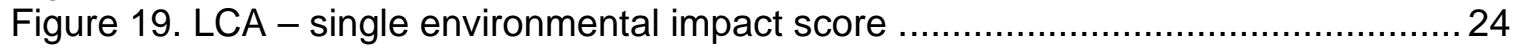

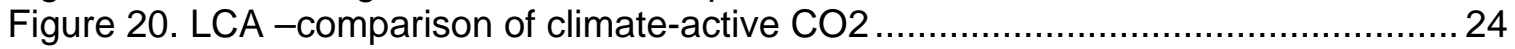

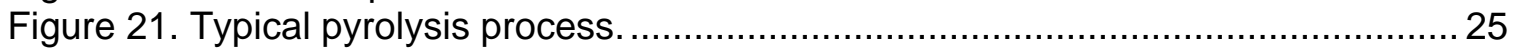

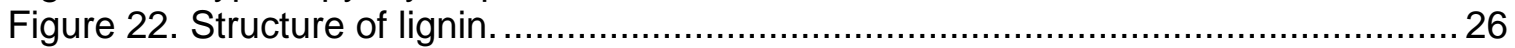

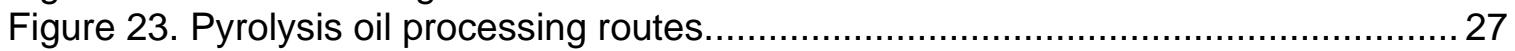

Figure 24. Process flow for hydrotreating/hydrocracking of pyrolytic lignin. ..................29

Figure 25. Adiabatic pre-reformer for the aqueous-phase of pyrolysis oil......................32

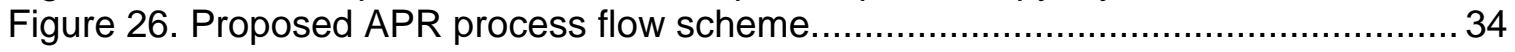

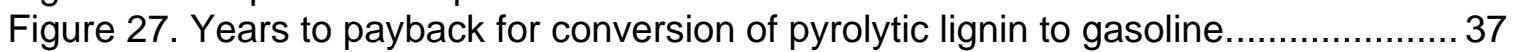

Figure 28. Years to payback for combined process................................................... 38

Figure 29. Typical hydrocracking refinery processing crude FT liquids. ..................... 40 


\section{LIST OF TABLES}

Table 1. Availability of biorenewable feedstocks in U.S."' '....................................... 3

Table 2. Summary of FAME experimental results.................................................. 12

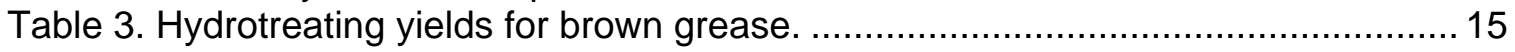

Table 4. Hydrotreating free fatty acids. .......................................................... 15

Table 5. Hydrodeoxygenation versus decarboxylation theoretical yields...................... 19

Table 6. Green diesel experimental summary. .................................................. 20

Table 7. Biodiesel and green diesel properties ...................................................... 21

Table 8. Comparison of biodiesel and green diesel production processes...................21

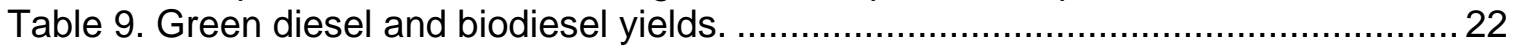

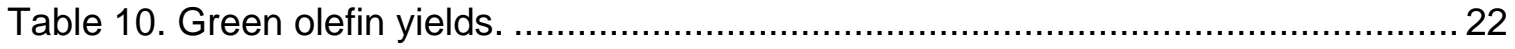

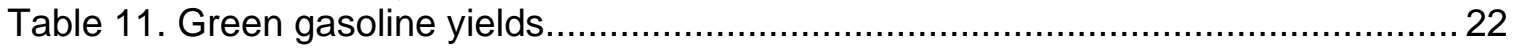

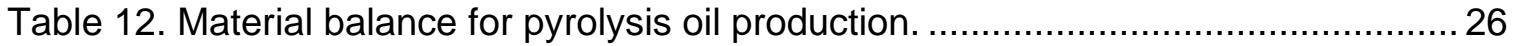

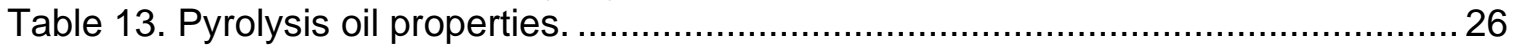

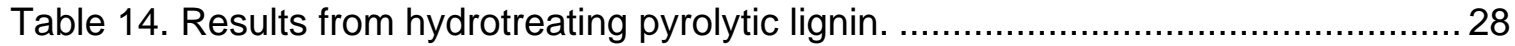

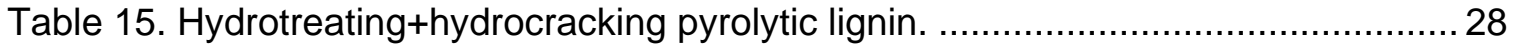

Table 16. Yield estimate for hydrotreating/hydrocracking pyrolytic lignin. ....................28

Table 17. Yields for FCC conversion of pyrolysis oil, pyrolytic lignin and HT pyrolysis oil.29

Table 18. Carbon residue results .................................................................... 30

Table 19. Product properties of total liquid products from FCC testing at 1000F and 5/1

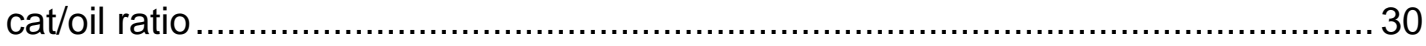

Table 20. Composition of aqueous-phase compounds from pyrolysis oil ...................... 31

Table 21. Pre-reformer syngas composition for the aqueous phase of pyrolysis oil....... 31

Table 22. Reforming equilibrium reactions for APR of pyrolysis oil components ............33

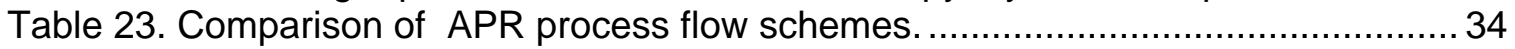

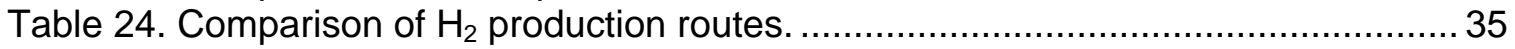

Table 25. Hydrothermal processing experiment conditions. ...................................... 35

Table 26. Product properties of hydrothermally processed pyrolytic lignin....................36

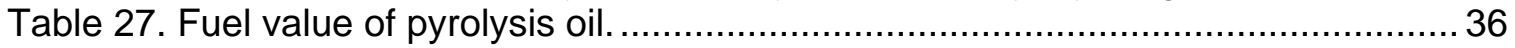

Table 28. Incentives for gasoline production from pyrolytic lignin............................ 37

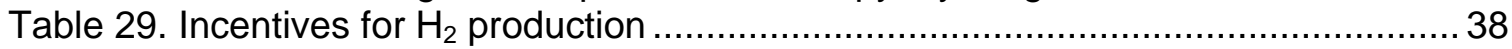

Table 30. Overall incentives for use of pyrolysis oil for fuel and gasoline production.... 38

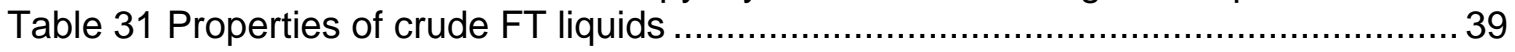

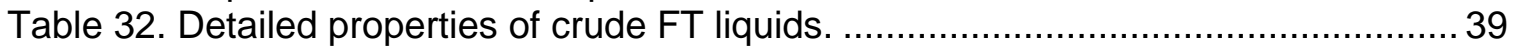

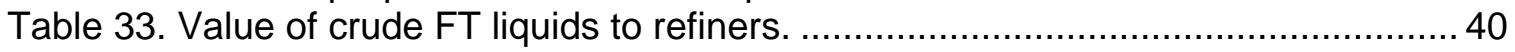

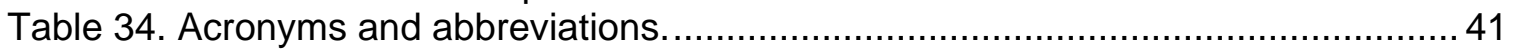




\section{EXECUTIVE SUMMARY}

The purpose of this study was to evaluate the potential for using biorenewable feedstocks in oil refineries. Economic analyses were conducted, with support from process modeling and proof of principle experiments, to assess a variety of potential processes and configurations. The study identified a number of promising opportunities for biorenewables in existing or new refining operations.

The work was performed as a joint project with the National Renewable Energy Laboratory (NREL), and Pacific Northwest National Laboratory (PNNL). NREL provided pyrolysis oil feedstocks and biorenewable expertise. PNNL provided feedstocks and biorenewable processing expertise; PNNL also conducted some of the proof of principle experiments. The DOE provided $\$ 80,000$ of the total $\$ 230,000$ funding for the project.

The study considered two primary alternatives: the production of biodiesel and green diesel from vegetable oils and greases and opportunities for utilization of pyrolysis oil. Green diesel produced from hydrotreating vegetable oil and grease was identified as one of the best options for refiners, agricultural producers, and forest products producers. Green diesel has superior product properties, requires less capital investment to produce, and has a lower environmental impact than biodiesel. Green diesel is economically attractive under two conditions: (1) using a low-cost feedstock such as brown grease; or (2) if vegetable oil feedstocks are subsidized.. Green gasoline and green olefins, which are produced by cracking vegetable oils and grease in an FCC unit, are also economically attractive, particularly if eligible for subsidies.

Processing of pyrolysis oils represents a longer term opportunity, since pyrolysis oils are currently available only in small quantities. However, unlike vegetable oils and greases, they have the potential to provide a significant portion of future transportation fuels (60\%). The study evaluated options for using crude pyrolysis oil as well as two of its fractions - pyrolytic lignin and the water-soluble phase .

Experimental work confirmed that pyrolytic lignin can be converted to gasoline with reasonable $\mathrm{H}_{2}$ consumption using mild hydrotreating followed by hydrocracking. The economics of this process are increasingly attractive with increased crude oil price or decreased pyrolysis oil price with increased production. At a price of $\$ 50 / \mathrm{bbl}$ for crude, the analysis predicted payback in three years.

The water-soluble phase of pyrolysis oil is suitable for generating hydrogen. Most, or all, of the hydrogen used in a typical refinery can be provided by steam reforming 5200 bpd of the water soluble portion of pyrolysis oil. A small portion of this hydrogen can be used to provide hydrogen for hydrotreating the pyrolytic lignin to make gasoline. The economics of hydrogen formation from the water soluble portion of pyrolysis oil become attractive when there is a $\mathrm{CO}_{2}$ credit of $\$ 30 /$ ton and pyrolysis oil cost is $\$ 10 / \mathrm{bbl}$. Since the pyrolysis oil used for hydrogen production would replace purchased natural gas, this is a way to reduce nearly $20 \%$ of refinery emissions of climate-active $\mathrm{CO}_{2}$. However, pyrolysis oil price must drop before this process becomes economically attractive.

Crude pyrolysis oil can be substituted for purchased natural gas as a fuel in refinery boilers and furnaces, also reducing $\mathrm{CO}_{2}$ emissions. Pyrolysis oil is less costly than natural gas by $\$ 1.2 / M M B T U$ and therefore represents an economically viable substitute for natural gas in a refinery setting.

The high oxygen content of pyrolysis oil imposes constraints on processing in standard metallurgy and current economics for hydrotreating pyrolysis oil assume a standalone unit is required. Initial hydrothermal treatment under mild conditions may provide a low cost approach 
to reduce the oxygen content and allow processed in standard equipment. More experimental work is needed to determine the viability and economic impact of hydrothermal treatment.

Hydrotreating and hydrocracking, technologies which were developed for oil refineries, were found to be particularly useful for processing vegetable oil, greases, and pyrolysis oils. The level of hydrogen required for hydrotreating can be controlled by processing conditions and catalyst, since the same materials which catalyze hydrodeoxygenation also catalyze decarboxylation. Optimization of this technology for biorefineries will lead to better utilization of these biofeedstocks for conversion to fuels and chemicals.

A key barrier to the use of biorenewables in oil refineries is that available quantities are small relative to the size of most refinery processing equipment. Refiners are naturally resistant to risking catalysts and run time in large petroleum processing units, for the sake of processing small amounts of biofeedstocks. Skid mounted, standalone green diesel, or pyrolysis oil hydrotreating units solve this problem by allowing biorenewables to be processed separately from petroleum fractions. These skid mounted units could also be used by agricultural and forest producers. 


\section{StUdy GoALS AND BAsis}

\section{II.1 Study Goals}

The overall goal of this study was to evaluate the economics of using biomass-derived feedstocks (biofeedstocks) in petroleum refineries. The technical work was divided into three tasks: modeling of refinery options to project yields and costs (Task 1); a variety of scoping experiments (Task 2); and, analysis of costs and process economics (Task 3).

Several alternatives were evaluated:

- Processing of biofeedstocks in existing refinery equipment

- Coprocessing of biofeedstocks with crude oil fractions in existing refinery equipment

- Blending biofeedstocks with petroleum feeds

In addition, new processing steps were evaluated that would enable more effective use of biofeedstocks in refining operations.

Two classes of biofeedstocks were considered:

- Vegetable oils and greases derived from crops such as corn, soy, canola and rapeseed

- Pyrolysis oil derived from forest waste

A number of processing options was considered for each type of biofeedstock. In each case, one or more candidate processing schemes was modeled. Experiments were conducted as needed to determine the key processing parameters required to understand cost and economic impact of biofeedstock use in a particular process. Cost estimates were developed and used in a broader evaluation of the potential process economics. This report summarizes the results of the process models and supporting experiments. Additional details are provided in the supporting Appendix.

This Final Report is organized by processing option, rather than by task, to more clearly present the alternatives. The basis and assumptions used in the study are outlined in Section II.2. Section III describes opportunities for utilizing vegetable oils and greases, particularly in the production of biofuels. Section IV describes the evaluation of opportunities for processing or coprocessing pyrolysis oil to produce gasoline, aromatics or hydrogen. The value of processing FischerTropsch liquids in biorefineries was also evaluated, described in Section V. Lists of acronyms and abbreviations and key references are located in Sections VI and VII, respectively. The Appendix provides a summary of key experiments (Appendix Tables 1 and 2) and additional background for the study basis.

\section{II.2 STUDY BASIS}

\section{II.2.1 Market and Supplies}

Table 1. Availability of biorenewable feedstocks in U.S. ${ }^{1,2,3,4,5}$

\begin{tabular}{|l|l|c|c|}
\hline & Definition & $\begin{array}{c}\text { U.S. Production } \\
\text { (bpd) }\end{array}$ & $\begin{array}{c}\text { Available for } \\
\text { Conversion to } \\
\text { Fuels (bpd) }\end{array}$ \\
\hline Vegetable oils & $\begin{array}{l}\text { Produced from soybeans, corn, } \\
\text { canola, palm }\end{array}$ & 194,000 & 33,500 \\
\hline $\begin{array}{l}\text { Recycled } \\
\text { products }\end{array}$ & Yellow grease, brown (trap) grease & 51,700 & 33,800 \\
\hline Animal fats & Tallow, lard, fish oil & 71,000 & 32,500 \\
\hline Pyrolysis oil & $\begin{array}{l}\text { Produced by pyrolysis of wood } \\
\text { slash, waste and other biomass } \\
\text { waste }\end{array}$ & 1,500 & 750 \\
\hline
\end{tabular}




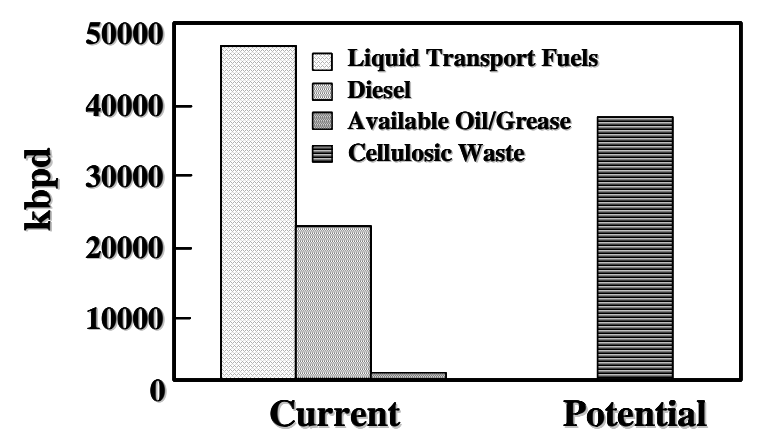

(a)

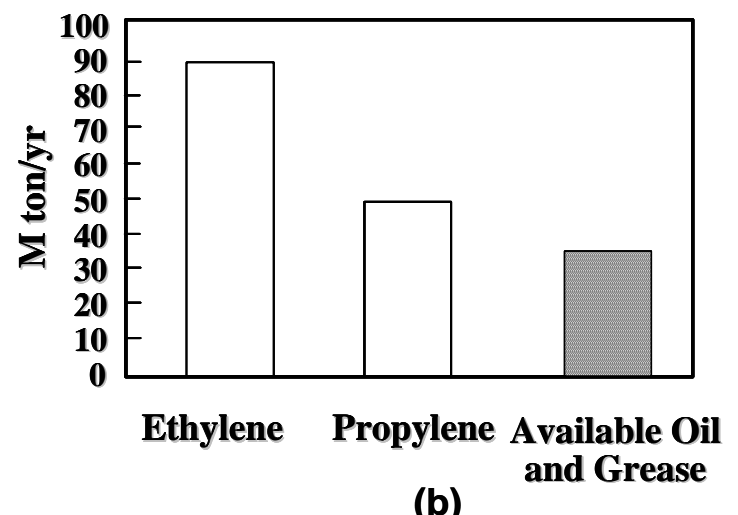

(b)

Figure 1. Global feedstock supplies.

(a) Availability of oil and grease relative to other fuels. ${ }^{6,78,9}$

(b) Potential contribution to chemicals production. ${ }^{10,11}$

Roughly 100,000 bpd of oil and grease are currently available in the U.S. for conversion to fuels (Table 1).Oils and grease are available today and are likely to make an increasing contribution to the world's fuel supply in the near term, in part due to government-mandated targets (see Appendix, Table 3). For example, the U.S. has mandated that $2.5 \%$ of diesel be generated from biorenewable sources by 2010. However, quantities of oil and grease are limited. In contrast, very little pyrolysis oil is produced at present but the potential supply is much larger. As shown in Figure 1 (a), significant levels of cellulosic waste are available globally for production of pyrolysis oil if conversion to transportation fuels becomes economically attractive. Therefore, pyrolysis oils have a far greater long term potential for replacing transportation fuels. Chemicals are a much smaller market than transportation fuels and oils and grease feedstocks could play a significant role, particularly for olefin production, as shown in Figure 1.

\section{II.2.2 Feedstock costs and product prices}

The study took into account both feedstock costs and the projected prices of potential products. The economic analysis was primarily based on a West Texas Intermediate (WTI) crude feedstock price of \$40 per barrel. The impacts of price increases to \$50 and \$60 per barrel of crude were also explored. Biofeedstock prices were based upon an average of the $2003-2004$ values reported in the Chemical Marketing reporter (See Appendix, Table 4). Figure 2 shows the trend in feedstock prices in \$/ton during the 2003 - 2004 period.

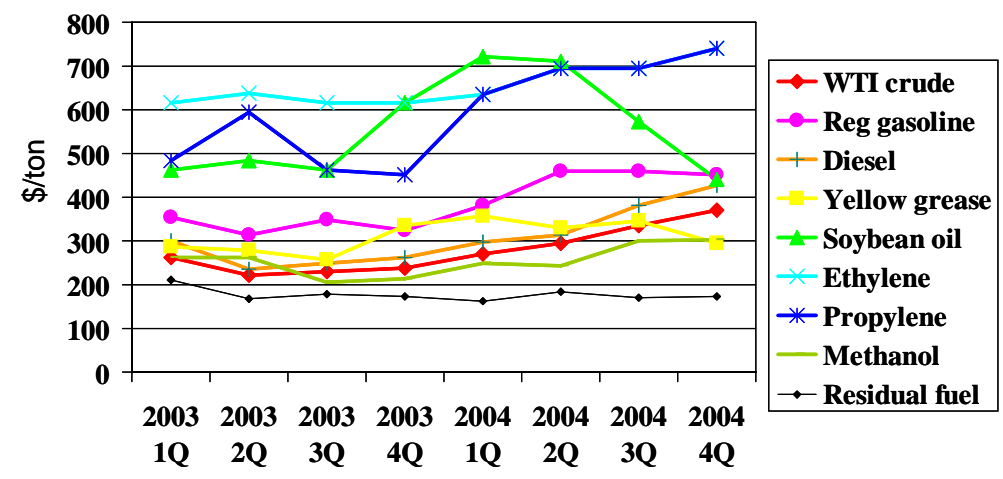

Figure 2- Average feedstock prices.

Note that $\$ 306 /$ ton $=\$ 40 / b b l$ for WTI crude (2nd quarter 2004) 
A number of factors impact the estimated price of biofuels. The following factors were included in the analysis:

- Capital costs. Capital costs were estimated for equipment modifications or for new plants, depending upon process requirements.

- Transportation costs. Transportation costs vary depending on the location of the refinery and the location of the biofeedstock. A number of U.S. refineries are located near sources of biomass feedstock, specifically oil and grease production facilities and agricultural and wood resources (Appendix, Figures 1 and 2). A transportation charge of $\$ 2$ per barrel was assumed for biofeedstocks based on typical rail transportation costs for grease and oils.

- $\quad \mathbf{C O}_{2}$ credits. The use of pyrolysis oil as a fuel would generate a $\mathrm{CO}_{2}$ credit which could be traded. Currently $\mathrm{CO}_{2}$ is trading for $\$ 10 /$ ton but is expected to reach $\$ 30 /$ ton in 5 years.

- Subsidies. Potential subsidies were calculated based on the subsidies for biodiesel shown in Table 5 of the Appendix.

- Cetane and octane numbers. Cetane number (see Section III.3) affects the price of both green diesel and biodiesel. The value of $\$ 0.13 /$ cetane-bbl was used to reflect the impact of cetane number on prices; the impact of octane number was represented as \$0.50/octane-bbl.

Figure 3 compares the prices of biofeedstocks projected in this study to those of petroleum-based feedstocks. While some biofeedstocks are significantly more expensive than petroleum-based alternatives, others are expected to be less expensive, particularly if supported with government subsidies.

The assumptions used to project the cost of pyrolysis oil are summarized in Table 6 and Table 7 of the Appendix. In the best case, the projected cost of \$4.8/MMBTU for pyrolysis oil is significantly higher than that of fuel oil (\$4.2/MMBTU) on a heating value basis. Subtracting a \$30/ton petroleum feedstock price credit would reduce the pyrolysis oil cost to $\$ 4.1 / \mathrm{MMBTU}$, but inclusion of transportation charges increases the cost of pyrolysis oil to $\$ 4.7 / \mathrm{MMBTU}$, still significantly higher than heavy fuel oil. A major factor is a capital charge of \$81MM for a 6800 bpd pyrolysis unit, which boosts pyrolysis oil from $\$ 9 / \mathrm{bbl}$ to $\$ 16 / \mathrm{bbl}$ in the case of a $\$ 30 /$ ton feedstock.

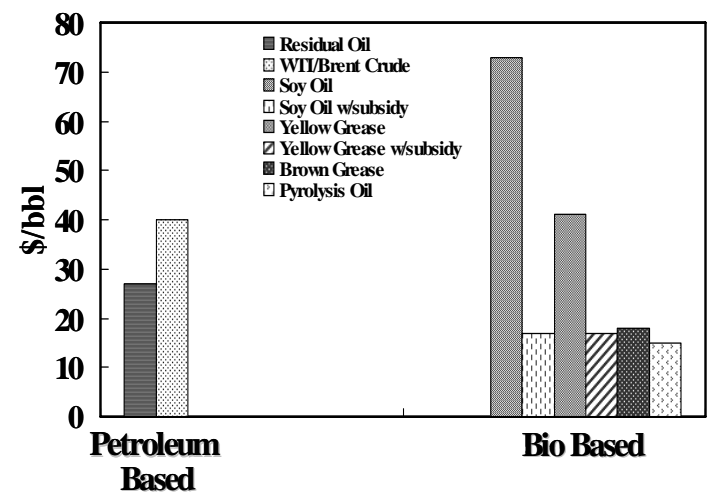

Figure 3. Biorenewable and petroleum feedstock prices.

\section{II.2.3 Refinery Basis}

The study was based upon a standard 150,000 bpd U.S. oil refinery. Two typical configurations and process units are pictured in Figure 4 and Figure 5. Almost all refineries contain fluid catalytic crackers (FCC's), reformers and a variety of hydrotreaters. Many refineries contain hydrocrackers which crack vacuum gas oil (VGO) to make gasoline or diesel. 


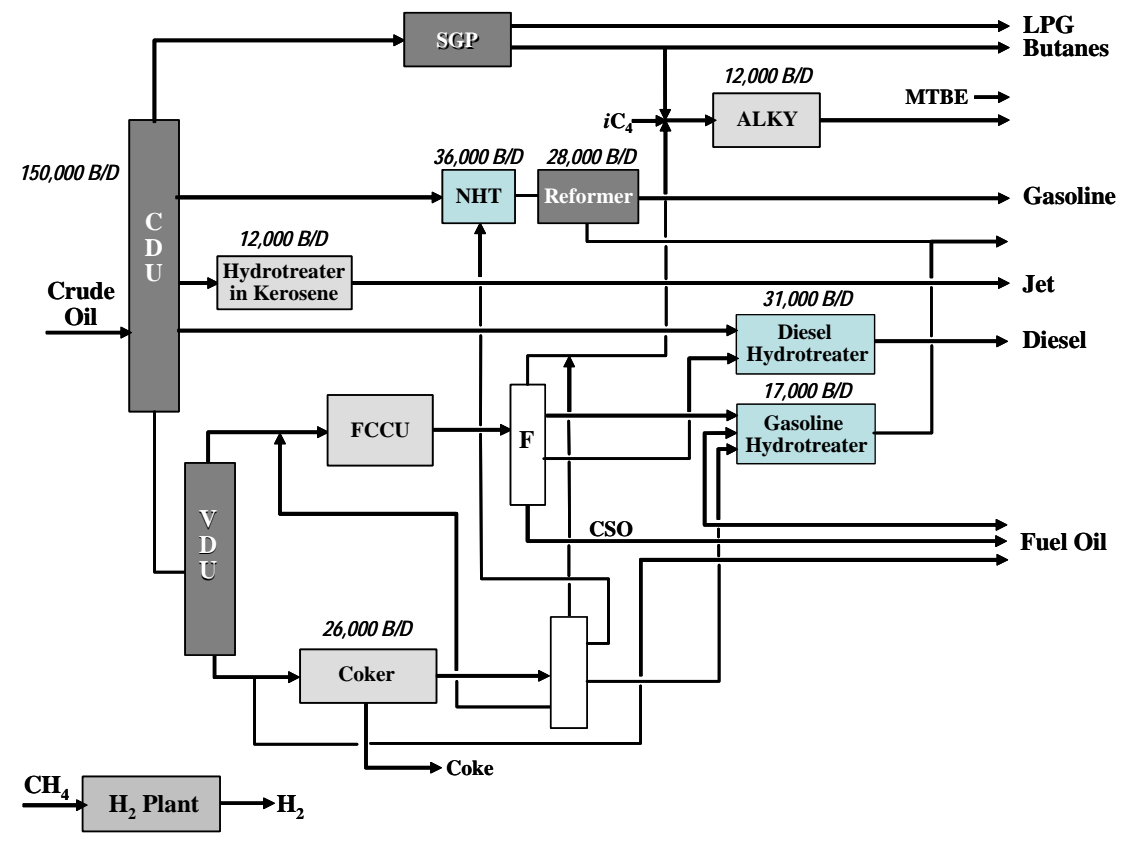

Figure 4. Typical U.S. refinery.

The ability to process biofeedstocks in existing refineries is affected by their high oxygen and acid content. For example, oils and greases typically contain $11-12 \%$ oxygen while pyrolysis oils may contain $35-45 \%$ oxygen. The acidity of feeds processed in a crude oil refinery is typically measured by the Total Acid Neutralization (TAN) number, defined as the milligrams of potassium hydroxide required to neutralize one gram stock. The TAN numbers for grease and pyrolysis oil make it difficult to process these materials in standard refinery equipment. However they may be processed in 317 stainless steel clad vessels. Other properties of typical biofeedstocks are summarized in Table 8 of the Appendix.

Some of the biofeedstock processing options considered in the study require added hydrogen. Almost all refineries include hydrogen plants to supply hydrogen for hydrotreatment to remove sulfur from diesel and gasoline. The economic analyses presented here assumed an average U.S. hydrogen plant supplying 25 million cubic feet per day of hydrogen using a natural gas feed. 


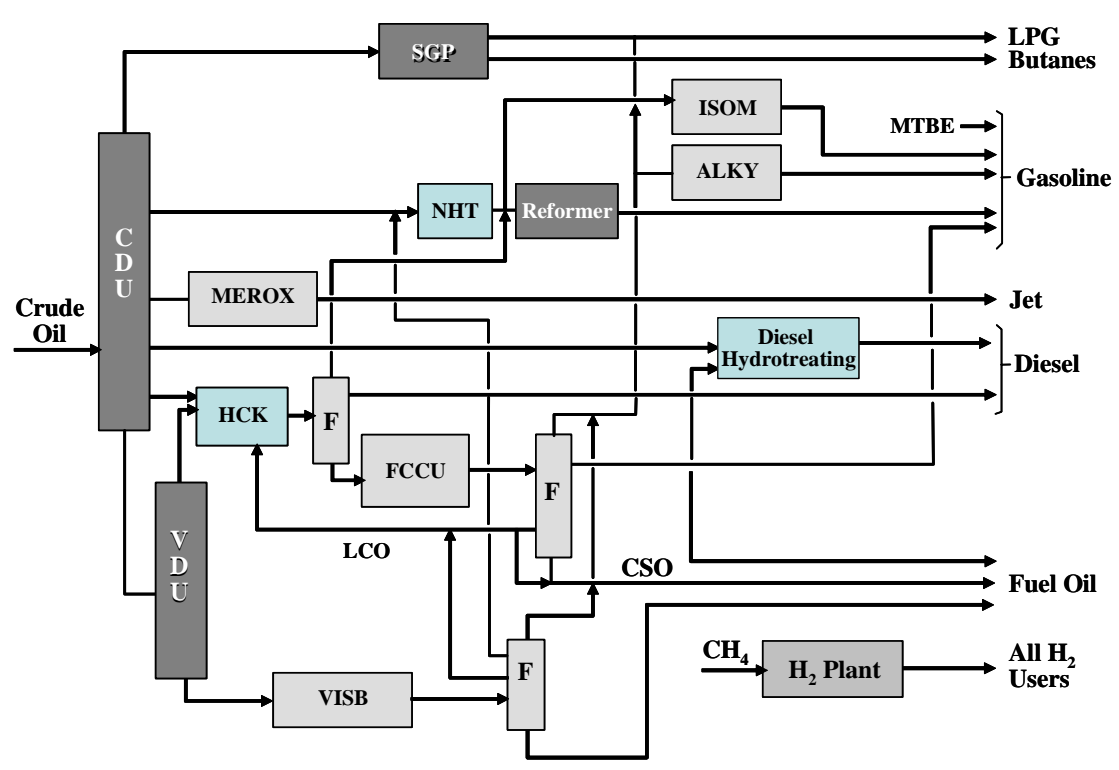

Figure 5. Typical U.S. hydrocracking refinery. 


\section{Refinery Opportunities for Vegetable OILS AND GREASE}

Five separate processing routes for vegetable oil and grease were compared, including biodiesel, green diesel, green gasoline, green olefins and green detergent. The alternatives are illustrated in Figure 6. Biodiesel is differentiated from green diesel in the study. Biodiesel is typically composed of fatty acid methyl esters (FAME). "Green diesel” refers to an acceptable diesel pool blend component produced from a suitable biomass. Green diesel here refers to hydrocarbons produced from biofeedstocks that boil in a typical distillate fuel boiling range and do not contain oxygen in their molecular structure.

Biodiesel production is discussed in Section III.1, together with enabling technologies to facilitate the use of existing refining facilities. Green diesel production by either coprocessing in existing units or processing in new standalone units is evaluated in Section III.2. Biodiesel and green diesel are compared in Section III.3. The production of green gasoline and olefins is reviewed in Section III.4. This section concludes with an overall assessment of process economics and life cycle analysis in Section III.5.

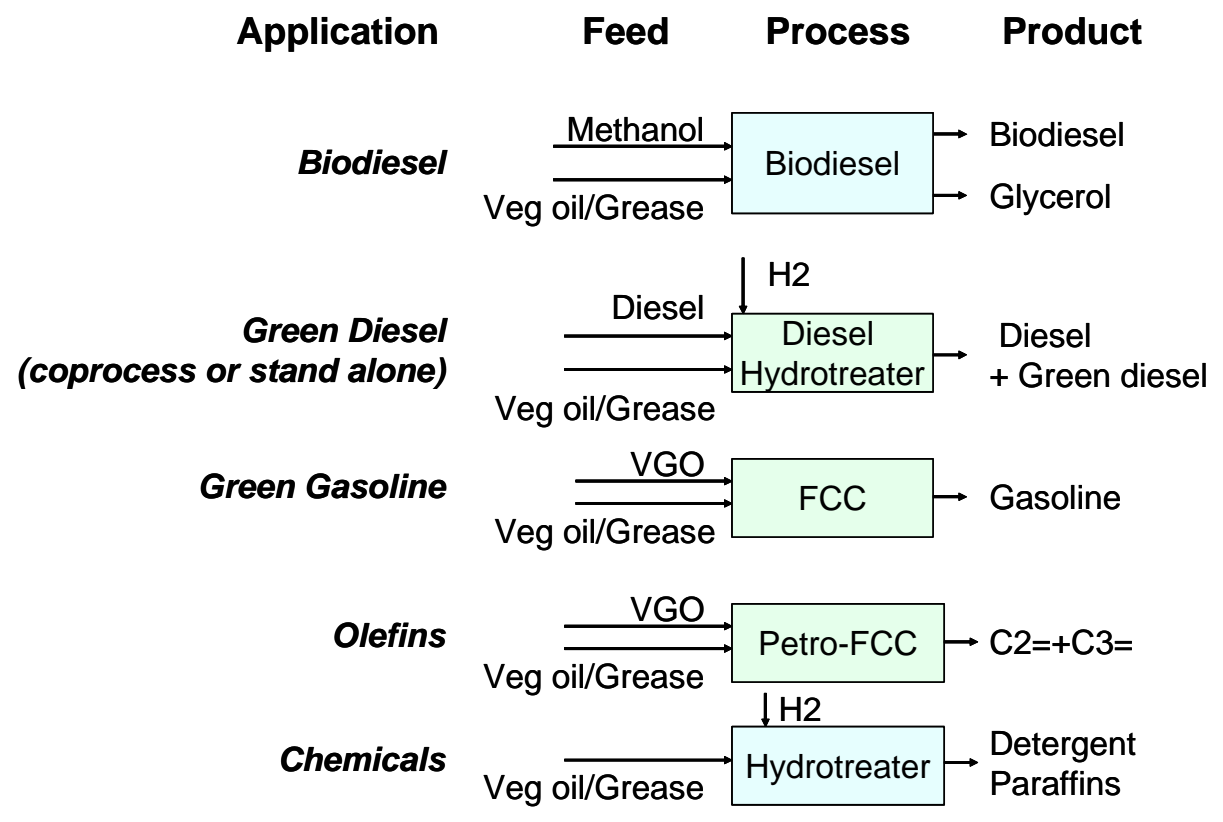

Figure 6. Vegetable oil and grease processing routes.

\section{III.1 Biodiesel (Fatty Acid Methyl Ester) Production}

Due to environmental regulations and changing requirements in fuel specifications, the processing requirements for petroleum products are changing. For example, limits placed on the amount of sulfur in motor fuels have led certain refiners to install new hydrotreating capacity while in some cases shutting down existing treating units. Such events can provide the refiner an opportunity to retrofit existing process equipment, such as storage tanks, pumps, heat exchangers, reactors, separators, and columns, to bio-fuel production. The economic viability of such retrofits is highly dependent on availability and cost of renewable feedstock(s) and the markets for the refined products. The study investigated options and enablers for retrofitting existing units to produce fatty acid methyl esters (FAME). 


\section{III.1.1 Fatty Acid Methyl Ester Production in Existing Refining Units}

The study considered two specific examples of retrofitting existing refining equipment to Fatty Acid Methyl Ester (FAME) production from biofeedstocks:

- retrofitting a UOP Merox unit, and

- retrofitting a UOP MTBE unit.

In both cases, there is potential to significantly reduce the investment cost associated with FAME production, not only within the battery limits of the unit but also by using existing refinery infrastructure to minimize the overall costs.

\section{Merox Unit Retrofit}

UOP Merox (mercaptan oxidation) units have been used by refiners for over 50 years to remove mercaptan compounds from light fuel streams and to sweeten gasoline and jet fuel streams. In the Merox process, mercaptans are catalytically converted to non-odorous disulfide compounds. Depending on the application, one of several different processing schemes may be employed, involving mercaptan extraction or fixed-bed sweetening. Four alternatives are illustrated in Figure 7.
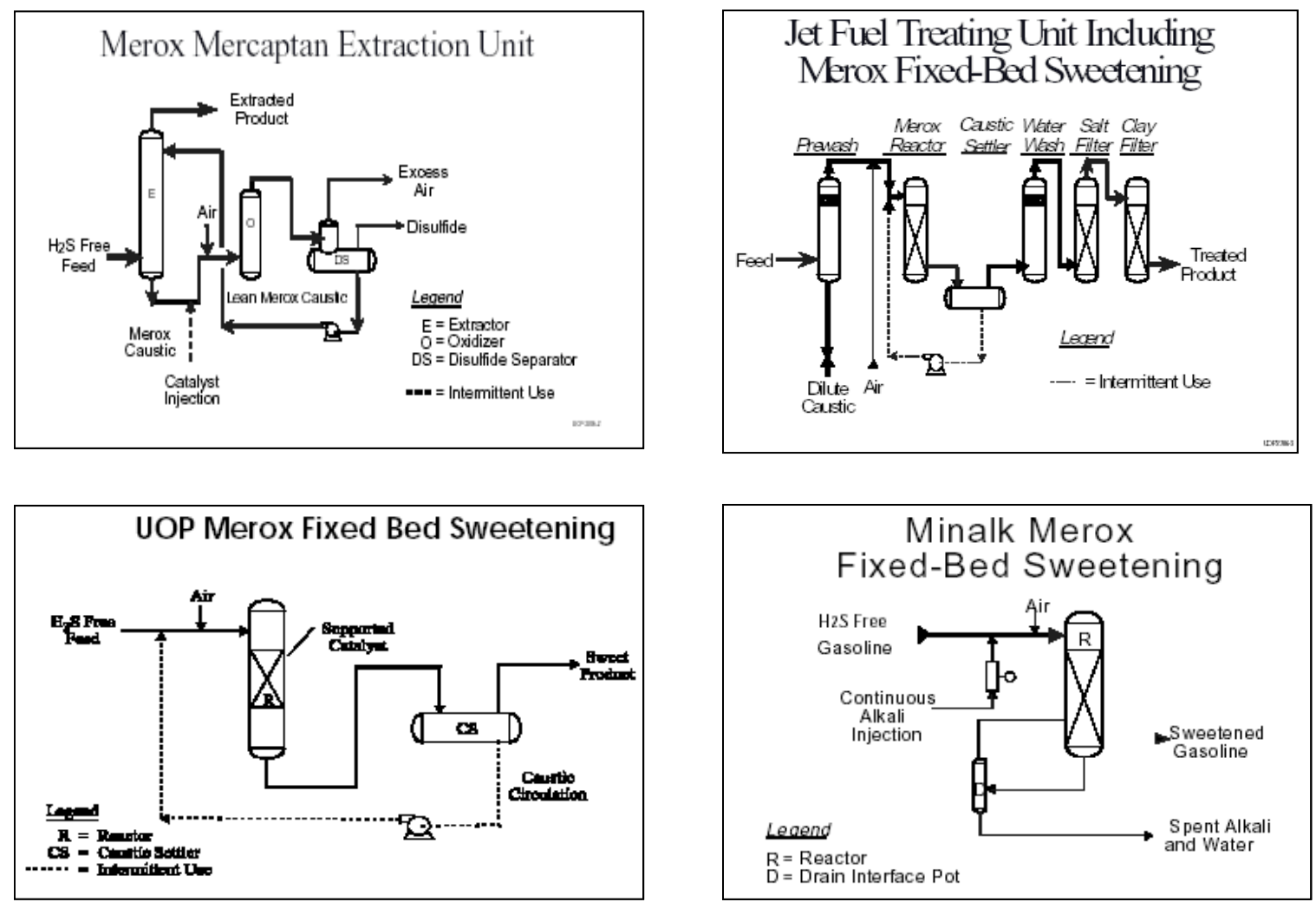

Figure 7. UOP Merox processing schemes.

When a new hydrotreater is installed to lower the amount of sulfur in a gasoline product, existing Merox equipment can become available for retrofit to bio-fuel service. For example, existing liquid extraction columns can be used as a feed or product wash column in a FAME production plant. Likewise, existing pumps, exchangers, reactors, separators, and caustic handling equipment can be reused in the esterification of soybean or rapeseed oil. 
Figure 8 illustrates a potential retrofit application wherein existing extraction and fixed bed conversion equipment is reused. The retrofit requires that a heterogeneous catalyst be developed for use in conjunction with an existing Merox fixed-bed reactor/separator to trans-esterify triglycerides in the presence of excess methanol and phase separate the crude glycerol product. Either a mixing device and/or co-solvent might be used to ensure adequate mixing of the triglyceride and methanol in the reactor,

The FAME-rich product phase is then routed to an existing Merox extractor tower for further purification by counter-current water wash (and drying). The crude glycerol co-product could either be recovered and sold or routed to another refining unit (such as FCC) for conversion by cracking. Another option is to install new equipment for glycerol purification. Since glycerol prices are expected to drop significantly as world-wide biodiesel production rates increase, the reuse of crude glycerol as a refinery feedstock may be more economically attractive than purification.

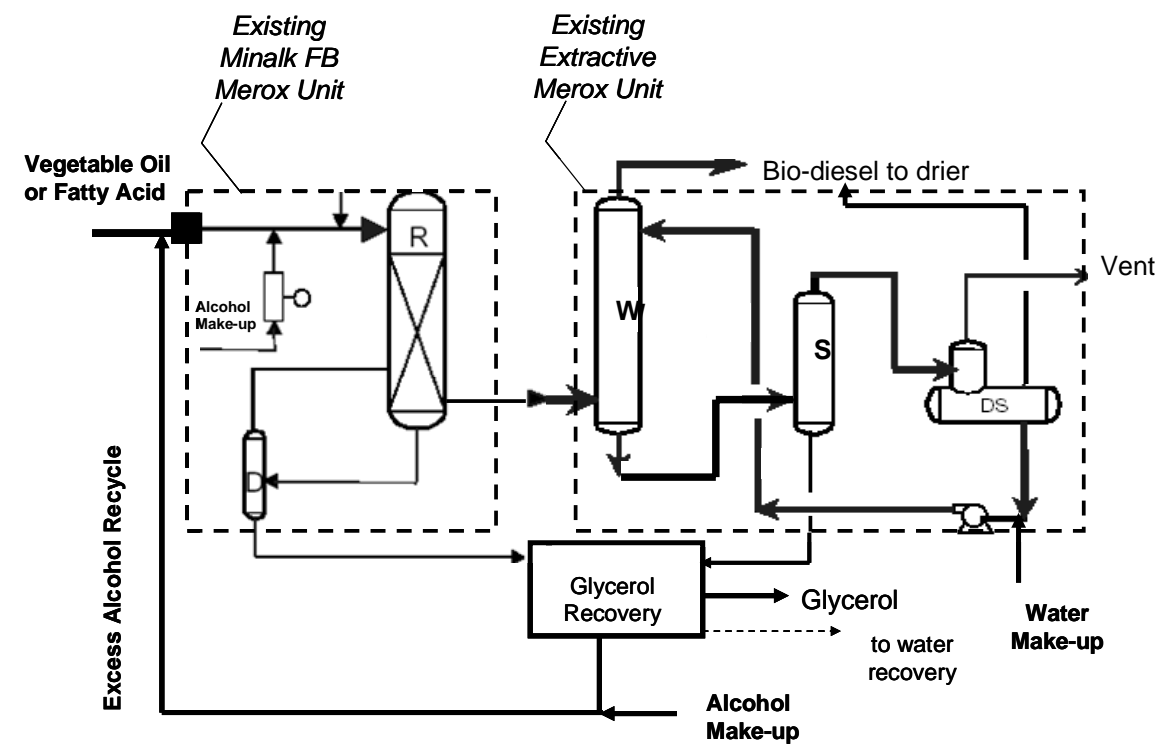

Figure 8. Possible Merox unit retrofit to FAME service.

\section{MTBE Unit Retrofit}

UOP MTBE units have been used by refiners for about 25 years to convert $\mathrm{C}_{4}$ olefins from fluid catalytic cracking units (FCCs) to methyl tertiary butyl ether (MTBE). The process is somewhat analogous to a FAME production unit in that methanol is reacted with the feedstock to convert it to a fuel-blending component. Figure 9 illustrates one version of the MTBE flow scheme. While many MTBE units are still operating in refineries elsewhere, units located in US refineries are being shut down or revamped to alternate service due to new regulations prohibiting the addition of ethers to gasoline. 


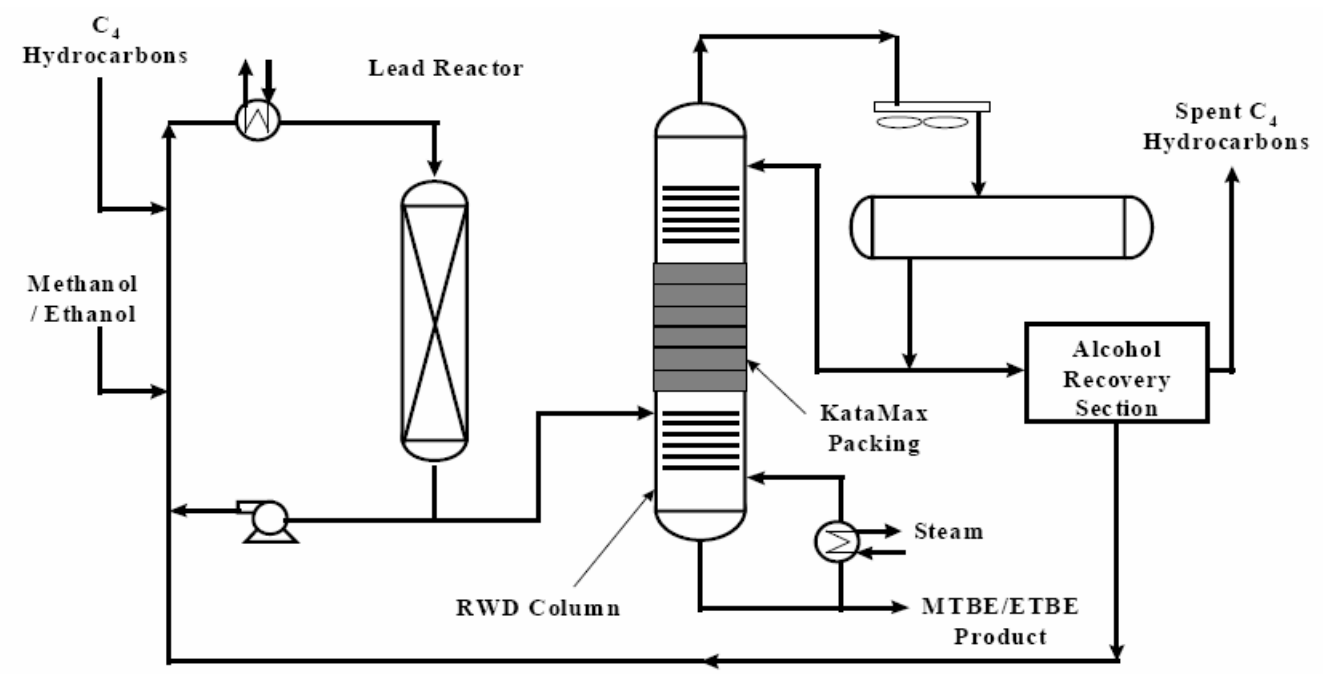

Figure 9. UOP MTBE (Ethermax) technology

A typical MTBE unit includes one or more fixed bed reactors where methanol (or ethanol) is reacted with butenes to form the corresponding ether. A portion of the reactor effluent is recycled to control the reactor exotherm. Unreacted feed components are separated from the higher-boiling ether product in a product fractionator. In Ethermax units, catalytic packing is used in the rectification section of the fractionating column to enhance conversion. Excess alcohol is then recovered and recycled back to the primary etherification reactor.

Retrofit of existing MTBE fixed-bed reactors to trans-esterify triglycerides in the presence of excess methanol also requires that a heterogeneous catalyst be developed. To ensure adequate mixing of the triglyceride and methanol in the reactor, either a pre-mixer and/or co-solvent would be used. The existing fractionation section would have to be modified to separate the higher boiling point FAME and glycerol products. However, it is expected that existing alcohol recovery equipment could be reused in biodiesel service.

\section{III.1.2 Retrofit Enablers}

The economic viability of retrofitting existing equipment for FAME production from biofeedstocks is highly dependent upon identifying a heterogeneous catalyst that can achieve high single-pass conversion under the normal reactor operating conditions of existing units $\left(<100^{\circ} \mathrm{C}\right)$. Because a typical FAME production unit has a relatively low processing capacity compared to most existing Merox or MTBE units, the unit turndown needs to be evaluated on a case-by-case basis. In principle, excess processing capacity can be judiciously used to provide longer reaction and/or separation times and to enhance high one-pass conversions of triglycerides.

\section{Preliminary Heterogeneous Catalyst Study}

There are incentives for development of a heterogeneous catalyst for FAME production whether it is employed in an existing or new unit:

- reduce operating costs (specifically consumption of chemicals)

- $\quad$ simplify product purification (eliminate caustic, acid, and salt byproducts)

- reduce generation of unwanted byproducts (soap stocks, wastewater, etc.)

- produce a more valuable glycerol product

Preliminary economic analyses suggest that cash cost of FAME production can be reduced by $\sim 5 \%$ or more with the development of a heterogeneous catalyst. 
A series of small-scale batch autoclave tests was performed to screen potential catalyst candidates using refined soy bean oil feedstock purchased from Aldrich and methanol. For each experiment, methanol, vegetable oil and catalyst were added to the autoclave in a prescribed ratio after which the vessel was sealed, heated to reaction temperature and stirred for a prescribed amount of time. In some cases, a co-solvent was added to ensure good contacting between the liquid phases. Afterwards, the products were phase-separated, excess methanol and co-solvent was removed and the oil phase was sent for analyses. A summary of operating conditions and analyses of the oil product from these tests is summarized in Table 2.

Table 2. Summary of FAME experimental results.

\begin{tabular}{|c|c|c|c|c|c|c|c|c|}
\hline & & & & \multicolumn{5}{|c|}{ <---Glyceride Compounds ---> } \\
\hline$T \& t$ & Run & CoSolvent & Catalyst & FAME & MONO & $\underline{\mathrm{DI}}$ & TRI & Glycerol \\
\hline $55 \mathrm{C}, 2 \mathrm{hrs}$ & 486 & Yes & A1 & 0.18 & 0.01 & 0.68 & 99.13 & 0.01 \\
\hline $55 \mathrm{C}, 2 \mathrm{hrs}$ & 487 & Yes & A1 & 0.05 & $<0.01$ & 1.09 & 98.86 & $<0.01$ \\
\hline 80 C. 4 hrs & 496 & Yes & $\mathrm{A} 2$ & 0.08 & 0.01 & 0.77 & 99.14 & $<0.01$ \\
\hline 80 C. 4 hrs & 496 & Yes & A3 & 0.08 & 0.01 & 0.77 & 99.14 & $<0.01$ \\
\hline 55 C. 2 hrs & 481 & Yes & 11 & 0.6 & 0.04 & 1.62 & 97.74 & 0.00 \\
\hline 55 C. 2 hrs & 482 & Yes & 12 & 0.01 & 0.10 & 1.73 & 98.16 & $<0.01$ \\
\hline 80 C. 4 hrs & 497 & Yes & 13 & 0.65 & 0.04 & 1.89 & 97.42 & $<0.01$ \\
\hline 80 C. 4 hrs & 495 & Yes & B1 & 3.08 & 0.36 & 6.44 & 90.12 & $<0.01$ \\
\hline $55 \mathrm{C}, 2 \mathrm{hrs}$ & 489 & Yes & $\overline{C 1}$ & 6.58 & 1.09 & 12.43 & 79.87 & 0.03 \\
\hline $55 \mathrm{C}, 2 \mathrm{hrs}$ & 493 & No & $\mathrm{C} 2$ & 22.82 & 0.51 & 6.73 & 69.87 & 0.07 \\
\hline $55 \mathrm{C}, 2 \mathrm{hrs}$ & 484 & No & M1 & 54.73 & 0.79 & 6.37 & 37.62 & 0.49 \\
\hline $55 \mathrm{C}, 2 \mathrm{hrs}$ & 485 & Yes & M1 & 77.28 & 6.74 & 6.96 & 8.72 & 0.29 \\
\hline $80 \mathrm{C}, 4 \mathrm{hrs}$ & 490 & Yes & M1 & 86.32 & 5.18 & 4.45 & 3.45 & 0.60 \\
\hline $80 \mathrm{C}, 4 \mathrm{hrs}$ & 491 & Yes & M1 & 10.63 & 1.01 & 9.96 & 78.36 & 0.04 \\
\hline $55 \mathrm{C}, 4 \mathrm{hrs}$ & 492 & Yes & $\overline{A M 1}$ & 31.44 & 0.53 & 4.23 & 63.53 & 0.27 \\
\hline $60 \mathrm{C}, 4 \mathrm{hrs}$ & 498 & Yes & AM1 & 31.97 & 0.27 & 3.43 & 64.1 & 0.23 \\
\hline & & & Solid & & ---Glyce & Comp & Is ---> & \\
\hline$T \& t$ & Run & CoSolvent & Catalyst & FAME & MONO & DI & $\underline{\text { TRI }}$ & Glycerol \\
\hline$\overline{80 \mathrm{C}}, 4 \mathrm{hrs}$ & 500 & Yes & B2 & 0.02 & 0.01 & $0 . \overline{6} 7$ & $9 \overline{99.31}$ & 0.01 \\
\hline $80 \mathrm{C}, 4 \mathrm{hrs}$ & 501 & Yes & B3 & 2.61 & 0.14 & 9.0 & 88.25 & 0.01 \\
\hline $80 \mathrm{C}, 4 \mathrm{hrs}$ & 502 & Yes & B4 & 97.78 & 1.35 & 0.72 & 0.06 & 0.09 \\
\hline $80 \mathrm{C}, 4 \mathrm{hrs}$ & 503 & Yes & B5 & 97.45 & 1.62 & 0.67 & 0.01 & 0.26 \\
\hline $80 \mathrm{C}, 4 \mathrm{hrs}$ & 509 & No & B5 & 97.48 & 0.88 & 0.6 & 0.04 & 1.04 \\
\hline $80 \mathrm{C}, 4 \mathrm{hrs}$ & 511 & Yes & B6 & 96.70 & 2.33 & 0.86 & 0.01 & 0.11 \\
\hline $80 \mathrm{C}, 4 \mathrm{hrs}$ & 506 & Yes & B7 & 81.63 & 8.45 & 8.31 & 1.07 & 0.54 \\
\hline $80 \mathrm{C}, 4 \mathrm{hrs}$ & 507 & Yes & B8 & 73.71 & 5.22 & 14.91 & 5.75 & 0.41 \\
\hline
\end{tabular}

Several catalyst formulations (M1 and B4-B8) showed high one pass conversion of triglyceride to FAME at mild operating conditions $\left(<100^{\circ} \mathrm{C}\right)$. These catalysts all require further development to ensure that the high activity can be maintained under the expected continuous flow conditions associated with a commercial processing environment.

\section{Financial Incentives For Retrofits}

There are additional financial incentives associated with retrofitting existing refining equipment such as Merox and MTBE units to FAME production, including: 
- leveraging existing land and refinery infrastructure,

- reducing capital investment for processing equipment, and

- capturing subsidies associated with production of renewable fuels.

However, the metallurgy of the existing equipment (typically carbon steel) may limit the processing of high free fatty acid (FFA) feedstocks. Preliminary economic analyses suggest that it is possible to reduce the overall investment requirements by $50 \%$ or more. Coupling the lower capital expenditures with renewable fuel subsidies make the potential payback on new capital reasonably short ( $<2$ years).

\section{III.1.3 Conclusions}

In this preliminary analysis, potential retrofits of existing Merox and MTBE units to FAME production appear promising under the right circumstances:

- a heterogeneous catalyst is developed for operation under mild conditions $\left(<100^{\circ} \mathrm{C}\right)$

- an appropriate combination of feed price, feed availability, and product market.

- adequate metallurgy for the proposed feedstock in the existing unit

Several promising heterogeneous catalysts were identified in UOP's laboratory screening test. However, the screening test only evaluates initial catalyst activity. The next step is to subject the most promising candidates to continuous-flow testing at operating conditions consistent with the anticipated commercial processing environment to ensure the high activity can be maintained.

It should be noted that for all the biodiesel catalysts that achieved high conversion, it was discovered that base had leached into the liquid phase so these tests were not completely heterogeneous but had a homogenous component as well. When the leachable base was removed from the catalyst with highest conversion, the conversion was much lower (less than $50 \%$ ). Therefore further work to obtain a stable base catalyst will be needed in order to commercialize this process.

Assuming that an acceptable catalyst formulation is identified, then a realistic set of assumptions for plant capacity, feedstock cost, feedstock quality and product requirements need to be identified as the basis for a more detailed feasibility study. 


\section{III.2 Green Diesel Production}

“Green diesel” refers to an acceptable diesel pool blend component produced from a suitable biofeedstock. In contrast to biodiesel discussed in Section III.1, green diesel hydrocarbons do not contain oxygen in their molecular structure. Biofeedstocks that are of particular interest for green diesel production are plant oils and greases.

\section{III.2.1 Green Diesel Production Approaches}

Two alternatives were evaluated for producing green diesel from biofeedstocks, illustrated in Figure 10:

- (a) co-processing oil or grease in an existing hydroprocessing unit, and

- (b) processing oil or grease in a standalone process unit.

The two case studies are summarized in Sections III.2.2 and III.2.3, respectively. Supporting experiments are summarized in Section III.2.4.

\section{III.2.2 Green Diesel Production - Co-Processing Biofeedstocks in an Existing Unit}

(a) Pretreat and Co-process
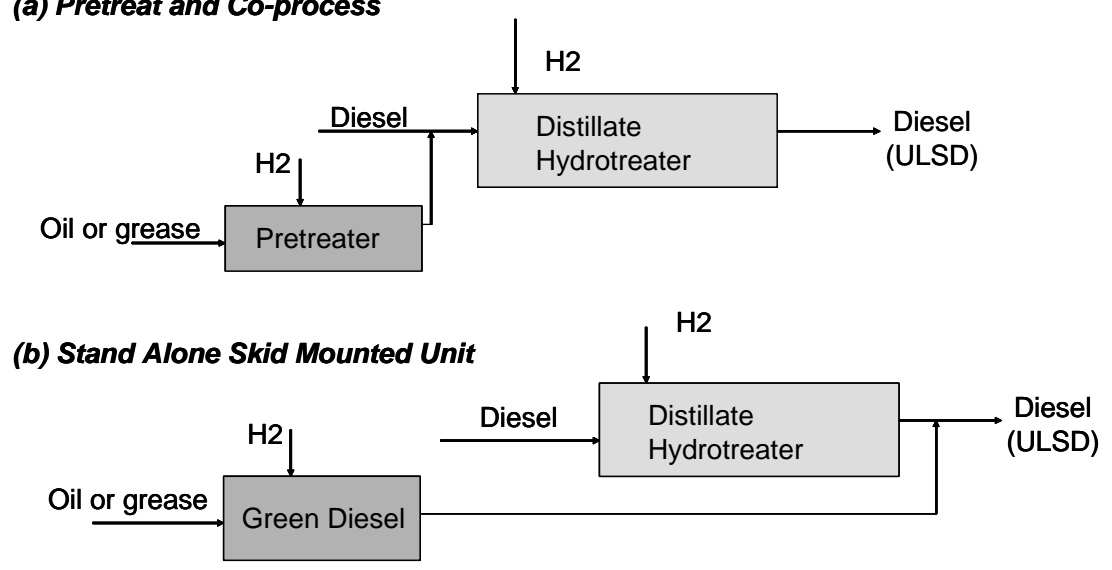

Figure 10. Alternatives for green diesel production.

The process unit for the biofeedstock co-processing a biomass source was a distillate hydrotreater for ultra-low sulfur diesel (ULSD). The base case was a hydrotreating unit with the following specifications:

- $\quad$ straight-run diesel feed from a blend of Middle-East crudes with less than 10\% FCC light cycle oil

- 35,000 bpd, 950 psig separator pressure, 1.1 LHSV, and 6,000 scfb total gas rate

- chemical hydrogen consumption of $1.1 \mathrm{wt}$ \% relative to fresh feed

- heat release of $160 \mathrm{Btu} / \mathrm{lb}$

- 30 month cycle time with a state-of-the-art Co/Mo catalyst.

- activity limited catalyst cycle with a catalyst temperature cycle of $27^{\circ} \mathrm{F}$. 
Table 3. Hydrotreating yields for brown grease.

\begin{tabular}{|l|c|}
\hline Components & Wt\% \\
\hline \hline Feeds & 100 \\
\hline Brown grease & 2.9 \\
\hline $\mathrm{H}_{2}$ & 0.04 \\
\hline \hline Products & 0.7 \\
\hline $\mathrm{H}_{2} \mathrm{~S}+\mathrm{NH}_{3}$ & 2.4 \\
\hline $\mathrm{C} 1$ to $\mathrm{C} 4$ & 0.0 \\
\hline $\mathrm{Naptha}$ & 12.7 \\
\hline $\mathrm{CO}_{2}$ & 0.0 \\
\hline $\mathrm{H}_{2} \mathrm{O}$ & 87.2 \\
\hline $\mathrm{nC} 17$ & 102.9 \\
\hline $\mathrm{nC} 18$ & Total
\end{tabular}

The objective of the co-processing case study was to produce a "G5" diesel pool in which $5 \%$ of the diesel pool contains "green diesel". Since the United States does not currently subsidize bio-diesel or green diesel production, the biomass source of choice is one with an inexpensive feed cost, such as brown grease with $100 \%$ free fatty acids. The hydroprocessing conditions are assumed to completely favor hydrodeoxygenation (HDO). In other words, oxygen in the biofeedstock is removed by reaction with hydrogen to form water and the C18 n-paraffin. For G5 diesel production at constant crude-based diesel feed rate, the biomass feed rate to the distillate hydrotreating unit must be approximately $5.8 \%$ of the crude feed rate, or 2050 bpd relative to the base case. In addition, the crude rate and crude slate are not changed to accompany the additional feed into the distillate hydrotreating unit. The estimated distillate yield is shown in Table 3. These yields assume no yield loss from production of light ends such as methane, ethane, LPG components, or naphtha.

Table 4 summarizes the expected hydrogen consumption and heat release for fatty acid components of the model brown grease, compared with the crude oil-based feed. Using the model brown grease composition shown in the third column, the estimated hydrogen consumption for hydrodeoxygenation is $3.0 \mathrm{wt} \%$. The anticipated heat release is approximately $385 \mathrm{Btu} / \mathrm{lb}$.

Table 4. Hydrotreating free fatty acids.

\begin{tabular}{|r|c|c|c|c|c|c|c|}
\hline Feed & C:= & $\begin{array}{c}\text { \% in } \\
\text { Model } \\
\text { Feed }\end{array}$ & MW & $\begin{array}{c}\text { H2 } \\
\text { FFA I }\end{array}$ & $\begin{array}{c}\text { Total Heat } \\
\text { Consumed } \\
\text { (wt\% feed) }\end{array}$ & $\begin{array}{c}\text { Release } \\
\text { (Btu/lb) }\end{array}$ & Br No \\
\hline Free Fatty Acid & & & & & & & \\
\hline Stearic Acid & $18: 0$ & 25 & 284.47 & 3 & 2.13 & 175 & 0 \\
\hline Oleic Acid & $18: 1$ & 45 & 282.46 & 4 & 2.85 & 367 & 57 \\
\hline Linoleic Acid & $18: 2$ & 25 & 280.44 & 5 & 3.59 & 562 & 114 \\
\hline Linolenic Acid & $18: 3$ & 5 & 278.43 & 6 & 4.34 & 760 & 172 \\
\hline Diesel & & & & & 1.08 & 160 & 2.5 \\
\hline
\end{tabular}

The effects of the following factors on the start-of-run average bed temperature (activity) and deactivation rate were analyzed using UOP-proprietary distillate hydrotreating reactor correlations:

- properties of the brown grease feed such as sulfur, oxygen, and olefin content

- heat release from olefin saturation and hydrodeoxygenation of brown grease

- increased space velocity

- "treat-gas” ratio, or the total gas (makeup plus recycle gas) ratio

Three cases were analyzed to demonstrate the individual effects of the variables relative to the base case: 
- Case I demonstrates the effect of brown grease feed properties. Case I is the base case with 5.8\% biomass added to the fresh feed while maintaining the total fresh feed rate. The crude-based feed rate is reduced to approximately $33100 \mathrm{bpd}$ and supplemented with 1900 bpd brown grease. The product contains approximately 5\% green diesel, as desired.

- Case II demonstrates the effect of increasing space velocity to accompany the additional biomass feed. Case II maintains the ratio between the feed types of Case I and increases total fresh feed rate to maintain the feed rate of crude in the base case. The refinery crude slate and crude rate is not changed from the base case. The treat-gas ratio is maintained at the base-case ratio, under the assumption that the recycle gas compressor is not capacitylimited.

- Case III builds upon Case II by limiting the recycle gas compressor capacity to the basecase absolute capacity.

The results of analyzing the three cases of brown grease co-processing are depicted in Figure 11 through Figure 13; the results are expected to represent the general behavior of low or no-sulfur biofeedstocks such as plant oils and greases.

Figure 11 shows the effect of co-processing brown grease on the catalyst temperature cycle, defined as the end-of-run (EOR) peak temperature minus the SOR peak temperature. For the purpose of this study, the end-of-run peak temperature is fixed at the base-case value. Brown grease shows has an activity advantage regarding desulfurization. In this study, the start-of-run (SOR) average bed temperature $(\mathrm{ABT})$ is reduced by approximately $2^{\circ} \mathrm{F}$. However, the activity advantage is eroded by the heat release of brown grease, which is nearly 2-1/2 times higher than diesel. When the space velocity is increased in Case II, the corresponding increase in released heat raises

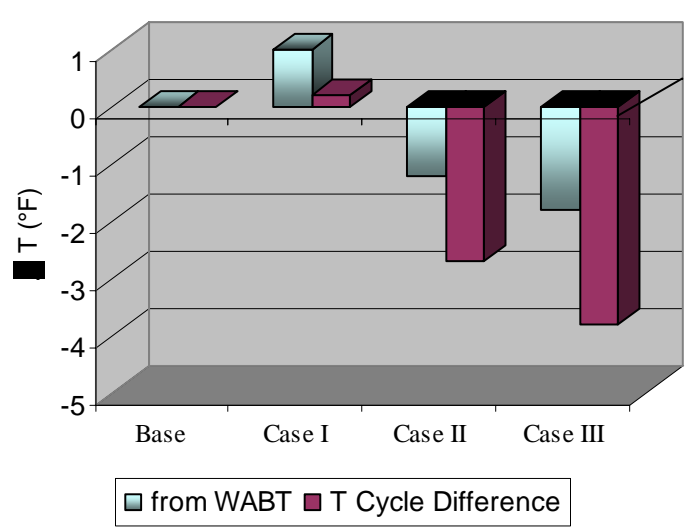

Figure 11. Effect of co-processing brown grease on catalyst temperature cycle. the SOR ABT by approximately $3^{\circ} \mathrm{F}$, consequently decreasing the catalyst temperature cycle. Capping the recycle gas compressor absolute capacity in Case III limits the system's ability to control the catalyst bed temperature rise and, hence, the catalyst SOR ABT increases further, decreasing the temperature cycle by almost $4^{\circ} \mathrm{F}$ relative to the base case temperature cycle of $27^{\circ} \mathrm{F}$.

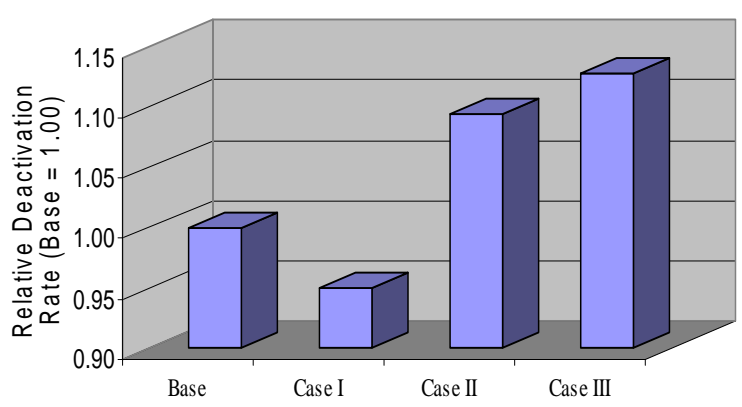

Figure 12. Effect of co-processing brown grease on catalyst deactivation rate.
Figure 12 shows the relative deactivation rates for the cases analyzed. The sulfur content of the overall feed decreases when the crude-based feed is diluted with a biofeedstock containing little or no sulfur. The severity of the hydrotreating catalyst processing conditions is consequently reduced for the same product sulfur content. As a result, the deactivation rate decreases. As a consequence of further increasing the feed rate and decreasing the hydrogen circulation rate over the catalyst, the catalyst deactivation increases by approximately 
$20 \%$ over Case I. One important factor not included in this analysis of catalyst stability is water production.

The catalyst cycle length, shown in Figure 13 , is determined by the temperature cycle and the deactivation rate. The cycle length for G5 diesel production, without decreasing the crude-based diesel rate or increasing the recycle gas compressor capacity, decreases by 6 to 7 months (Cases II and III). This reduced cycle time has economic consequences - for example, 2 to 3 days per year production loss and increased catalyst and associated turnaround costs.

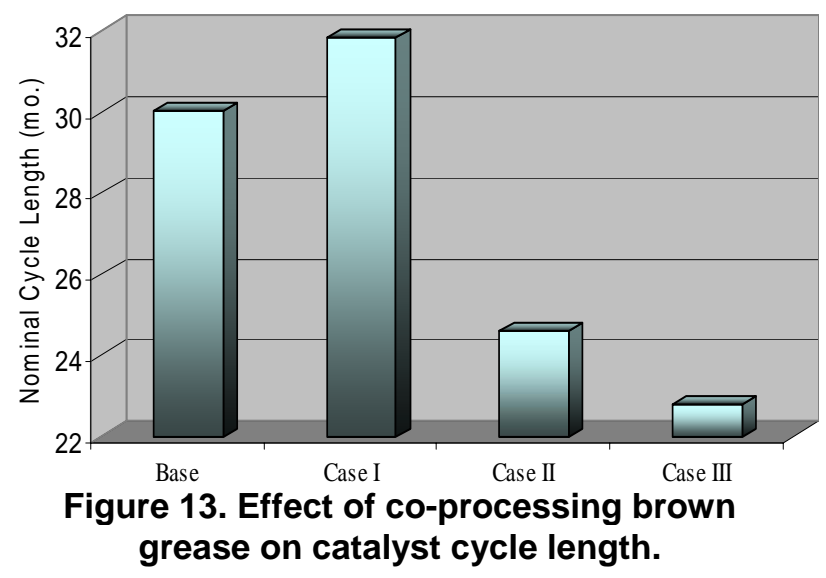

The study also evaluated the impact of co-processing brown grease on reactor metallurgy and on the cloud point of the resulting diesel pool. The feed section metallurgy is carbon steel in hydroprocessing units such as hydrotreaters and hydrocrackers. There is a graduation of metallurgy from low-chrome through austenitic stainless steel in the combined feed exchangers. The fired heater tubes, reactor cladding and associated reactor circuit piping are typically 321 or 347 stainless steels. The Total Acid Numbers (TAN) of plant oils and greases range from 2 to 200. A TAN number of 0.5 to 0.6 is an industrially-accepted limit before considering upgrades to the process unit metallurgy. Therefore, the reactor section metallurgy of a hydroprocessing unit must be upgraded if any significant quantity of an economically-attractive biofeedstock is to be processed. The cost was estimated for upgrading the reactor section metallurgy to 317L stainless steel in the base case distillate hydrotreater and found to be substantial - approximately 7 to 8 million dollars. Additional capital costs that were not included are costs for brown grease tankage and brown grease pretreatment equipment for possible dewatering, acid washing, ion exchange, and/or desalting.

Distillates from brown grease and other similar biofeedstocks contain primarily n-paraffin. The nparaffin content will decrease the cloud point of the diesel pool from 2 to $3^{\circ} \mathrm{F}$ per percent of nparaffin content. Therefore, assuming that all diesel components in the diesel pool are hydrotreated to make ultra-low sulfur diesel, G5 diesel production may increase the cloud point of the diesel pool by 10 to $15^{\circ} \mathrm{F}$. A diesel isomerization catalyst would be required to counteract the cloud point increase and preserve the green diesel molecules in the diesel pool. Unfortunately, such isomerization catalysts are typically noble metal catalysts and would require a two-stage hydroprocessing scheme, which is not typical for distillate hydrotreating units, necessitating major unit modifications.

In summary, co-processing of biomasses such as plant oils and greases in a typical refinery distillate hydrotreating unit has some drawbacks for green diesel production:

- The chemical nature of the biofeedstocks significantly increases hydrogen requirements under conditions that favor hydrodeoxygenation.

- The heat release from these feeds substantially reduces the catalyst cycle length.

- High TAN number feeds incur significant capital costs for metallurgy upgrading. Other capital costs may include feed pre-processing equipment to remove contaminants. 
- Typical hydrotreating unit configurations do not permit remediation of increased cloud point due to n-paraffins in the green diesel component of the diesel pool.

- The process conditions for hydrotreating units for ultra-low sulfur diesel production favor HDO, producing water that may adversely affect catalyst performance.

In conclusion, standard refinery distillate hydrotreating units do not appear to be suitable for green diesel production in a co-processing scheme.

\section{III.2.3 Green Diesel Production - Processing Biofeedstocks in a Stand-Alone Unit}

Green diesel production in a standalone unit appears to address the issues identified in Section III.2.2 for co-processing schemes:

- catalyst performance can be improved through feed pretreatment

- a process can be designed to favor a different deoxygenation mechanism

- a simpler isomerization process can be used to prevent cloud point reduction

- the unit can be specifically designed to handle biofeedstocks

One possible flow scheme for a standalone unit is shown in Figure 14.

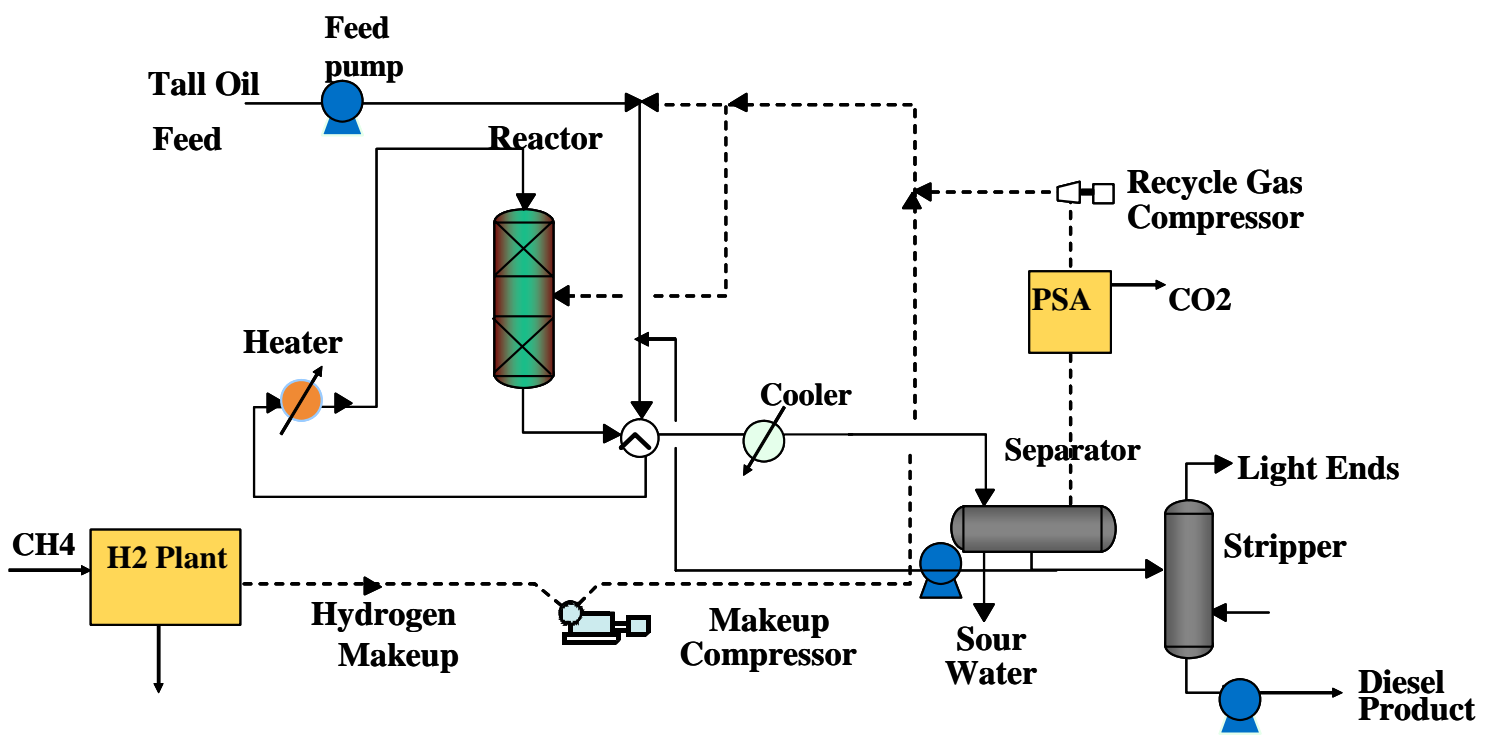

Figure 14. Proposed flow scheme for standalone production of green diesel.

Plant oils and yellow and brown greases may contain water, alkali metals (such as sodium, potassium), phosphorous, ash, and other contaminants. Metals permanently deactivate hydroprocessing catalysts. In a standalone unit, a pre-processing step would remove contaminants from the biofeedstock. using a combination of technologies such as hydrocyclones, desalting, acid washing, ion exchange, or fixed guard bed catalyst systems. This is a distinct advantage over 
a co-processing system. A typical strategy for metals removal is to provide a less active sacrificial bed of hydrodemetallization (HDM) catalyst in front of the active hydrodesulfurization (HDS) catalyst. In existing distillate hydrotreaters, either active catalyst would be removed to load HDM catalyst or the metals would be allowed to deposit on the active HDS catalyst. Both choices would decrease the catalyst cycle length of an existing unit.

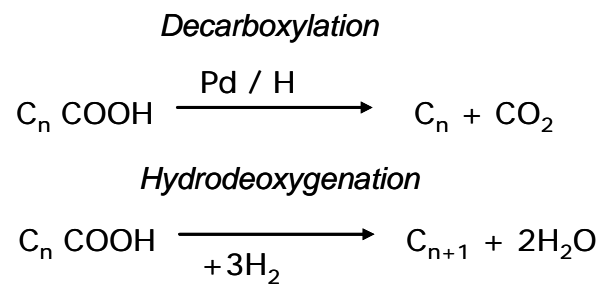

Figure 15. Decarboxylation vs Hydrodeoxgenation
The processing conditions to produce ultra-low sulfur diesel (ULSD) in an existing unit highly favor HDO, with the drawbacks outlined in Section III.2.2. An alternative mechanism, decarboxylation (DeCO2), removes oxygen in the biomass carboxyl groups as carbon dioxide instead of as water. In a standalone unit, catalyst and processing conditions can be selected to shift the oxygen removal mechanism from HDO to DeCO2. Decarboxylation and hydrodeoxygenation are illustrated in Figure 15.
Gas phase DeCO2 is discussed for several model compounds by Maier. ${ }^{12}$ Table 5 compares the estimated yields of DeCO2 with HDO for the model brown grease. There are several clear advantages for DeCO2:

- Chemical hydrogen consumption is limited to olefin saturation, therefore significantly lower.

- Lower chemical hydrogen consumption reduces the hydrogen plant capital or hydrogen purchases and the makeup hydrogen compressor size.

- Water is not produced as a reaction product, thereby preserving catalyst performance.

- Rejected $\mathrm{CO}_{2}$ can be captured in a relatively pure state as a product. From a greenhouse gas emissions viewpoint, the proposed green diesel process would not only be $\mathrm{CO}_{2}$ neutral, but actually produce additional $\mathrm{CO}_{2}$ credits.
Table 5. Hydrodeoxygenation versus decarboxylation theoretical yields

\begin{tabular}{|l|c|c|}
\hline Components & $\begin{array}{c}\text { DeCO2 } \\
\text { Wt\% }\end{array}$ & $\begin{array}{c}\text { HDO } \\
\text { Wt\% }\end{array}$ \\
\hline \hline \multicolumn{3}{|l|}{ Feeds } \\
\hline Brown grease & 100 & 100 \\
\hline $\mathrm{H}_{2}$ & 0.8 & 2.9 \\
\hline \hline Products & 0.04 & 0.04 \\
\hline $\mathrm{H}_{2} \mathrm{~S}+\mathrm{NH}_{3}$ & 0.6 & 0.7 \\
\hline $\mathrm{C}_{1}$ to $\mathrm{C}_{4}$ & 2.5 & 2.4 \\
\hline $\mathrm{Naptha}$ & 15.5 & 0.0 \\
\hline $\mathrm{CO}_{2}$ & 0 & 12.7 \\
\hline $\mathrm{H}_{2} \mathrm{O}$ & 82.2 & 0.0 \\
\hline $\mathrm{nC} 17$ & 87.2 & 87.2 \\
\hline $\mathrm{nC} 18$ & 100.8 & 102.9 \\
\hline \hline
\end{tabular}

Decarboxylation can not be considered in a unit producing ULSD for two reasons: (1) DeCO2 is favored over HDO at lower temperatures and pressures than the conditions required for deep desulfurization of traditional feedstocks; (2) the production of $\mathrm{CO}_{2}$ will reduce hydrogen partial pressure unless the purge rate from the high-pressure separator, and subsequently, the make-up hydrogen rate are both increased. In a stand-alone unit, a pressure swing adsorption unit (PSA) system in the recycle gas stream can be provided to remove $\mathrm{CO}_{2}$. In this way, recycle gas purge, recycle gas and makeup gas compression are minimized.

The relevant biofeedstocks have low concentrations of sulfur and nitrogen compounds relative to standard feedstocks. This makes n-paraffins in the green diesel product amenable to hydroisomerization without a true two-stage hydroprocessing unit such as would be required in a 
co-processing scheme. A hydroisomerization reactor directly follows the olefin saturation / decarboxylation stage in the flow scheme of Figure 14.

A standalone unit can be design from the outset with metallurgy appropriate to the high TAN numbers of the candidate biofeedstocks. Upgrading most of the metallurgy to 317L stainless steel allows poorer quality and less expensive feeds (higher free fatty acid content) to be processed than would be possible in a typical hydroprocessing unit. However, the capital cost of the unit is obviously increased. Coupon testing must be done to determine whether the proposed metallurgy provides adequate corrosion protection. The estimated inside battery limits capital cost for a 2000 bpd standalone green diesel unit is approximately $\$ 6,000$ to 7,000 per barrel.

\section{III.2.4 Green Diesel Experimental Results}

Background information on green diesel is available from Arbokem/Canmet, Fortum Oil, and most recently OMV. Arbokem has the key patent in green diesel production which expires in $2008 .^{13}$ Initially it was thought that yield estimates could be generated from literature and modeling results alone. Our initial yield estimates assumed that hydrodeoxygenation would be the primary mechanism for oxygen removal, as reported by Canmet/Arbokem from their initial studies $^{14}$ run at 700-2200 psi and 350-450C.

However, experiments performed in this project showed that both hydrodeoxygenation and decarboxylation occur, with the results summarized in Table 6. Decarboxylation is favored at lower pressures and hydrodeoxygenation increased with increasing pressure. Decarboxylation results in odd number paraffin production and $\mathrm{CO}_{2}$ formation whereas hydrodeoxygenation results in even carbon number paraffin production; therefore the ratio of $\mathrm{nC} 17$ to $\mathrm{nC} 18$ is a measure of the DeCO2/HDO ratio. Standard hydrotreating catalysts of NiMo, CoMo and Pd all showed activity for both reactions. Furthermore it was demonstrated that the process could be run at lower temperatures than cited in the Arbokem patent and heavy material boiling above diesel range, which Arbokem produced, could be eliminated or reduced with proper choice of catalyst and conditions. Also, most experiments were done at 500psi which is well below the pressures cited in the Arbokem patent.

Table 6. Green diesel experimental summary.

\begin{tabular}{|l|c|c|c|c|}
\hline & $\mathbf{5 2 4}$ & $\mathbf{5 3 1}$ & $\mathbf{1 3 1 6 - C 3}$ & 1316-C4 \\
\hline \hline Feed & Vegetable oil & Vegetable oil & Vegetable oil & Vegetable oil \\
\hline Catalyst & HCT (NiMo) & N200 (CoMo) & HCT (NiMo) & HCT (NiMo) \\
\hline Test Unit & Autoclave & Autoclave & Plt 1316-B1 & PIt 313-B1 \\
\hline WHSV & 1.9 & 1.7 & 0.8 & 0.3 \\
\hline Temperature (C) & $300-350$ & $300-350$ & 325 & 310 \\
\hline Pressure (psia) & 500 & 500 & 500 & 500 \\
\hline \hline Products & 1.7 & 1.2 & 4.9 & 9.9 \\
\hline \% water & 12.7 & 13.4 & 2.6 & 1.9 \\
\hline \% CO ${ }_{2}$ CO & 7.0 & 5.2 & 3.4 & 3.9 \\
\hline \% Light HC & 79 & 80 & 88.3 & 84 \\
\hline \% diesel+ & 0 & 3.2 & 0.3 & 0.3 \\
\hline \%heavy & $90+$ & $91+$ & 85 & 99 \\
\hline \%deoxygenation & 3.0 & 2.1 & 0.6 & 0.49 \\
\hline nC17/nC18 & & & & \\
\hline
\end{tabular}


Further testing is recommended to develop an optimized process. These experiments were proofof-principle (POP) experiments, so good material balances were not achieved. In the autoclave, liquid and catalyst are charged to the reactor and $\mathrm{H}_{2}$ gas is constantly flowing. For autoclave tests, losses are treated as gas which is calculated by difference so gas yield is overestimated and liquid yield underestimated. Gas composition changed throughout the test period because the test was not at steady state and true material balance and gas weights were not obtained.

The most active hydrotreating catalysts, such as UF-310 and UF-210 Stars, were not tested in these POP tests because of difficulties in presulfiding these materials. Therefore, there is considerable opportunity for improvement during development of a green diesel process, if pursued.

\section{III.3 Comparison of Biodiesel and Green Diesel Process and Properties}

It is useful to compare biodiesel and green diesel properties and process since they represent two different approaches for making diesel fuel from vegetable oil. Selected properties are compared in Table 7. Green diesel has excellent diesel fuel properties including an extremely high cetane number (see Section III.3). Cetane number is a measure of a diesel fuel's ignition delay, e.g. the time period between the start of injection and start of combustion of the fuel, and affects the price of both green diesel (80 cetane) and biodiesel (55 cetane). Biodiesel has lower heating value because of its oxygen content. Biodiesel also has other undesirable properties such as high density, and high NOx emissions. Overall, Table 7. Biodiesel and green diesel properties green diesel appears to be a superior product.

Table 8 compares the processes by which biodiesel and green diesel are produced. The biodiesel process is fairly complicated, requiring multiple distillations and purifications. Green diesel is totally feed flexible and can handle low cost feedstocks like brown grease with high free fatty acid content without problems. Biodiesel requires methanol as feed and produces glycerol as a byproduct. Glycerol price is expected to drop significantly to $\$ .10 / \mathrm{lb}$ as biodiesel production increases. Green diesel only requires hydrogen as a feed and produces only diesel and propane as a product so its value is not affected by methanol or glycerol price. Biodiesel requires a homogeneous catalyst, resulting in higher chemical

Table 8. Comparison of biodiesel and green diesel production processes.

\begin{tabular}{|l|l|l|}
\hline & Biodiesel & Green Diesel \\
\hline Complexity & $\begin{array}{l}\text { High- } \\
\text { multistages }\end{array}$ & low \\
\hline Feedstocks & $\begin{array}{l}\text { Sensitive to } \\
\text { level of FFA }\end{array}$ & $\begin{array}{l}\text { No sensitivity } \\
\text { to FFA }\end{array}$ \\
\hline Requires & $\begin{array}{l}\text { Methanol - } \\
10 \%\end{array}$ & H2 -2-3\% \\
\hline Byproduct & Glycerol & Propane \\
\hline Catalyst & Homogeneous & Heterogeneous \\
\hline
\end{tabular}
costs. 
As shown in Table 9, biodiesel does have an advantage in yields of diesel product per lb of vegetable oil feed. This is due to the fact that the oxygen in vegetable oil is retained in the biodiesel product where as the oxygen in vegetable oil is rejected green diesel as water or $\mathrm{CO}_{2}$. However, the overall cost of biodiesel production is projected to be nearly twice that of green diesel.

\section{III.4 GREen GASOLINE AND GREEN OLEFINS PRODUCTION}

Table 9. Green diesel and biodiesel yields.

\begin{tabular}{|r|c|c|}
\hline \multicolumn{1}{|l|}{ Feed } & Biodiesel & Green Diesel \\
\hline$\%$ Oil or Grease & 100 & 100 \\
\hline$\%$ H2 & & $1.5-3.8$ \\
\hline Products & & \\
\hline$\%$ water,CO2 & & $12-16$ \\
\hline$\%$ Lt HC & & $2-5$ \\
\hline$\%$ diesel & 96 & $83-86$ \\
\hline glycerol & 12 & .025 \\
\hline Operating cost \$/gal & .05 & \\
\hline
\end{tabular}

Vegetable oils and greases can be processed in an FCC to produce high yields of gasoline and oils. ACE microactivity tests were completed to determine the yields and product properties. The gasoline produced has high octane number and the vegetable oil produces a lot of high valued olefins at PetroFCC conditions (severe conditions design to maximize olefins production) compared to vacuum gas Oil (VGO), as shown in Table 10. The yields from processing vegetable oil and grease compared to VGO are shown in Table 10 and Table 11 .

Table 10. Green olefin yields.

\begin{tabular}{|l|l|l|}
\hline & VGO & $\begin{array}{l}\text { Vegetable } \\
\text { Oil/Grease }\end{array}$ \\
\hline $\mathrm{C}_{2} \mathrm{P}+$ Methane & 4.1 & 4.1 \\
\hline $\mathrm{C}_{2}=$ & 8.6 & 8.7 \\
\hline $\mathrm{C}_{3} \mathrm{P}$ & 2.0 & 2.1 \\
\hline $\mathrm{C}_{3}=$ & 22.0 & 22.4 \\
\hline $\mathrm{C}_{4} \mathrm{~S}$ & 15.0 & 13.5 \\
\hline Gasoline & 27.3 & 23.0 \\
\hline LCO & 9.5 & 5.0 \\
\hline CSO & 5.0 & 3.0 \\
\hline Coke & 6.5 & 6.5 \\
\hline Water & 0 & 11.7 \\
\hline RON of Gasoline & 94.8 & 96.8 \\
\hline
\end{tabular}

Table 11. Green gasoline yields

\begin{tabular}{|l|c|c|}
\hline & VGO & $\begin{array}{c}\text { Vegetable } \\
\text { Oil/Grease }\end{array}$ \\
\hline $\mathrm{C}_{2}=$ & 1.5 & 1.9 \\
\hline $\mathrm{C}_{3} \mathrm{P}$ & 0.7 & 0.8 \\
\hline $\mathrm{C}_{3}=$ & 4.0 & 4.6 \\
\hline $\mathrm{C}_{4} \mathrm{~S}$ & 7.9 & 6.6 \\
\hline Gasoline & 45.5 & 45.4 \\
\hline LCO & 17.5 & 11.4 \\
\hline CSO & 19.5 & 13.1 \\
\hline Coke & 3.4 & 4.5 \\
\hline Water & 0 & 11.7 \\
\hline RON of Gasoline & 92.1 & 94.8 \\
\hline
\end{tabular}

The acid number for typical total FCC product is 0.016. In one experiment, the acid number of the biofeedstock was 0.6 which is slightly elevated and raises concerns about corrosion. At a $5 \%$ level, however, the biofeedstock contribution would be only 0.03 , and the net acid number would be 0.045 , which is well below the problem where corrosion issues occur. 


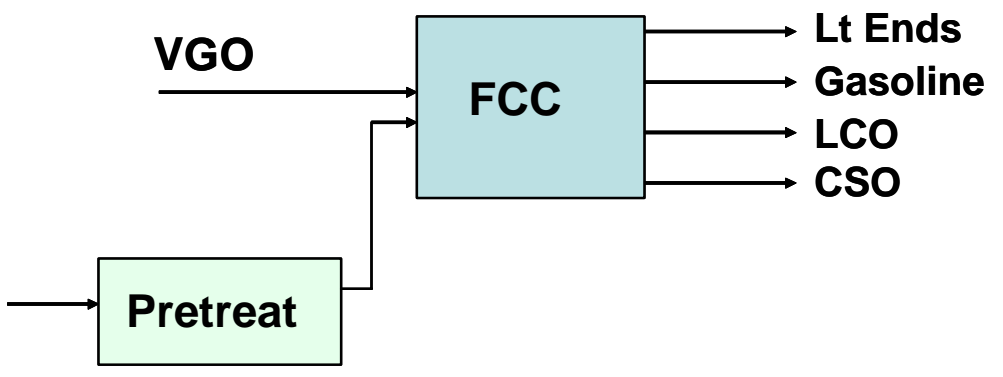

Figure 16. FCC processing approach.

In order to process vegetable oil and grease a separate feed system and pretreater would be best to remove metals (e,g, Ca,K ) which would poison the FCC catalyst and to avoid metallurgy issues in the feed system when processing greases. A suggested processing scheme is shown in Figure 16.

\section{III.5 EConomic Assessment AND Life CyCle AnALysis}

Economic comparisons for the various processing options are shown in Figure 17 and Figure 18. The cost estimate procedure has the following qualifications: These costs represent U.S.A. Gulf Coast erection to UOP standards for new equipment on a January 2005, open shop (non-union) labor basis. The equipment costs have an anticipated accuracy of $-15 \% /+30 \%$. The estimated erected cost (EEC) is a factored cost, which includes installation, associated bulk items (such as instruments, electrical, piping, and civil), indirects, and contractor's home office expenses. These costs are classified as inside battery limits (ISBL) for this estimate. The

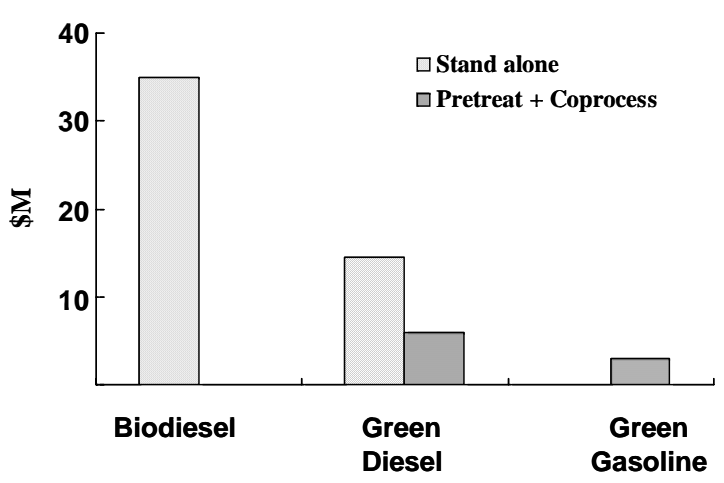

Figure 17. Capital costs of biofuels production from oils and greases.

EEC is derived by multiplying the total equipment cost by a factor - the factor being obtained from an historical database which records average equipment cost versus total erected cost from previous detailed cost estimates developed by UOP Cost Estimating. The EEC has an anticipated accuracy of $-30 \% /+50 \%$. The EEC is for battery limits only. Indirect costs, home office expenses included in the EEC are not based on single equipment item installations; these equipment items are assumed to be part of a larger / typical refinery project.

Figure 18 summarizes the economic analysis of biofuels and chemicals production from oils and greases through comparison of their net present values (NPV). The NPVs of four products are shown as function of feedstock. Biodiesel is the least cost-competitive product for any feedstock, due to the high capital cost of biodiesel production.

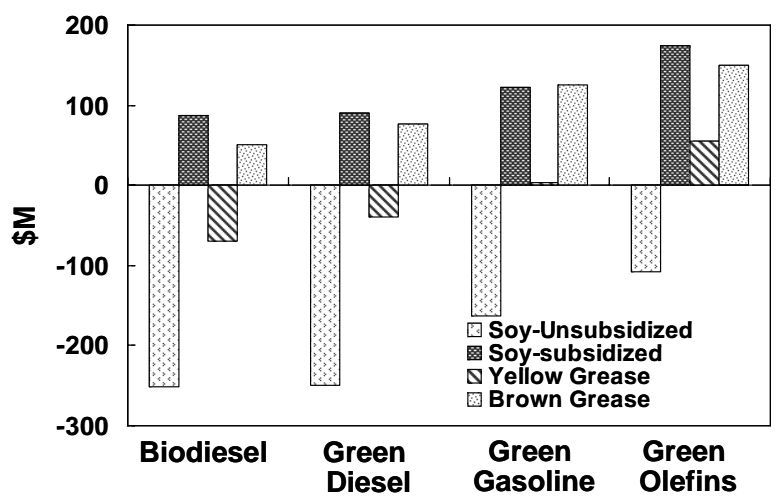

Figure 18. NPV comparison of biofuels and chemicals. 
The effects of potential subsidies on NPV are illustrated in Figure 18. ${ }^{15,16,17,18}$ Brown grease does not require subsidies to be an economically-viable feed for any of the products, because of its low cost. However, subsidies would have a significant impact on the viability of all soy-based products, as can be seen by comparing the NPV with and without subsidies. Note that only biodiesel is subsidized currently in the U.S, while all options are on equal footing in the EU.

A life-cycle analysis (LCA) of the various vegetable oil processing routes was conducted using the Simapro LCA program. LCA is a method to determine and compare the environmental impact of alternative products or processes "from cradle to grave". In this case, the scope of the analysis was from extraction through combustion. For analysis purposes, it was assumed that all fuels have the same performance in transportation use. In reality, biodiesel contains $12 \%$ oxygen and has much lower fuel efficiency than the other fuels; this effect is not reflected in the results. The primary focus of the analysis was on fossil energy consumption and emission of greenhouse gases, though other impact categories are included.

The results of the analysis are shown in Figure 19 and Figure 20. In general,, the green products have much lower total environmental impact score (Figure 19) and produce less $\mathrm{CO}_{2}$ (Figure 20) than petroleum diesel. Of the biofuels, green diesel and green gasoline have the lowest environmental impacts and $\mathrm{CO}_{2}$ production. The environmental impacts of biodiesel production are increased by the fact that it requires methanol which is produced from natural gas. Methanol production is a very energy-intensive process so it brings with it a strong environmental burden.

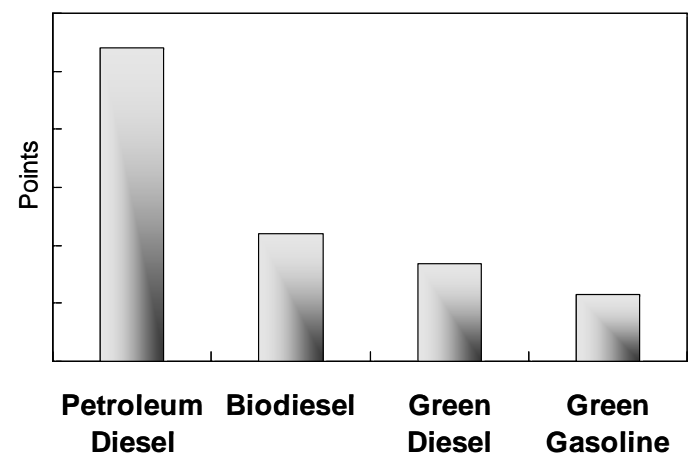

Figure 19. LCA - single environmental impact score .

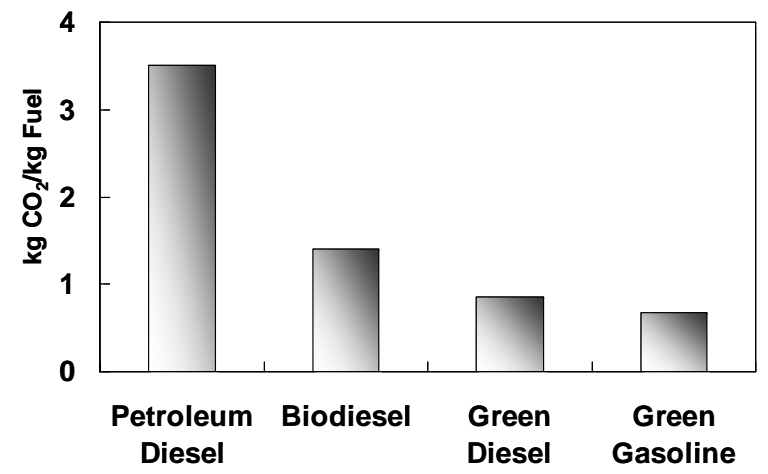

Figure 20. LCA -comparison of climate-active $\mathrm{CO} 2$ 


\section{Refinery OpPoRTUNITIES FOR PyROLysis OIL}

Pyrolysis oil, or bio-oil, is the material produced from pyrolysis of wood waste. Pyrolysis oil can be used as a substitute for fossil fuels to generate heat, power, and/or chemicals. Transportation fuels such as methanol and Fischer-Tropsch fuels can be derived from pyrolysis oil through synthesis gas processes. Pyrolysis oil is also a potential feedstock for hydrogen production. In addition, a wide range of chemicals can be extracted or derived from pyrolysis oil.

Section IV.1 outlines the properties of pyrolysis oil and alternatives for its utilization in refineries. This study investigated several processing options:

- Hydrotreating pyrolytic lignin to produce aromatics and gasoline (Section IV.2)

- Co-processing with vacuum gas oil (VGO) (Section IV.3)

- Aqueous Phase Reforming (APR) of water-soluble components to produce hydrogen (Section IV.4)

The study also investigated hydrothermal processing of pyrolysis oil and techniques for blending pyrolysis oil with other feedstocks (Section IV.5).

\section{IV.1 BaCkgRound AND PRocessing OPtIONS}

The properties of pyrolysis oil depend on the specific feedstock and conditions of the production process, such as temperature, period of heating, ambient conditions, and the presence of oxygen, water and other gases. A typical process for producing pyrolysis oil is shown in Figure 21. Wood biomass such as sawdust, forest "slash", or wood waste from mills is ground to very small sizes and injected into a fluidized bed reactor. The fluidized bed typically consists of a circulating, noncatalytic material such as sand. The temperature and contact time are optimized to maximize liquid yields. Typical products from the pyrolysis process are gases, such as carbon oxides and light hydrocarbons like methane and ethane, and the pyrolysis oil itself, which consists of watersoluble oxygenated compounds and "pyrolytic lignin".

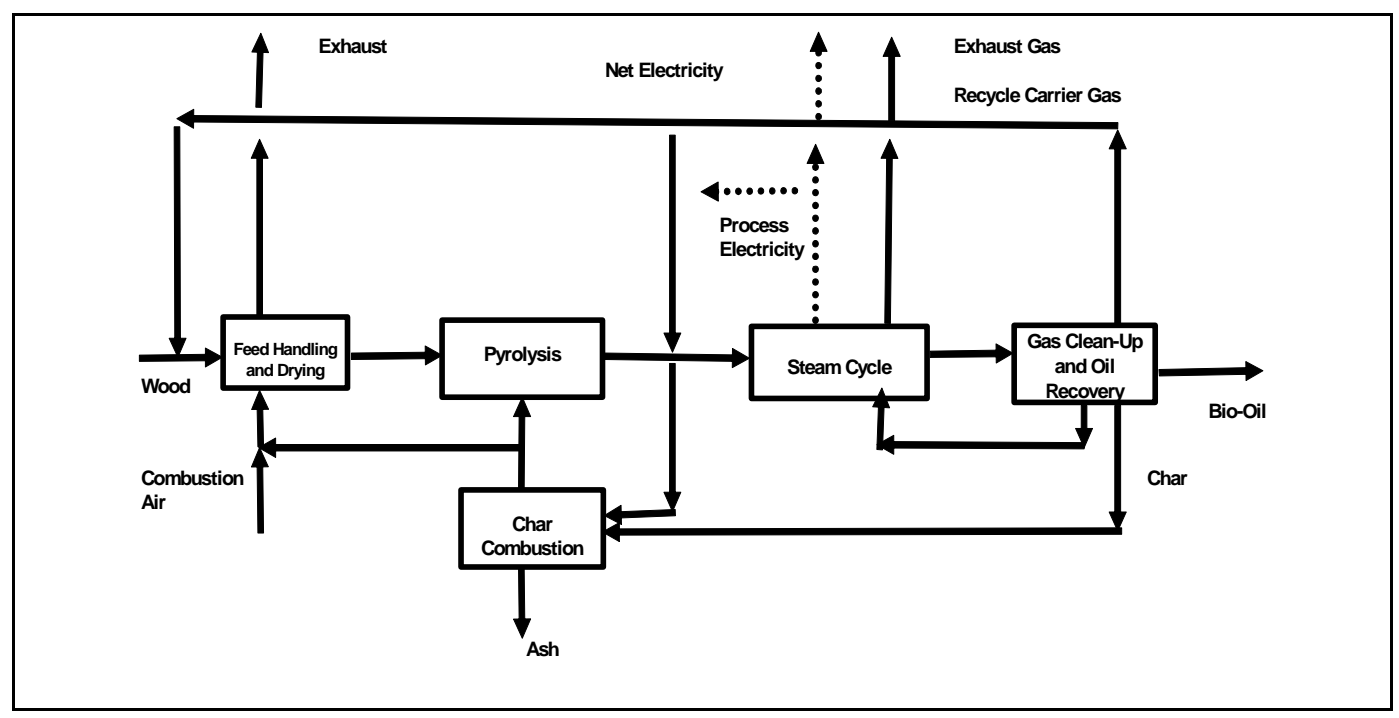

Figure 21. Typical pyrolysis process. 
Table 12. Material balance for pyrolysis oil production.

\begin{tabular}{|l|l|}
\hline \multicolumn{2}{|l|}{ Feed } \\
\hline Biomass (forest waste, tpd) & 2400 \\
\hline Product \\
\hline Pyrolysis Oil (tpd) & 1440 \\
\hline Pyrolysis Oil (bpd) & 7500 \\
\hline Capital Cost & $\$ 88 \mathrm{MM}$ \\
\hline
\end{tabular}

The cost of pyrolysis oil is significantly affected by the high capital cost of the production complex. The economics of pyrolysis oil utilization could be improved by reducing these capital costs. The typical quantity of oil produced from forest waste in a pyrolysis unit is shown in Table 12 .

Pyrolysis oil consists of an oil fraction, insoluble pyrolytic lignin, and a mixture of water-soluble components. The pyrolytic lignin is similar in structure to the lignin originating from the wood biomass, but has been reduced in molecular weight from the thermal conversion in the pyrolysis process. Pyrolytic lignin is much more hydrocarbon-like than the water-soluble pyrolysis oil since it has less oxygen. It is produced from the pyrolysis oil either by adding water to precipitate out the insoluble components or by gravity separation. Gravity separation yields more pyrolytic lignin and a higher water content. Pyrolytic lignin produced by gravity separation had a much high acidity than pyrolytic lignin produced by water precipitation. This suggests that acetic acid and other carboxylic acids are entrained in the pyrolytic lignin during gravity separation. The general properties of pyrolysis oil are summarized in Table 13.

It is believed that the pyrolytic lignin is produced from thermal degradation of the lignin fraction of the biomass and

Table 13. Pyrolysis oil properties.

\begin{tabular}{|l|c|c|c|}
\hline & $\begin{array}{l}\text { Pyrolysis } \\
\text { Oil* }\end{array}$ & $\begin{array}{l}\text { Pyrolytic } \\
\text { Lignin }\end{array}$ & $\begin{array}{l}\text { Water } \\
\text { Soluble } \\
\text { Pyrolysis } \\
\text { Oil }\end{array}$ \\
\hline $\begin{array}{l}\text { Weight \% } \\
\text { MF }\end{array}$ & 100 & 30.0 & 70.0 \\
\hline$\%$ C & 44.7 & 64.2 & 36.3 \\
\hline$\%$ \% & 7.2 & 6.1 & 7.6 \\
\hline$\%$ \% & .2 & .3 & 0.16 \\
\hline$\%$ \%O & 47.9 & 29.7 & 55.7 \\
\hline $\begin{array}{l}\text { Acid } \\
\text { Number }\end{array}$ & $70-150$ & $30-150$ & $70-150$ \\
\hline $\begin{array}{l}\text { Heating } \\
\text { value } \\
\text { LHV Btu/lb }\end{array}$ & 6,560 & 10,200 & 5,000 \\
\hline
\end{tabular}

therefore has essentially the same structure as lignin except a lower molecular weight. The structure of lignin is shown in Figure 22. It consists mostly of individual benzene rings connected via oxygen and short propane linkages. Breaking this structure at the oxygen linkages should yield aromatic gasoline and propane.

The options for utilizing pyrolysis oil in refineries are affected by its high acid number, high water content, high oxygen content and high metal content, particularly potassium and calcium. Pyrolysis oil processing schemes for the refinery are shown in Figure 23.

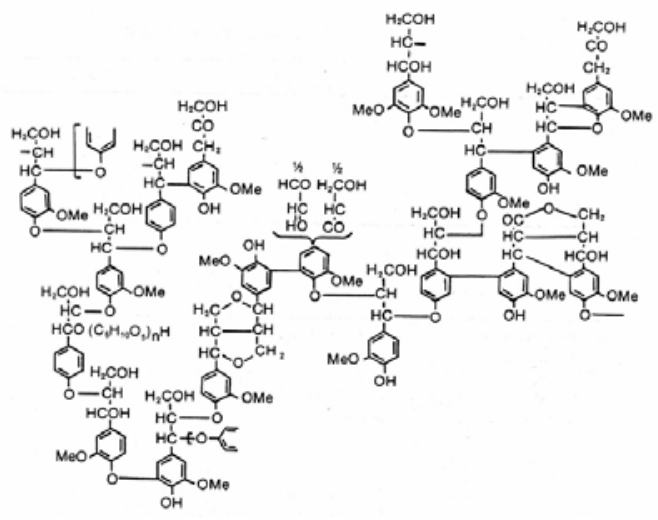

Figure 22. Structure of lignin. 


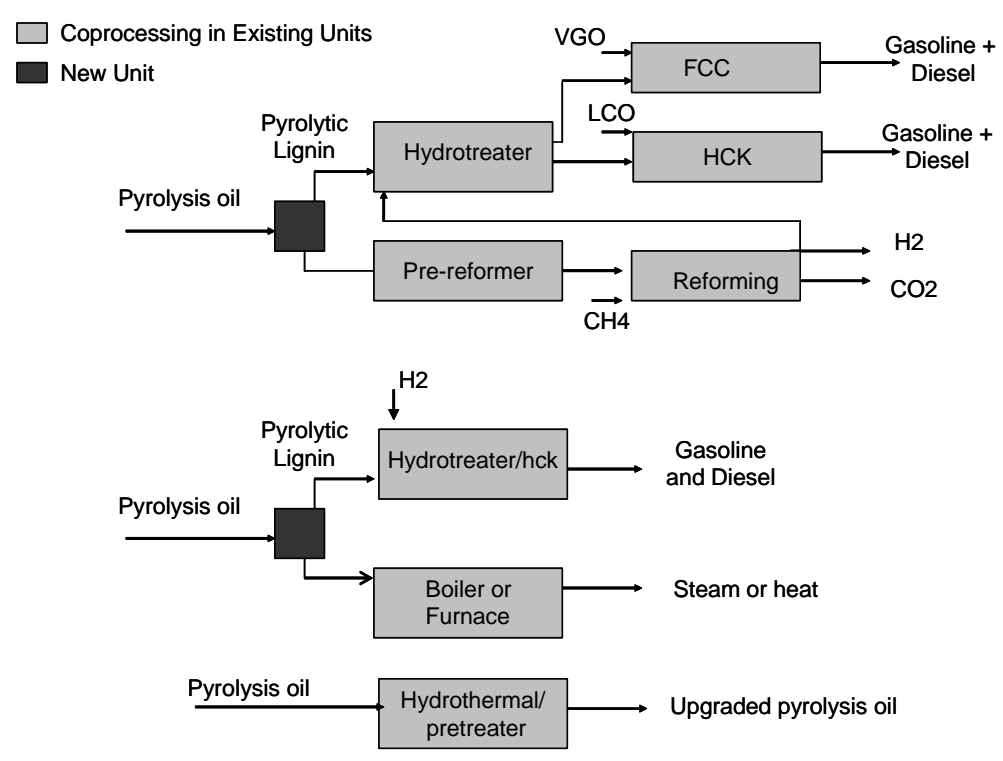

Figure 23. Pyrolysis oil processing routes.

Metals can be removed with guard beds or ion exchange. Metals removal is required before processing because these materials will typically poison catalysts. The high water content and very high oxygen content make it difficult to blend the pyrolysis oil with common refinery intermediate streams such as VGO. However it was found that proper additives can be used to form stable microemulsions. This is discussed more thoroughly in Section IV.3.

The most serious problem for pyrolysis oil processing is the high acid number of the pyrolysis oils which causes corrosion in standard refinery units. Pyrolysis oils can probably be processed using 317 stainless steel cladding, which is not standard in refinery units. Therefore pyrolysis oils require pre-processing in a 317 stainless steel system to reduce the acid number before processing in typical refinery units.

\section{IV.2 Gasoline And Aromatics Production from Pyrolytic Lignin}

In previous studies, whole pyrolysis oil was hydrotreated at high pressures (2000 - $2500 \mathrm{psi})$ and low space velocities(0.1 - 0.2 LHSV). The resulting hydrotreated oil was then cracked in an FCC or hydrocracker to produce gasoline. At these high pressures and low space velocities, hydrodeoxygenation predominates. Large quantities of hydrogen are required to generate water during hydrodeoxygenation because of the high level of oxygen (46\%) in pyrolysis oil. This approach is unlikely to be commercially viable because of the high hydrogen requirement and the high capital cost of the hydrotreatment step.

Because of its molecular structure, removing oxygen from pyrolytic lignin naturally generates materials in the gasoline boiling range. Pyrolytic lignin has a lower oxygen content than pyrolysis oil and therefore requires less hydrogen. Furthermore, decarboxylation is increasingly favored at lower pressure, which also reduces hydrogen consumption. Note that the same type of metal catalysts (Ni,Co,Pd,Pt) catalyze both reactions.

Two catalysts were tested for hydrotreating pyrolytic lignin:

- PNNL hydrotreated Dynamotive pyrolytic lignin using a Pd coated carbide catalyst in a continuous pilot plant. 
- UOP hydrotreated Dynamotive pyrolytic lignin using a Ni-Mo catalyst in a batch autoclave.

The results are shown in Table 14.

Table 14. Results from hydrotreating pyrolytic lignin.

Both tests were successful at reducing the acid number, boiling point and oxygen content of the oil. The UOP catalyst appeared to be more active for oxygen removal at lower pressure and higher space velocity. Further tests will be required to optimize the process conditions and test the long term stability and activity of the UOP HCT catalyst (a newer-generation hydrotreating catalyst). However these tests suggest that pyrolytic lignin can hydrotreated under mild conditions, and that more active catalysts can be developed for this application to enable operation at higher space velocities and lower pressures.

The product from the PNNL hydrothermal test was then hydrocracked using a NiMo catalyst in a batch autoclave. The combination of hydrotreating and hydrocracking resulted in 96\% oxygen removal and a very high level of conversion to gasoline, with the properties shown in Table 15. An even better process would use a more active catalyst in the hydrotreating step such as the HCT catalyst. It is likely that the aromatics production can be increased and of naphthene production reduced by further process and catalyst optimization.

Estimates of the overall yield were developed for the overall two step process, based on the experimental results. These estimates, shown in Table 16, were used as a basis for economic calculations.

Commercially, hydrotreating and hydrocracking would be done in a single process unit with two catalyst vessels and intermediate water removal. However, since gravity-separated pyrolytic lignin has such a high acidity, hydrotreatment in vessels clad with 317 stainless steel would be required before coprocessing in existing hydroprocessing or hydrocracking units. The industry standard for refinery vessels is that the

Table 15. Hydrotreating+hydrocracking pyrolytic lignin.

\begin{tabular}{|l|c|}
\hline & PNNL HT + HCK \\
\hline LHSV, Step 1 & 0.22 \\
\hline LHSV, Step 2 & 1.5 \\
\hline Catalyst, Step 1 & Pd/C \\
\hline Catalyst, Step 2 & Ni/Mo \\
\hline Pressure, Step 1 & $1900-2000$ \\
\hline Pressure, Step 2 & 1500 \\
\hline Liquid yield \% & 32.4 \\
\hline \% Oxygen removal & 96 \\
\hline \% Naphtha in liquid & 80 \\
\hline
\end{tabular}

Table 16. Yield estimate for hydrotreating/hydrocracking pyrolytic lignin.

\begin{tabular}{|r|c|c|}
\hline \multicolumn{1}{|r|}{ Feed } & Wt\% & bpd \\
\hline Pyrolytic lignin & 100 & 2250 \\
\hline Product & $4-5$ & \\
\hline Light ends & 15 & \\
\hline Gasoline & 30 & 1010 \\
\hline Diesel & 8 & 250 \\
\hline Water, $\mathrm{CO}_{2}$ & $51-52$ & \\
\hline
\end{tabular}


total acid number of the blend must be less than 0.6. Therefore the TAN for the hydrotreated lignin product would have to drop below 6 for a $10 \%$ blend or below 12 for a $5 \%$ blend. This should be achievable with a more active catalyst in the first step.

The total quantities of gasoline produced and pyrolytic lignin processed is relatively small by refinery standards. After hydrotreating, which requires 317 SS, most of the lignin conversion and upgrading has been performed, so it will generally be more cost-effective to perform the entire process in a single new skid-mounted refinery unit (Figure 24). There are a few cases in which refinery hydrotreating/hydrocracking units have already been designed with 317 because they are processing high naphthenic acid crudes. These units would be ideal for processing pyrolytic lignin but are relatively rare.

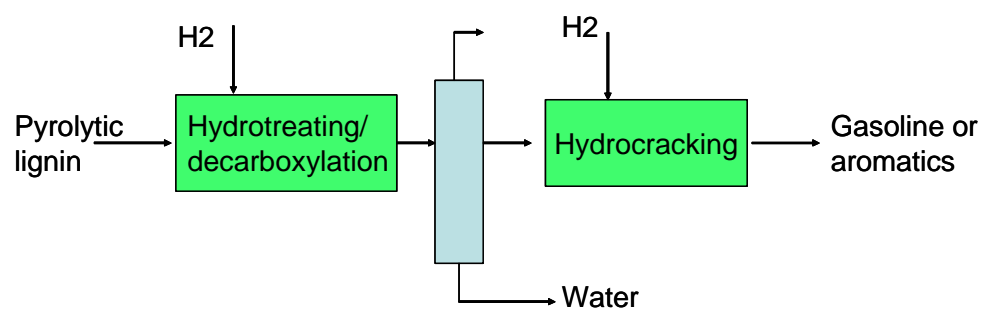

Figure 24. Process flow for hydrotreating/hydrocracking of pyrolytic lignin.

\section{IV.3 COPROCESSING WITH VGO IN AN FCC}

Small FCC pilot tests (ACE tests) were run to determine the crackability of pyrolysis oil blended with vacuum gas oil (VGO), pyrolytic lignin blended with VGO, and neat hydrotreated pyrolysis oil from PNNL. In the blends, the VGO serves as a hydrogen donor. Stable blends are needed for the pilot plant injector system although two separate feed systems and nozzles could be used in commercial units. Stable blends were prepared using Hypermer surfactants. Hypermer is a nonionic polymeric surfactant made by Uniqema. ${ }^{19}$

The results are shown in Table 17. Compared to VGO, the pyrolysis oil, pryrolytic lignin and hydrotreated pyrolytic lignin tend to form high levels of coke. On an incremental basis, the pyrolysis oil formed $84 \%$ coke+water+COx and the lignin formed $70 \%$ coke +water+CO2 from the biofeeds. On an incremental basis the pyrolysis oil formed $16 \%$ coke and the pyrolytic lignin formed 27\% coke. This is consistent with results reported on FCC cracking of neat pyrolysis oils

Table 17. Yields for FCC conversion of pyrolysis oil, pyrolytic lignin and HT pyrolysis oil.

\begin{tabular}{|l|c|c|c|c|}
\hline & VGO & $\begin{array}{c}\text { 20\%Pyrolysis } \\
\text { oil } \\
\text { 80\%VGO } \\
\text { blend) }\end{array}$ & $\begin{array}{c}\text { 20\%Pyrolytic } \\
\text { Lignin } \\
80 \% \text { VGO } \\
\text { Blend }\end{array}$ & $\begin{array}{c}\text { HT Pyrolytic } \\
\text { Lignin } \\
\text { (PNNL) }\end{array}$ \\
\hline $\mathrm{C}_{\mathbf{2}^{-}}$ & 2.0 & 3.3 & 3.6 & 3.8 \\
\hline $\mathrm{C}_{3} \mathrm{P}$ & 1.2 & 2.1 & 2.4 & .7 \\
\hline $\mathrm{C}_{3}=$ & 5.9 & 6.1 & 6.3 & 2.6 \\
\hline C4 & 11.1 & 13.5 & 14.3 & 2.7 \\
\hline Gasoline & 42.7 & 40.6 & 41.3 & 28.8 \\
\hline LCO & 14.8 & 9.1 & 9.7 & 15.6 \\
\hline CSO & 18.5 & 4.8 & 4.7 & 6.2 \\
\hline coke & 3.8 & 7.1 & 9.2 & 16.1 \\
\hline Water $+\mathrm{CO}_{2}$ & 0 & 13.5 & 8.5 & 23.5 \\
\hline
\end{tabular}


and the carbon residue results for the samples shown in Table $18 .^{20,21,22}$

Table 18. Carbon residue results

\begin{tabular}{|l|c|}
\hline & Carbon Residue Test \\
\hline Pyrolysis oil & 21 \\
\hline Pyrolytic lignin & $27-29$ \\
\hline Hydrotreated pyrolysis oil (HT82) & 6.7 \\
\hline
\end{tabular}

For the blends of VGO with pyrolysis oil or pyrolytic lignin, the acid bio-oils appeared to increase the crackability of the VGO and shift VGO yields toward increased light ends and lower LCO and CSO which is an economically attractive outcome. The neat hydrotreated lignin (HT82) had unexpectedly high coke levels. Any follow-up tests should test blends of the hydrotreated lignin with VGO to determine whether any synergies exist for blending this material with VGO. VGO and hydrotreated lignin form stable blends without need for surfactant. The high levels of coke obtained with $20 \%$ blends would be unacceptable for most FCC units but $5 \%$ blends might be possible. Further testing of 5\% blends would be required to determine the viability of this approach. The properties of full boiling range liquid samples produced from the pilot plant test are shown in Table 19.

Table 19. Product properties of total liquid products from FCC testing at 1000F and 5/1 cat/oil ratio

\begin{tabular}{|l|c|c|}
\hline & $\begin{array}{c}\text { 80\% VGO and } \\
\text { 20\% pyrolytic } \\
\text { lignin }\end{array}$ & $\begin{array}{c}\text { Hydrotreated } \\
\text { pyrolytic lignin }\end{array}$ \\
\hline$\% \mathrm{C}$ & 88.6 & 89.5 \\
\hline$\% \mathrm{H}$ & 9.3 & 9.5 \\
\hline$\% \mathrm{O}$ & .38 & .56 \\
\hline
\end{tabular}

As an alternative to blending, coprocessing pyrolytic lignin and pyrolysis oil with VGO in an FCC might be possible if a separate feed system were used to inject the pyrolysis oil or pyrolytic lignin. There are three concerns which would need to be addressed in order to determine the viability of this approach:

- Would the metallurgy of the FCC riser system be affected by injecting highly acid material or would the material react quickly enough to avoid problems?

- Would any acidic or other undesirable products be formed that would adversely affect the liquid product quality and downstream processing?

- Would any acid materials be formed which would cause corrosion of downstream recovery equipment?

Co-injection of pyrolytic lignin in an FCC would be possible if the lignin was separated via water precipitation to keep the acid number below 35. The FCC is typically the largest unit in the refinery and so the lignin will be diluted to about $1.5 \%$ pyrolytic lignin in the VGO feed. For a 50,000 bpd unit (typical for an average 150,000 bpd refinery) this would only allow 750 bpd of pyrolytic lignin in the feed. For a large 100,000 bpd FCC, 1500 bpd of pyrolytic lignin could be processed. Co-injection would also be possible if the pyrolytic lignin was previously hydrotreated to reduce the acid number. Since the FCC is the biggest unit and the heart of most refineries, much more development work would be required to minimize refiner risk before such an approach would be viable. 


\section{IV.4 H2 PRODUCTION FROM PYROLYSIS OIL}

Pyrolytic lignin is deficient in hydrogen, making this portion of pyrolysis oil a poor feed for reforming into hydrogen. On the other hand, the organic compounds in the water-soluble phase are suitable for transformation into hydrogen. Table 20 shows the nominal composition used for the water-soluble phase organics on a moisture-free basis.

The following properties of the water-soluble phase of the pyrolysis oil must be considered in a $\mathrm{H}_{2}$ production process:

- The hydrogen content of the aqueous-phase organic compounds is substantially lower than that of typical hydrogen reforming

Table 20. Composition of aqueousphase compounds from pyrolysis oil

\begin{tabular}{|l|l|}
\hline Component & Wt\% \\
\hline Glyoxal & 10 \\
\hline Formic acid & 14 \\
\hline Hydroxyacetaldehyde & 17 \\
\hline Acetic acid & 17 \\
\hline Ethylene Glycol & 2 \\
\hline Acetol & 5 \\
\hline Sugars and sugar anhydrides & 35 \\
\hline
\end{tabular}
feeds such as methane, LPG or naphtha.

- The organic compounds for reforming are in a water solution.

- The water-soluble phase consists of organic acids such as formic and acetic acids, with implications for processing unit metallurgy.

- Higher molecular weight carbohydrates such as sugars and anhydro-sugars are likely to carbonize to tar or char while preheating to typical reforming temperatures.

There are several technologies for converting hydrocarbons and biomasses into hydrogen. However, steam reforming is the primary technology for hydrogen generation in refineries and therefore the focus of the analysis of integrating pyrolysis oil into refining for hydrogen production (IV.4.1). The Aqueous Phase Reforming (APR) technology offered by Virent Energy Systems may be an alternate technology but most likely would be implemented in a stand-alone unit (Section IV.4.2).

\section{IV.4.1 Integration of Pyrolysis Oil Reforming into Refinery Hydrogen Plants}

The pyrolysis oil production basis for this study is 7500 bpd of pyrolysis oil. The aqueous phase is 70 lv\% of the pyrolysis oil including water. The aqueous phase includes $30 \mathrm{lv} \%$ water. Therefore, approximately $3650 \mathrm{bpd}(60500 \mathrm{lb} / \mathrm{h})$ of aqueous phase components on a moisture free basis is available for reforming to hydrogen.

Adiabatic pre-reforming is the technology of choice to integrate reforming of the aqueous phase of pyrolysis oil into an existing hydrogen plant. For the nominal composition shown in Table 20 and assuming equilibrium at the reactor outlet, the resulting pre-reformer synthesis gas composition is found in Table 21. Figure 25 shows the proposed process flow scheme. The pre-reformer is an adiabatic fixed bed reactor operating at relatively low temperatures. Superheated steam is mixed with the preheated aqueous phase to produce a steam-oxygenates ratio of 1:1 (mass/mass). The preheated aqueous phase is mixed with the superheated steam as close as possible to the catalyst bed. Steam reforming, shift-gas and
Table 21. Pre-reformer syngas composition for the aqueous phase of pyrolysis oil.

\begin{tabular}{|l|c|}
\hline Component & $\begin{array}{c}\text { Composition } \\
\text { (wt\%) }\end{array}$ \\
\hline $\begin{array}{l}\text { Sugars and Sugar } \\
\text { Anhydrides }\end{array}$ & 35.4 \\
\hline Glyoxal & 10.3 \\
\hline Hydroxyacetaldehyde & 16.9 \\
\hline Formic Acid & 14.1 \\
\hline Acetic Acid & 16.5 \\
\hline Ethylene Glycol & 2.3 \\
\hline Acetol & 4.5 \\
\hline
\end{tabular}




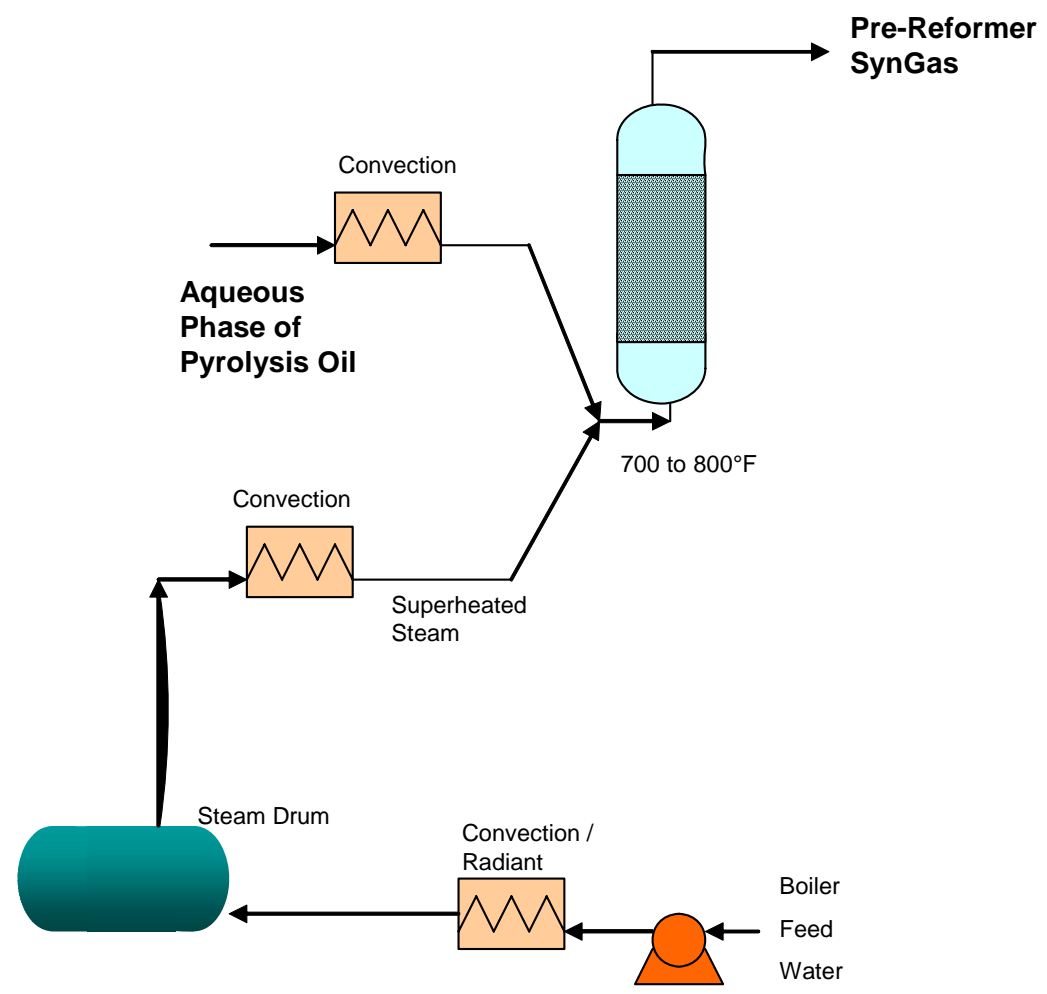

Figure 25. Adiabatic pre-reformer for the aqueous-phase of pyrolysis oil.

methanation reactions occur in the adiabatic pre-reforming catalyst. Overall, the pre-reforming is highly exothermic for the aqueous phase composition. The pre-reformer synthesis gas is delivered without heat integration directly to the main steam reforming reactor.

Based on the acidity of the feed, 317L stainless steel is the proposed metallurgy for the feed pump, fired heater, reactor cladding and associated piping and valves. The installed inside battery limits capital cost is approximately $\$ 15$ to $20 \mathrm{MM}$, or $\$ 5500 / \mathrm{bbl}$ feed.

Two cases were compared:

- Case I - Hydrogen production from steam reforming of methane alone for the base refinery hydrogen production rate, 25MM scfd.

- Case II - Reforming of the target quantity of the pyrolysis oil aqueous phase with adiabatic pre-reforming - $3650 \mathrm{bpd}, 60,500 \mathrm{lb} / \mathrm{h}$. Natural gas is supplemented in the main steam reforming plant as required to produce the baseline quantity of hydrogen. The steam to feed ratio is varied to observe the effect on $\mathrm{H}_{2}$ production and utility requirements. The effect on reforming catalyst stability is not addressed for the decreasing steam ratios.

The analysis determined that the natural gas feed to the SMR reactor section can be completely displaced with the aqueous phase of the pyrolysis oil to produce at least the baseline $\mathrm{H}_{2}$ generation rate of $25 \mathrm{MMscfd}$. The $\mathrm{CO}_{2}$ emission per unit of hydrogen production is reduced by approximately 50 to $65 \%$ because components in the aqueous phase of the pyrolysis oil do not contribute to $\mathrm{CO}_{2}$ emissions while all carbon in the natural gas feed for SMR is eventually emitted as $\mathrm{CO}_{2}$. 
The hydrogen COP is approximately 50\% higher for integrated adiabatic reforming of the aqueous phase of pyrolysis oil than for SMR. Feed costs represent two-thirds of the hydrogen $\mathrm{COP}$ and almost the entire COP for SMR. The projected decrease in $\mathrm{CO}_{2}$ emission per unit of hydrogen is not sufficient to make up the difference through $\mathrm{CO}_{2}$ credits. The delivered cost of pyrolysis oil must be reduced for this process to be competitive with SMR.

\section{IV.4.2 Aqueous Phase Reforming (APR) of the Aqueous Phase of Pyrolysis Oil}

The Aqueous Phase Reforming (APR) process is a concept patented by Virent Energy Systems. A parametric simulation study was performed examining the effects of reaction temperature and pressure on hydrogen generation and cost of production for APR of pyrolysis oil with the composition shown in Table 20. The ranges of temperature and pressure of interest were those cited by the patent and other public literature from Virent Energy Systems: 350 to $500^{\circ} \mathrm{F}$ and less than 1000 psia. APR was modeled with the PRSV thermodynamic property package in a process simulator using reforming equilibria for the reactions in Table 22. The effects of temperature and pressure on hydrogen generation indicate that the extent of reaction is favored by increasing temperature and pressure. Vaporization of the feed in the fired heater is energy intensive. Therefore, in this analysis, the upper limit of temperature was bounded by the saturated liquid temperature at a given pressure.

A proposed flow scheme for the APR process is shown in Figure 26. The aqueous phase of the pyrolysis oil and recycled water are heated up to reaction conditions through exchange with the reactor effluent and a fired heater. Pressure, temperature and the water recycle rate can be

Table 22. Reforming equilibrium reactions for APR of pyrolysis oil components

\begin{tabular}{|l|l|}
\hline Component Reforming & Equilibrium Reaction \\
\hline Acetic Acid Reforming & $\mathrm{CH}_{3}(\mathrm{COOH})=2 \mathrm{H}_{2}+2 \mathrm{CO}$ \\
\hline Acetol Reforming & $\mathrm{CH}_{3}(\mathrm{CO}) \mathrm{CH}_{2} \mathrm{OH}=4 \mathrm{H}_{2}+3 \mathrm{CO}$ \\
\hline Ethylene Glycol Reforming & $\mathrm{H}_{2} \mathrm{C}(\mathrm{OH}) \mathrm{C}(\mathrm{OH}) \mathrm{H}_{2}=3 \mathrm{H}_{2}+2 \mathrm{CO}$ \\
\hline Formic Acid Reforming & $\mathrm{H}(\mathrm{COOH})=\mathrm{H}_{2} \mathrm{O}+\mathrm{CO}$ \\
\hline Glyoxal Reforming & $\mathrm{H}(\mathrm{CO})(\mathrm{CO}) \mathrm{H}=\mathrm{H}_{2}+2 \mathrm{CO}$ \\
\hline Hydroxyacetaldehyde Reforming & $\mathrm{H}_{2} \mathrm{C}(\mathrm{OH})(\mathrm{CO}) \mathrm{H}=2 \mathrm{H}_{2}+2 \mathrm{CO}$ \\
\hline Sugar Reforming & $\mathrm{C}_{6} \mathrm{H}_{12} \mathrm{O}_{6}=6 \mathrm{H}_{2}+6 \mathrm{CO}$ \\
\hline Water Gas Shift & $\mathrm{CO}+\mathrm{H}_{2} \mathrm{O}=\mathrm{H}_{2}+\mathrm{CO}_{2}$ \\
\hline
\end{tabular}

optimized to economically maximize the conversion to hydrogen. After exchanging heat with the reactor feed, the reactor effluent is cooled by an air cooler and the predominantly liquid recycle is separated from the synthesis gas. The synthesis gas is primarily composed of carbon oxides and hydrogen. A Pressure Swing Adsorption (PSA) unit is used to purify the $\mathrm{H}_{2}$ and reject a tail gas.

Process modeling suggests that part of the plant will be exposed to hot acetic vapor which poses metallurgical challenges. The corrosivity of acetic acid solutions (and other organic acids like formic acid) is very dependent on process conditions and existing contaminants. 316 SS may not be an acceptable metal of design for boiling acetic acid solutions at concentrations of $10 \%$ or higher. Copper or alloys of copper and nickel may be viable alternatives, especially in oxygenfree environments, unless the material is transferred from tankage where oxygen content is a real concern. Development of a commercial APR process will require corrosion testing at the various process conditions found throughout the process. 


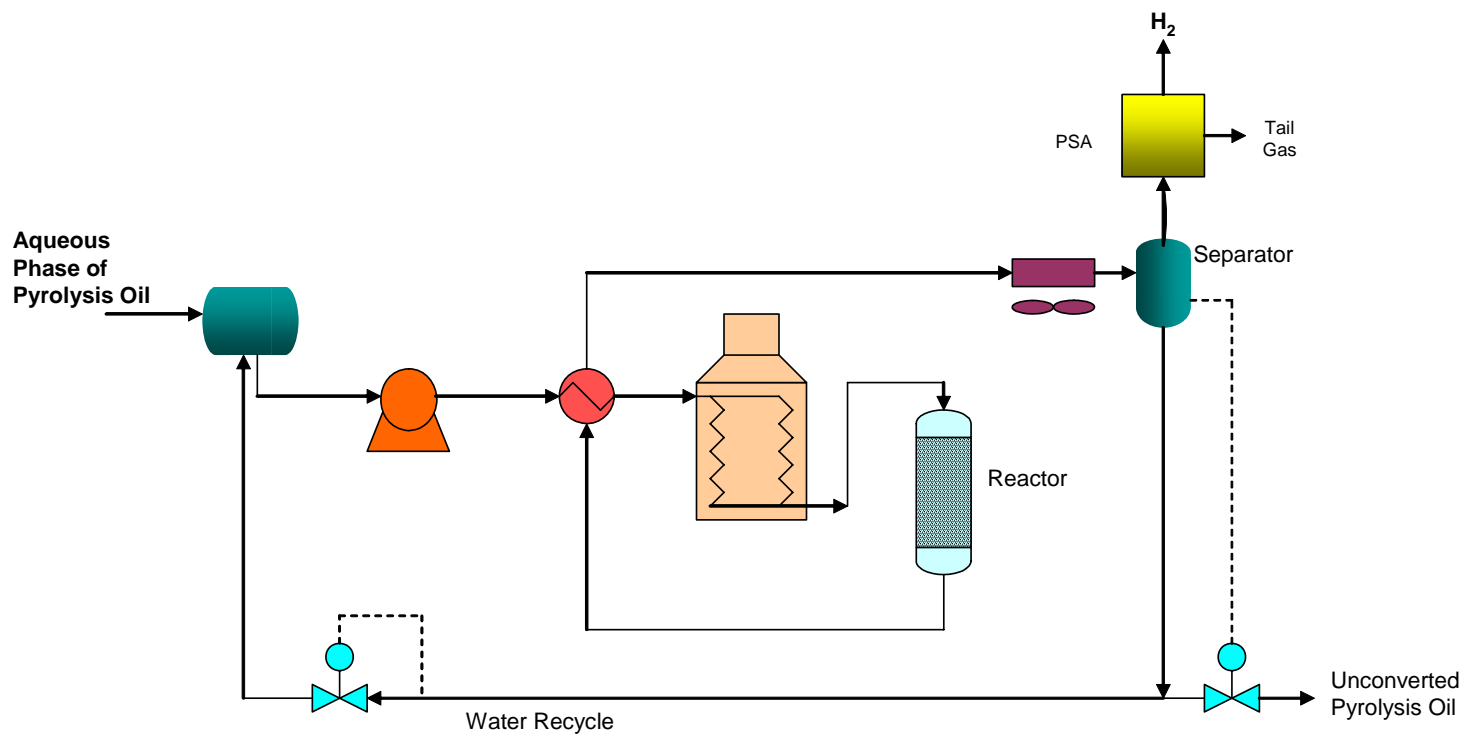

Figure 26. Proposed APR process flow scheme.

The most conservative approach is to use titanium Grade-II clad carbon steel. The difference in erected cost between Ti-clad and 316SS is surprisingly small - within 5\%. The total installed inside battery limits capital cost is approximately \$65 MM for the APR plant based on the proposed flow scheme and the baseline hydrogen production rate of $25 \mathrm{MMscfd}$.

The hydrogen COP from pyrolysis oil aqueous phase reforming is appreciably higher than SMR. Alternate design concepts were considered to increase economic feasibility by reducing capital investment and COP. The most promising is similar to the flow scheme of Figure 26, but without liquid recycle. A summary of the COP and estimated capital costs comparing the initially proposed flow scheme and the low acetic-acid conversion alternative are presented in Table 23, assuming \$16/bbl for pyrolysis oil. The process results in low acetic acid conversion and includes recovery of the

Table 23. Comparison of APR process flow schemes.

\begin{tabular}{|l|c|c|}
\hline Process Concept & $\begin{array}{c}\text { COP } \\
\mathbf{( \$ / l b ~ H}_{\mathbf{2}}\end{array}$ & $\begin{array}{c}\text { EEC } \\
\text { (MM } \mathbf{~} \text { US) }\end{array}$ \\
\hline $\begin{array}{l}\text { Preliminary } \\
\text { Process Design - } \\
\text { complete acetic } \\
\text { acid conversion } \\
\text { process }\end{array}$ & 0.65 & 65 \\
\hline $\begin{array}{l}\text { Low acetic acid } \\
\text { conversion process }\end{array}$ & 0.48 & 10 \\
\hline
\end{tabular}
acetic acid as a net product. Two distillation columns could be used for acetic acid recovery. Waste water and non-condensable light ends are vented overhead in the first column. Purified acetic acid is recovered in the overhead of the second column; tar or other heavier by-products are removed in the bottoms. With elimination of recycle and assuming efficient oxygenate reforming of the feed pyrolysis oil, the COP can be reduced to approximately $\$ 0.48 / \mathrm{lb}$, which includes acetic acid fractionation utilities. Acetic acid fractionation costs are approximately $\$ 0.06 / \mathrm{lb} \mathrm{H}_{2}$ generated. 
Table 24 compares the capital costs and production capacity for the three routes to generate hydrogen from the watersoluble portion of pyrolysis oil: steam methane reforming, partial oxidation and liquid phase reforming. All are based on 7,500 bpd pyrolysis oil feed that has been separated into the lignin and water-soluble fractions.
Table 24. Comparison of $\mathrm{H}_{2}$ production routes.

\begin{tabular}{|l|c|c|}
\hline & $\begin{array}{c}\text { EEC Capital } \\
\text { Cost (\$MM) }\end{array}$ & $\begin{array}{c}\text { Production Capacity } \\
\text { (MMSCFD) }\end{array}$ \\
\hline Steam reforming & 24 & 28.7 \\
\hline Partial oxidation & 37 & 15.9 \\
\hline $\begin{array}{l}\text { Liquid phase } \\
\text { reforming }\end{array}$ & 30 & 33.3 \\
\hline
\end{tabular}

\section{IV.5 Hydrothermal Processing and Blending Studies}

Supporting studies were conducted to investigate the potential for pretreating pyrolysis oil by hydrothermal processing and for improvements to pyrolysis oil blending properties.

\section{Hydrothermal Processing}

Hydrothermal processing is a simple pretreatment step which could be done in the field to reduce the costs of transporting pyrolysis oil by removing oxygen and reducing acidity. Batch autoclave tests were performed to hydrothermally process the pyrolytic lignin, pyrolysis oil and resid. In these tests, water is mixed with pyrolytic lignin and the mixture is heated up to 300 or $350 \mathrm{C}$. The pressure is maintained so that the mixture is kept in the liquid phase. The experimental conditions are shown in Table 25. The catalysts were cobalt and nickel compounds.

Table 25. Hydrothermal processing experiment conditions.

\begin{tabular}{|c|c|c|c|c|c|c|c|c|c|c|c|}
\hline & 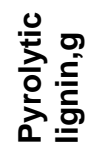 & $\begin{array}{l}\frac{0}{0} \\
\frac{0}{0} \\
\frac{1}{x}\end{array}$ & 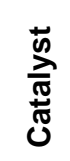 & 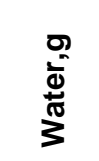 & 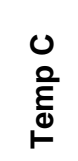 & 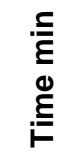 & @⿺ & 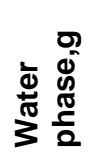 & 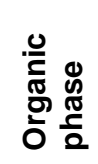 & 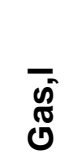 & 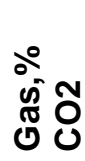 \\
\hline 1 & 75.7 & 0 & & 75.1 & 300 & 15 & 1380 & 69.9 & 69.9 & 2.2 & 33 \\
\hline 2 & 51.5 & 50.8 & & 50.1 & 350 & 15 & 1530 & 5 & 131.2 & 2.2 & 12 \\
\hline 3 & & 76.6 & & 75.2 & 350 & 15 & 2500 & 20.5 & 107.2 & & 11 \\
\hline 4 & 52.5 & 60.7 & & 50.6 & 350 & 120 & 2480 & 28.6 & 106.6 & 2.9 & 24 \\
\hline 5 & & 75.7 & & 75.0 & 350 & 120 & 2480 & 29.3 & 105.1 & .03 & 6 \\
\hline 6 & 77.8 & & Co & $>76.7$ & 350 & 20 & 2850 & & $\begin{array}{l}186 \\
\text { total }\end{array}$ & 2.8 & 55 \\
\hline 7 & 77.0 & & $\mathrm{Ni}$ & 75.1 & 350 & 20 & 2800 & 77.0 & 46.5 & 3.3 & 47 \\
\hline 8 & 75.1 & & & 75.3 & 300 & 15 & $2100 ?$ & 74.3 & 59.5 & 2.1 & 27 \\
\hline 9 & 75.0 & $\begin{array}{c}76 \\
\text { (pitch) }\end{array}$ & & & 250 & 15 & $480 ?$ & & 145 & 1.1 & 45 \\
\hline
\end{tabular}


The resid did not appear to improve with hydrothermal treatment, but the pyrolytic lignin lost oxygen as shown in Table 26. Unfortunately the product from hydrothermal treatment became more viscous as well (>1500 MPas @ 95 C) and some char formation is reported in Runs 6,7and 8. Hydrotreatment under $\mathrm{H}_{2}$ pressure breaks the molecules as the oxygen groups are removed, resulting in smaller molecules. Hydrothermal treatment does not have this effect and may result in polymerization of the molecules. As long as the aromatic rings have not condensed to form asphaltene structures, it may be possible to hydrocrack these materials to form aromatics in a hydrocracker. A key test would be to determine whether hydrothermally-treated pyrolytic lignin can be processed with LCO in a mild hydrocracker to produce aromatics. Since the hydrothermal process is a simple and relatively inexpensive option for pretreatment, more follow up work in this area is recommended.

\section{Blending Studies}

One of the big challenges with pyrolysis oils is the fact that they have limited solubility in typical hydrocarbon fractions and fuel products. Small amounts of materials can be extracted from pyrolysis oils into hydrocarbon phases but blending studies are difficult because the pyrolytic lignin or other heavy fractions of pyrolysis oils tend to coat onto beakers and equipment leading to poor material balance. Therefore to be conservative, only increases in the petroleum fraction phase (VGO or LCO) are counted as extracted material. Roughly 3\% pyrolytic lignin was extracted into LCO (light cycle oil) in blending tests and roughly $6 \%$ pyrolysis oil could be extracted into VGO when water was added to the pyrolysis oil phase.

However it was found that stable microemulsions of $20 \%$ pyrolysis oil or $20 \%$ pryolytic lignin in VGO or LCO could be formed when 1\% Hypermer 2296 and 1\% Hypermer 256SF surfactants were used. Also encouraging was the fact that the HT-82 sample of hydrotreated pyrolytic lignin was very soluble in both VGO and LCO.

\section{IV.6 Economic Analysis of Pyrolysis OIL Processing Options}

Table 27 shows that pyrolysis oil is intermediate in cost between heavy residual oil and natural gas on a \$MMBTU basis. Refiners could burn pyrolysis oil in furnaces designed for heavy fuel oil that have been shifted to natural gas to minimize $\mathrm{SO}_{2}$ emissions. This would also allow refiners to reduce $\mathrm{CO}_{2}$ emissions from boilers and fired Table 27. Fuel value of pyrolysis oil.

\begin{tabular}{|l|c|}
\hline & \$MMBTU \\
\hline Heavy Fuel Oil & 4.2 \\
\hline Natural Gas & 6 \\
\hline Pyrolysis Oil & 4.7 \\
\hline
\end{tabular}

heaters and obtain a $\mathrm{CO}_{2}$ credit. This is an immediate application for refiners and other industries using natural gas to minimize pollution. Minor capital investment would probably be needed to change burner tips and modify boilers to allow co-firing of natural gas and pyrolysis oil. It would be worth $\$ 5.6 \mathrm{MM} /$ year to substitute $5250 \mathrm{bbl} / \mathrm{d}$ of water soluble pyrolysis oil for natural gas in furnaces or boilers or $\$ 7.4 \mathrm{MM} /$ year to substitute $5250 \mathrm{bbl} / \mathrm{d}$ of pyrolysis oil itself. 
The baseline 5250 bpd of pyrolysis oil aqueous phase contains 3650 bpd water-soluble components on moisture free (m.f.) basis. Assuming the nominal composition in Table 20, the mass rate is $65,940 \mathrm{lb} / \mathrm{h}$ and the lower heating value of the m.f. organics is approximately 5600 $\mathrm{Btu} / \mathrm{lb}$. The water in this stream has no net heat value.

To raise $1600 \mathrm{psig}, 700^{\circ} \mathrm{F}$ VHP superheated steam from ambient temperature boiler feed water requires 1.3 MMBtu per 1000lb steam. Therefore, burning the aqueous phase generates $370 \mathrm{MMBtu} / \mathrm{h}$ on a $100 \%$ efficiency basis. The efficiency basis is valid if the aqueous phase of the pyrolysis oil provides supplemental firing for the heat recovery-steam generation (HRSG) section of a cogeneration facility. Otherwise, 85 to $90 \%$ efficiency in a stand-alone boiler would be more appropriate. The amount of VHP superheated steam generated will be approximately 250,000 to $285,000 \mathrm{lb} / \mathrm{h}$. The steam generated is adequate for power generation or the steam could be generated at HP steam levels to drive 1 or 2 large refinery condensing turbines.

The economics for producing gasoline from pyrolytic lignin are shown in Table 28, assuming $\$ 18 /$ bbl pyrolysis oil (\$16/bbl +\$2/bbl transportation charges) and \$40/bbl crude. The incentives total to $4 \mathrm{MM} /$ year.

Table 28. Incentives for gasoline production from pyrolytic lignin.

\begin{tabular}{|c|c|c|}
\hline & \$/D & Quantities \\
\hline \multicolumn{3}{|l|}{ Feed } \\
\hline Pyrolytic lignin & 40,500 & 2250 bpd \\
\hline $\mathrm{H} 2$ & 25,680 & $21.4 \mathrm{tpd}$ \\
\hline \multicolumn{3}{|l|}{ Product } \\
\hline Light ends & $19,903 d$ & $64 \mathrm{tpd}$ \\
\hline Gasoline & 52,520 & $1,010 \mathrm{bpd}$ \\
\hline Diesel & 12,000 & $250 \mathrm{bpd}$ \\
\hline Utilities & $-4,800$ & \\
\hline Incentive & 12,843 & \\
\hline
\end{tabular}

The capital cost for a hydrotreating/hydrocracking unit producing $1,010 \mathrm{bpd}$ of gasoline is \$30 MM. Producing gasoline from pyrolytic lignin becomes economically attractive for $\$ 18 / \mathrm{bbl}$ pyrolysis oil at a crude price of $\$ 50 /$ bbl. As pyrolysis oil price decreases, producing gasoline from pyrolytic lignin becomes attractive at lower crude oil prices, illustrated in Figure 27 .There is a strong sensitivity to pyrolysis oil price at $\$ 40 / \mathrm{bbl}$ crude but the sensitivity decreases as crude oil price increases.

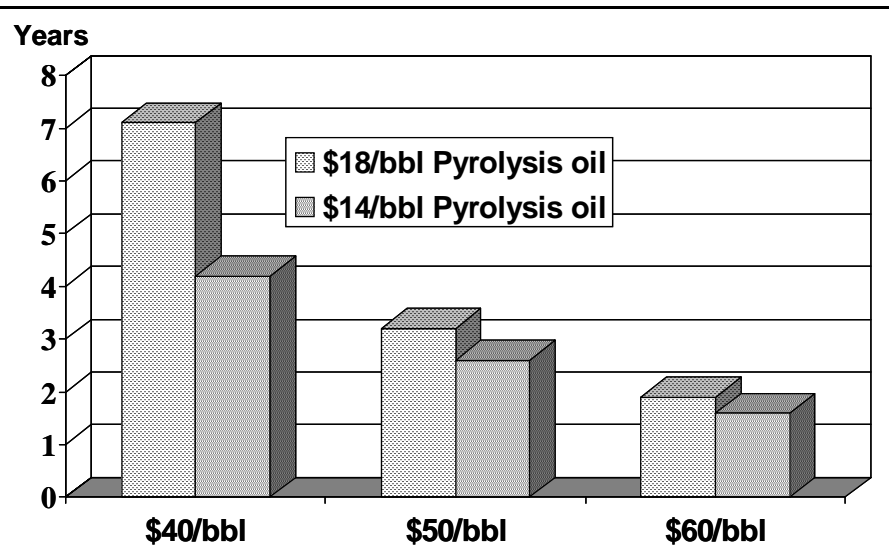

Figure 27. Years to payback for conversion of pyrolytic lignin to gasoline. 
Table 29 shows the incentives for producing $\mathrm{H}_{2}$ from the water-soluble portion of pyrolysis oil for $\$ 40 / \mathrm{bbl}$ crude and $\$ 10 / \mathrm{bbl}$ pyrolysis oil. Pyrolysis oil must be less than $\$ 12 / \mathrm{bbl}$ before there is a positive incentive for $\mathrm{H}_{2}$ production. The incentive is $\$ 3.5 \mathrm{MM} /$ year with the $\mathrm{CO}_{2}$ credit and \$0.3MM/year without.

The capital cost of a pre-reformer to add to an existing $\mathrm{H}_{2}$ plant is $\$ 15 \mathrm{MM}$. Unless pyrolysis oil price drops, it is better for a refiner to simply co-fire the aqueous phase pyrolysis oil as fuel, replacing natural gas which is used in the refinery.
Table 29. Incentives for $\mathrm{H}_{2}$ production

\begin{tabular}{|l|c|c|}
\hline & \$/D & Quantities \\
\hline Feed & & \\
\hline Water-soluble pyrolysis oil & 52,500 & $5.250 \mathrm{bpd}$ \\
\hline Products & & \\
\hline Hydrogen & 84,910 & 28 MMSCFD \\
\hline $\mathrm{CO}_{2}$ credit (\$30/ton) & 9,770 & \\
\hline Utilities & $-31,500$ & \\
\hline Incentive & 10,680 & \\
\hline
\end{tabular}

Table 30. Overall incentives for use of pyrolysis oil for fuel and gasoline production.

Table 30 shows the economics of cofiring the water soluble portion of pyrolysis oil and making gasoline from the pyrolyic lignin. Figure 28 shows the time to payback for conversion of the pyrolytic lignin to gasoline and co-firing of the water soluble pryolysis oil as a fuel substitute for natural gas.

\begin{tabular}{|l|c|c|}
\hline & \$/D & Quantity \\
\hline Feed & & \\
\hline Pyrolysis oil & 135,000 & $7500 \mathrm{bpd}$ \\
\hline Water Soluble Pyrolysis Oil & & $5250 \mathrm{bpd}$ \\
\hline Pyrolytic Lignin & & $2250 \mathrm{bpd}$ \\
\hline Products & & \\
\hline Fuel & 66174 & $5250 \mathrm{bpd}$ \\
\hline Lt Hydrocarbons & 19,303 & $64 \mathrm{tpd}$ \\
\hline Gasoline & 52,520 & $1010 \mathrm{bpd}$ \\
\hline Diesel & 12,000 & $250 \mathrm{bpd}$ \\
\hline $\mathrm{CO}_{2}$ credit (\$30/ton) & 19,060 & \\
\hline Utilities & -4800 & \\
\hline Incentive & 29257 & \\
\hline
\end{tabular}

Years

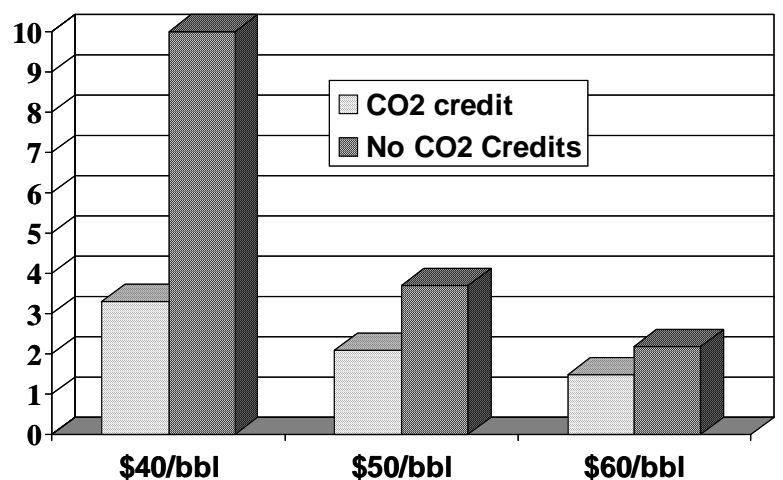

Figure 28. Years to payback for combined process. 


\section{OPPORTUNITIES FOR FISCHER TROPSCH LIQUIDS}

Another option for biorenewable use is gasification followed by Fischer-Tropsch (FT) synthesis from the syngas. The properties of crude FT liquids are summarized in Table 31 and Table 32. Crude FT liquids contain some oxygen and olefins which are easily removed by hydrotreating. The study calculated the value of FT liquid to a typical refiner if biorefineries chose to send them to the refinery rather than upgrade the FT themselves. The yields and properties are based on an iron fixed bed FT system marketed by Rentech.

Table 31 Properties of crude FT liquids

\begin{tabular}{|c|c|c|c|}
\hline & Crude & Resid & $\begin{array}{l}\text { Crude FT } \\
\text { Liquids }\end{array}$ \\
\hline$\%$ C & $83-86$ & 84.9 & 82.8 \\
\hline$\% \mathrm{H}$ & $11-14$ & 10.6 & 14.0 \\
\hline$\% \mathrm{~S}$ & $\begin{array}{l}0-4 \\
(1.8 a v g)\end{array}$ & 4.2 & - \\
\hline$\% \mathrm{~N}$ & $\begin{array}{l}0-1 \\
\text { (.1avg) }\end{array}$ & .3 & - \\
\hline$\% \mathrm{O}$ & - & - & 3.2 \\
\hline $\mathrm{H} / \mathrm{C}$ & $1.8-1.9$ & 1.5 & 2.0 \\
\hline Density & .86 (avg) & 1.05 & 0.82 \\
\hline TAN \# & $<1$ & $<1$ & Low \\
\hline $\begin{array}{l}\text { Heating } \\
\text { value } \\
\text { BTU/lb }\end{array}$ & 18,000 & 17,500 & 18,400 \\
\hline
\end{tabular}

Table 32. Detailed properties of crude FT liquids.

\begin{tabular}{|l|l|l|l|}
\hline & Naphtha & Diesel & Wax \\
\hline Wt\% & 19 & 21 & 60 \\
\hline Density & 0.76 & 0.79 & 0.85 \\
\hline BP, F & $70-320$ & $320-650$ & $650+$ \\
\hline Wt\% Oxygen & 6 & 6 & 1.3 \\
\hline Wt\% Saturates & 22 & 30 & 88 \\
\hline Wt\% Olefins & 48 & 14 & 6 \\
\hline Wt\% Alcohols & 26 & 16 & 6 \\
\hline
\end{tabular}

The configuration of a typical hydrocracking-based refinery was shown in Figure 5 of Section II.2.3. In order to maximize diesel production, the wax is cracked in a hydrocracker (HCK) to make diesel and the naphtha and diesel must be hydrotreated to remove oxygen and olefins.

There are a number of options possible for integration with a typical refinery. These include:

- Send FT Liquids to the crude tower if all diesel is hydrotreated. This places a penalty on gasoline produced (poor octane) but requires no capital.

- Send everything to the HCK. This results in yield loss from cracking diesel but requires no capital.

- Send FT liquids to their own tower, while sending the diesel and naphtha cut to DHT and the wax cut to HCK to produce diesel and naphtha. Capital is required for two towers and typical HCK conditions are not optimal for FT wax.

- Send FT liquids to their own tower, while sending the diesel and naphtha cut to DHT and the wax cut to low pressure HCK (converted DHT). Capital is required for two towers if DHT is available for use as HCK (optimal configuration).

Sending FT their own tower and processing the wax in the hydrocracker and the naphtha and diesel in the DHT is the best option, but does require a small investment in two distillation 
towers. The resulting configuration is shown in Figure 29. The value of the FT liquids to the refiner is shown in Table 33.

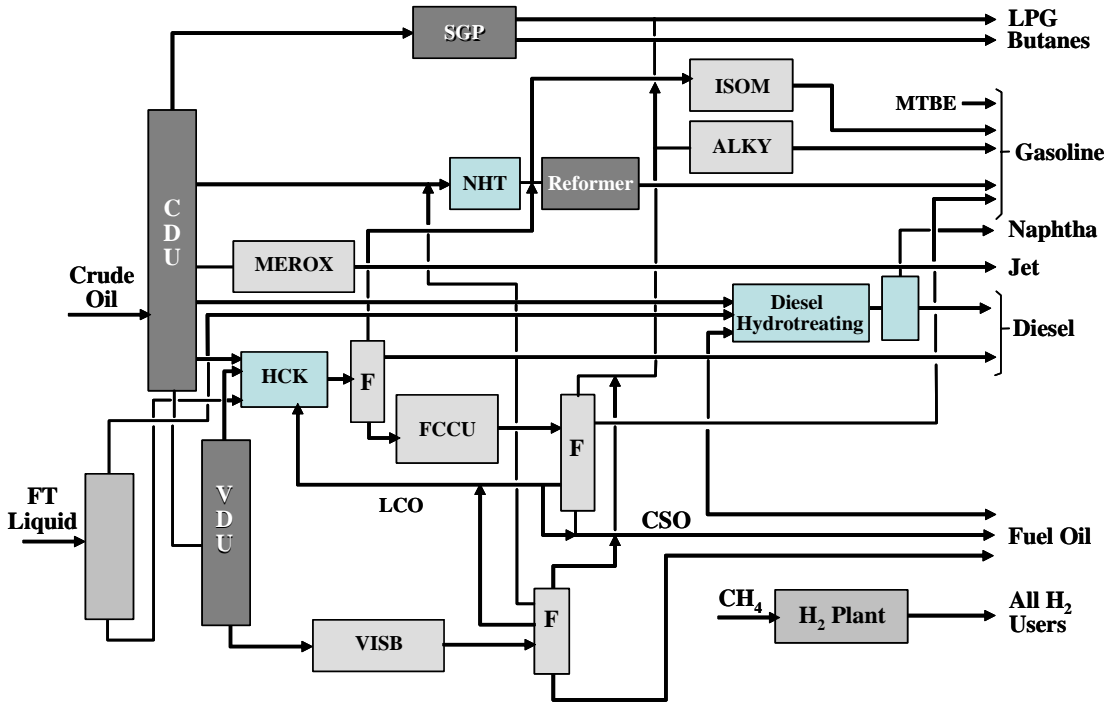

Figure 29. Typical hydrocracking refinery processing crude FT liquids.

Table 33. Value of crude FT liquids to refiners.

\begin{tabular}{|l|c|c|c|c|}
\hline & $\begin{array}{c}\text { Starting } \\
\text { wt\% }\end{array}$ & $\begin{array}{c}\text { Wt\% after } \\
\text { conversion }\end{array}$ & $\begin{array}{c}\text { Value } \\
\text { \$/ton }\end{array}$ & $\begin{array}{c}\text { Total } \\
\text { Value } \\
\text { \$/ton }\end{array}$ \\
\hline Lt ends & 19 & 3.7 & 320 & 11.8 \\
\hline Naphtha & 21 & 66.4 & 368 & 244.4 \\
\hline Diesel & 60 & & & \\
\hline Wax & & 3.5 & & \\
\hline Water & & -1.4 & 1200 & -16.4 \\
\hline $\mathrm{H}_{2}$ use & & & & -20 \\
\hline $\begin{array}{l}\text { Operating cost and } \\
\text { refinery margin }\end{array}$ & & & & 313 \\
\hline \multicolumn{1}{|c|}{ Total value \$/ton } & & & & \\
\hline
\end{tabular}




\section{ACRONYMS AND ABBREVIATIONS.}

Table 34 lists the acronyms and abbreviations used elsewhere in this report.

Table 34. Acronyms and abbreviations.

\begin{tabular}{|c|c|}
\hline $\begin{array}{l}\text { Acronym or } \\
\text { Abbreviation }\end{array}$ & Definition \\
\hline ABT & Average bed temperature \\
\hline APR & Aqueous phase reforming \\
\hline bbl & Barrel(s) \\
\hline bpd & Barrels per day \\
\hline bpsd & Barrels per stream day \\
\hline $\mathrm{Br} \mathrm{No}$ & Bromine Number \\
\hline COP & Cost of production \\
\hline CSO & Clarified Slurry Oil \\
\hline $\mathrm{DeCO} 2$ & Decarboxylation \\
\hline DHT & Distillate hydrotreater \\
\hline EEC & Estimated erected cost \\
\hline EOR & End of run \\
\hline FAME & Fatty acid methyl esters \\
\hline FCC & Fluid catalytic crackers \\
\hline FFA & Free fatty acid(s) \\
\hline FT & Fischer-Tropsch \\
\hline GJ & Gigajoule $=1.055 \mathrm{MMBtu}$ \\
\hline $\mathrm{HC}$ & Hydrocarbon(s) \\
\hline HCK & Hydrocracking \\
\hline HDM & Hydrodemetallization \\
\hline HDO & hydrodeoxygenation \\
\hline HDS & Hydrodesulfurization \\
\hline $\mathrm{HP}$ & High pressure \\
\hline HT & Hydrothermal \\
\hline $\mathrm{HT}$ & Hydrotreating \\
\hline LCA & Life-cycle analysis \\
\hline LCO & Light cycle oil \\
\hline LHSV & Liquid hourly space velocity \\
\hline LHV & Lower heating value \\
\hline LPG & Liquified petroleum gas \\
\hline $\mathrm{IV} \%$ & Liquid volume \% \\
\hline MCFD & Million cubic feet per day \\
\hline mf, m.f. & Moisture-free \\
\hline
\end{tabular}




\begin{tabular}{|l|l|}
\hline MMBtu & Million Btu \\
\hline MTBE & Methyl tertiary butyl ether \\
\hline NPV & Net present value \\
\hline POP & Proof of principle \\
\hline POX & Partial oxidation \\
\hline PRSV & Peng-Robinson-Stryjek-Vara \\
\hline PSA & Pressure swing adsorption \\
\hline scfb & Standard cubic feet per barrel \\
\hline SMR & Steam methane reforming \\
\hline SOR & Start of run \\
\hline SS & Stainless steel \\
\hline TAN & Total acid number \\
\hline tpd & Tons per day \\
\hline ULSD & Ultra-low sulfur diesel \\
\hline VGO & Vacuum gas oil \\
\hline VHP & Very high pressure \\
\hline WHSV & Weight hourly space velocity \\
\hline WTI & West Texas Intermediate \\
\hline
\end{tabular}




\section{REFERENCES}

${ }^{1}$ DOE/USDA. "Biomass as a Feedstock for a Bioenergy and BioProducts Industry: The Technical Feasibility of a Billion-Ton Annual Supply", April, 2005, pp xii and 3. Joint study by DOE and USDA. Available at: http://www.eere.energy.gov/biomass/pdfs/final_billionton_vision_report2.pdf.

${ }^{2}$ Growing Energy: How Biofuels Can Help End America's Oil Dependence, pg 35. Published by NRDC, December 2004. Available at http://www.bioproducts-bioenergy.gov/pdfs/NRDC-Growing-EnergyFinal.3.pdf.

${ }^{3}$ Lynd, et al. in World Congress on Industrial Biotech and Bioprocessing, Orlando, FL, April 20-22, 2005. (Liquid Transportation Fuels).

${ }^{4}$ Tyson, K. Shaine, “Oil and Fat R\&D”. Presentation by NREL to UOP, July 17, 2003.

${ }^{5}$ Tyson, K. Shaine, Bozeli,J, Wallace,R., Petersen Eugene, Moens,Lue, "Biomass Oil: Analysis Research Needs and Recommendations” NREL/TP-510-34796, June 2004.

${ }^{6}$ Pervin and Gertz, Inc. (Subscription only). www.pervingertz.com.

${ }^{7}$ Larsen, Eric D, et al.. Energy for Sustainable Development, 2000. "Expanding roles for modernized biomass energy” Energy for Sustainable Development, Volume IV, No. 3, October 2000.

${ }^{8}$ DOE/USDA. op. cit., pg 105.

${ }^{9} \mathrm{http}: / /$ www2.barchart.com/comfund/tallow.asp.

${ }^{10}$ Spath, P. L., Dayton, D. C. (2003) Preliminary Screening - Technical and Economic assessment of synthesis Gas to Fuels and Chemicals with Emphasis on the Potential for Biomass-Derived Syngas. NREL/TP-510-34929.

${ }^{11}$ Grange,P, Laureat,E.,Maggi,R, Centeno,A.,Delmon,B, “Hydrotreatment of pyrolysis oil from biomass:reactivity of the various categories of oxgenated compounds and preliminary technico-economic study , Catalysis Today 29 (1996)297-301.

${ }^{12}$ Maier, et al. Chem. Ber. 115, p. 808 - 812 (1982).

${ }^{13}$ Arbokem, U.S. patent \#4,992,605

${ }^{14}$ Canmet/Arbokem U.S. Patent \#4,992,605

${ }^{15}$ Radich, Anthony. Biodiesel Performance, Costs, and Use. Available at http://www.eia.doe.gov/oiaf/analysispaper/biodiesel/.

${ }^{16}$ USDA. USDA Agricultural Baseline Projections to 2012, Staff Report WAOB-2003-1 (Washington, D.C. February 2003). Available at www.ers.usda.gov/publications/waob031/waob20031.pdf. Cited by Energy Information Administration , Office of Integrated Analysis and Forecasting.

${ }^{17}$ National Biodiesel Board. Tax Incentive Fact Sheet. Available to members at: https://www.biodiesel.org/members/membersonly/files/pdf/fedreg/20041022_Tax_Incentive_Fact_Sheet.p df

${ }^{18}$ Aden, A. Memorandum prepared for UOP by NREL: “Biodiesel Information for UOP” January 18 - 19, 2005.

${ }^{19}$ www.uniqema.com/og/lit/hypermersurfactants.pdf.

${ }^{20}$ Samolada MC and Vasolos IA. Catalytic Cracking of Biomass Flash Pyrolysis Liquids” in Developments in Thermochemical Biomass Conversion, in Proceedings of the International Conference on Developments in Thermochemical Biomass Conversion.

${ }^{21}$ Samolada MC and Vasolos IA. Production of Transportation Fuels by Upgrading of Biomass Flash Pyrolysis Liquids via FCC Technology” in Proceedings of the $9^{\text {th }}$ European Bioenergy Conference 24-27 June 1996. Pergamon 1997, pp 1578-1583.

${ }^{22}$ Bormann, Konrad; Tilgner, Hartmut. Influence of rape seed oil triglycerides on the catalytic cracking of petroleum distillate. Erdoel, Erdgas, Kohle (1994), 110(2), 75-7. 


\title{
OPPORTUNITIES FOR BIORENEWABLES IN OIL REFINERIES
}

\author{
APPENDIX: \\ BACKGROUND AND EXPERIMENT SUMMARY
}

\section{Prepared For DOE}

\section{UOP}

25 East Algonquin Road

Des Plaines, Illinois 60017-5017

U.S.A. 
A select set of experiments performed in the project are summarized in Table 1 and Table 2.

Table 1. Experiment summary (Part I).

\begin{tabular}{|c|c|c|c|c|c|c|c|}
\hline Feed & 524 & $\begin{array}{l}529 \\
\text { getable o }\end{array}$ & 531 & $\begin{array}{c}535 \\
\text { HT-82 } \\
\text { ( HT lignin) }\end{array}$ & $\begin{array}{l}537 \\
\text { Pyro } \\
\text { (Dyr }\end{array}$ & $\begin{array}{l}\mathbf{5 3 8} \\
\text { gnin } \\
\text { ve) }\end{array}$ & $\begin{array}{l}540 \\
\text { Pyrolysis Oil }\end{array}$ \\
\hline \multicolumn{8}{|l|}{ Conditions } \\
\hline Temperature & $300-350$ & $300-350$ & $300-350$ & 370 & 350 & 350 & 350 \\
\hline Time at temp hr & 2.1 & 1.88 & 1.7 & 2 & 3 & 4 & 3 \\
\hline Catalyst & AS-250 & HCT-1 & N200 & $\mathrm{HC} 43$ & НСТ & HCT & HCT \\
\hline Cat amt ,g & 25 & 25 & 25 & 25 & 25 & 25 & 25 \\
\hline Feed amt & 75 & 75 & 75 & 75 & 75 & 150 & 75 \\
\hline WHSV & 1.4 & 1.6 & 1.76 & 1.5 & 1 & 1.5 & 1 \\
\hline LHSV & 0.91 & 1.40 & 1.26 & 0.96 & 0.67 & 1.01 & 0.67 \\
\hline Pressure psig & 500 & 500 & 500 & 1500 & 1500 & 1500 & 1500 \\
\hline \multicolumn{8}{|l|}{ Products } \\
\hline Water $\%$ of feed & 2 & 1.7 & 1.15 & 7.5 & 24.1 & 23.8 & 33 \\
\hline $\begin{array}{l}\text { Water from organic } \% \text { of } \\
\text { feed }\end{array}$ & & & & 4.6 & 12.4 & 12.1 & 6.3 \\
\hline Light liquids \% & 4.8 & 0.09 & 0.64 & 30 & 27.7 & 19.8 & 19 \\
\hline Diesel \% & 65.07 & 78.5 & 76.4 & 29.4 & 12.8 & 28.8 & 19.9 \\
\hline \multicolumn{3}{|c|}{$\begin{array}{l}\text { VGO \% (necessary to remove to } \\
\text { reach diesel spec) }\end{array}$} & 3.2 & & & & \\
\hline Total \% liquid product & 69.87 & 78.59 & 80.24 & 59.4 & 40.5 & 48.6 & 38.9 \\
\hline $\begin{array}{l}\text { Gas and lights( by } \\
\text { difference) }\end{array}$ & 28.13 & 19.71 & 18.61 & 33.1 & 35.4 & 27.6 & 28.1 \\
\hline Calculated $\mathrm{CO} 2+\mathrm{CO}$ & 10.9 & 12.7 & 13.4 & 18.4 & 24.0 & 18.6 & 37.1 \\
\hline Lt Hc and loss calc & 17.3 & 7.0 & 5.2 & 14.7 & 11.4 & 9.0 & -9.0 \\
\hline Total & 100 & 100 & 100 & 100 & 100 & 100 & 100 \\
\hline$\%$ triglyceride conversion & 100 & 100 & 100 & & & & \\
\hline$\% \mathrm{O}$ in liquid product & 3.4 & 1.3 & 0.9 & 1.8 & 4.8 & 7.3 & 5.5 \\
\hline$\% O$ in naphtha & & & & 1.3 & 5.9 & 7.2 & 8.6 \\
\hline \%Oxygen in diesel+ & 3.4 & 1.3 & 0.9 & 2.3 & 2.4 & 7.3 & 2.4 \\
\hline \%Oxygen removal & 81.2 & 90.1 & 91.3 & 94.5 & 94 & 90 & 96 \\
\hline$\%$ O to water & 15 & 12.8 & 9.8 & 34.36 & 58.53 & 57.80 & 53.33 \\
\hline$\%$ Organic $\mathrm{O}$ to water & & & & 31.79 & 48.13 & 47.40 & 29.60 \\
\hline$\%$ oxgen to Co and Co2 & 66.2 & 77.3 & 81.5 & 60.14 & 41.47 & 32.20 & 42.67 \\
\hline$\%$ feed to $\mathrm{CO} 2$ (calc) & 10.9 & 12.7 & 13.4 & 18.4 & 24.0 & 18.6 & 37.1 \\
\hline \%organic Oxygen to $\mathrm{Co}+\mathrm{Co} 2$ & & & & 62.7 & 45.9 & 42.6 & 66.4 \\
\hline \%NC15 & 6 & 9 & 8.9 & & & & \\
\hline \%IC15 & 2 & & 1.2 & & & & \\
\hline$\% N C 16$ & 3 & 3 & 4.6 & & & & \\
\hline$\% \mid C 16$ & 2 & 0.5 & 1.4 & & & & \\
\hline \%NC17 & 37 & 55 & 43.6 & & & & \\
\hline$\% \mathrm{iC} 17$ & 1.8 & 2 & 4.1 & & & & \\
\hline \%NC18 & 19.6 & 18.5 & 21.1 & & & & \\
\hline \%iC18 & 2 & 3.5 & 5.33 & & & & \\
\hline Total & 73.4 & 91.5 & 90.23 & & & & \\
\hline Feed \%Oxygen & 10.4 & 10.4 & 10.4 & 19.4 & 36.6 & 36.6 & 57 \\
\hline Feed density & 0.92 & 0.92 & 0.92 & 1.03 & 1.2 & 1.2 & 1.2 \\
\hline Acid number feed & & & & 34 & 168 & 168 & 75 \\
\hline Water in feed & & & & 2.9 & 11.7 & 11.7 & 26.7 \\
\hline Feed IBP & & & & 21 & & & \\
\hline Feed $10 \%$ & & & & 126.6 & & & \\
\hline Feed $30 \%$ & & & & 225.4 & & & \\
\hline Feed $50 \%$ & & & & 323 & & & \\
\hline Feed $70 \%$ & & & & 413 & & & \\
\hline Feed $90 \%$ & & & & 529 & & & \\
\hline Feed EP & & & & 607 & & & \\
\hline
\end{tabular}


Table 2. Experiment summary (Part II).

\begin{tabular}{|c|c|c|c|c|c|c|c|}
\hline Feed & 524 & $\begin{array}{c}529 \\
\text { vegetable oi }\end{array}$ & 531 & $\begin{array}{c}535 \\
\text { HT-82 } \\
\text { ( HT lignin) }\end{array}$ & $\begin{array}{l}537 \\
\text { Pyrc } \\
\text { (Dy }\end{array}$ & $\begin{array}{l}\mathbf{5 3 8} \\
\text { ynin } \\
\text { ve) }\end{array}$ & $\begin{array}{c}540 \\
\text { Pyrolysis Oil }\end{array}$ \\
\hline \multicolumn{8}{|l|}{ Acid number product } \\
\hline Acid number trap HC & & & & & 15.1 & 24.11 & 43 \\
\hline Acid number diesel & & & & & & 0 & \\
\hline Naphtha density & & & & 0.81 & & & \\
\hline \multicolumn{8}{|l|}{ Diesel density } \\
\hline \multicolumn{8}{|l|}{ Distillations } \\
\hline Product IBP C & & & & -8 & & & \\
\hline Product wt $10 \%$ & & & & 105 & & & \\
\hline Product 30\% & & & & 157 & & & \\
\hline Product 50\% & & & & 199.5 & & & \\
\hline Product $70 \%$ & & & & 246.5 & & & \\
\hline Product $90 \%$ & & & & 332 & & & \\
\hline Product EP & & & & 592 & & & \\
\hline$\% \mathrm{~m}$ TOC in water & & & & & 2.4 & 4.1 & 3.2 \\
\hline naphtha fischer water & & & & 946ppm & & & \\
\hline Naphtha IBPC & & & & -8 & 20 & -10 & 25 \\
\hline $10 \%$ & & & & 71 & 80 & 22 & 86 \\
\hline $30 \%$ & & & & 105 & 133 & 105 & 147 \\
\hline $50 \%$ & & & & 143 & 173 & 109 & 195 \\
\hline $70 \%$ & & & & 181 & 216 & 138 & 243 \\
\hline $90 \%$ & & & & 226 & 277 & 201 & 310 \\
\hline EP & & & & 321 & 459 & 312 & 422 \\
\hline Naptha \%C & & & & 86.1 & 82.7 & 78.4 & 78.6 \\
\hline Naptha \%H & & & & 12.6 & 11.4 & 10.1 & 11 \\
\hline Naphtha \%O by dif & & & & 1.3 & 5.9 & 11.5 & 10.4 \\
\hline Diesel_IBP & & & & 50 & 24 & & \\
\hline $10 \%$ & & & & 139 & 267 & & \\
\hline $30 \%$ & & & & 209 & 319 & & \\
\hline $50 \%$ & & & & 256 & 358 & & \\
\hline $70 \%$ & & & & 312 & 413 & & \\
\hline $90 \%$ & & & & 438 & 500 & & \\
\hline EP & & & & 592 & 600 & & \\
\hline Diesel \%C & 82.8 & 84.5 & 84.7 & 87.1 & 87.2 & 83.9 & 87.6 \\
\hline Diesel \%H & 13.7 & 14.2 & 14.4 & 10.3 & 10.4 & 8.8 & 10 \\
\hline Diesel \%O(by dif) & 3.5 & 1.3 & 0.9 & 2.6 & 1 & 7.3 & 2.4 \\
\hline Comment & $\begin{array}{l}\text { - Lots of } \\
\text { cracking } \\
\text { - No gas } \\
\text { samples } \\
\text { - Some } \\
\text { isom. }\end{array}$ & $\begin{array}{l}\text { - Less } \\
\text { cracking } \\
\text { - Some } \\
\text { gas } \\
\text { samples } \\
\text { - Less } \\
\text { isom. }\end{array}$ & $\begin{array}{l}\text { Too much } \\
\text { heavy } \\
\text { ends }\end{array}$ & & & & $\begin{array}{l}\text { some } \\
\text { coking }\end{array}$ \\
\hline
\end{tabular}


We provide here supporting information for the study basis outlined in Section II.2 of the report.

Table 3 lists some of the significant U.S. and international mandates that will drive increased use of biofuels in the next few years.

Table 3. Global mandates for biofuel usage.

\begin{tabular}{|l|c|c|c|c|}
\hline & $\mathbf{2 0 0 5}$ & $\mathbf{2 0 1 0}$ & Type & $\begin{array}{c}\text { 2010 Targets } \\
\text { (bbl/d) }\end{array}$ \\
\hline EU & $2 \%$ biofuels & $5.8 \%$ biofuels & Law & 200,000 \\
\hline U.S. diesel & $\begin{array}{c}\text { No \% but high } \\
\text { subsidies for } \\
\text { biodiesel }\end{array}$ & $2.5 \%$ & Goal & 100,000 \\
\hline U.S. ethanol & $2.2 \%$ of gasoline & $\begin{array}{c}3.5 \% \text { of } \\
\text { gasoline }\end{array}$ & Goal + Law & 325,000 \\
\hline India & & $5-10 \%$ & Goal & $80,000-160,000$ \\
\hline
\end{tabular}


Table 4 lists the base prices of feeds used in the study. Bio-feedstock prices were based upon an average of 2003 - 2004 values reported in the Chemical Marketing reporter.

Table 4. Base prices.

\begin{tabular}{|c|c|c|}
\hline & \$lunit & \$/ton \\
\hline WTI Crude & 40/bbl & 306 \\
\hline Arab Medium & $36.5 / \mathrm{bbl}$ & 237 \\
\hline Reg Gasoline & 49/bbl & 410 \\
\hline Premium gasoline & $52 / \mathrm{bbl}$ & 435 \\
\hline Diesel & $48 / \mathrm{bbl}$ & 343 \\
\hline Residual Oil & $27 / \mathrm{bbl}$ & 173 \\
\hline Methanol & $34 / \mathrm{bbl}$ & 275 \\
\hline Soy Oil without subsidy & $0.25 / \mathrm{lb}(\$ 73 / \mathrm{bbl})$ & 559 \\
\hline Soy Oil with subsidy & $0.06 / \mathrm{lb}(\$ 17 / \mathrm{bbl})$ & 132 \\
\hline Yellow Grease without subsidy & $0.14 / \mathrm{lb}(\$ 41 / \mathrm{bbl})$ & 310 \\
\hline Yellow grease with subsidy & $0.02 / \mathrm{lb}(\$ 6 / \mathrm{bbl})$ & 44 \\
\hline Brown Grease & $0.06 / \mathrm{lb}(\$ 18 / \mathrm{bbl})$ & 132 \\
\hline Pyrolysis Oil & 16/bbl & 83 \\
\hline Glycerol & $0.10 / \mathrm{lb}$ & 220 \\
\hline Methane( Natural Gas) & 6.0/MMBTU & 286 \\
\hline Toluene & $62 / \mathrm{bbl}$ & 450 \\
\hline Ethylene & & 695 \\
\hline Propylene & & 670 \\
\hline Propane & $31 / \mathrm{bbl}$ & 352 \\
\hline $\mathrm{H} 2$ & 3.1/MSCF & 1200 \\
\hline Benzene & & 700 \\
\hline Xylene & & 575 \\
\hline Crude tall oil & & 100 \\
\hline
\end{tabular}


Subsidies were calculated based on the subsidies for biodiesel shown in Table $5 .{ }^{1}$

Table 5. Biodiesel subsidies (feedstock prices from crop year 2003/04 projections).

\begin{tabular}{|l|c|c|c|c|c|}
\hline Feedstock & $\begin{array}{c}\text { Feedstock } \\
\text { Price,\$/lb }\end{array}$ & $\begin{array}{c}\text { Total } \\
\text { Production } \\
\text { Cost, } \\
\text { \$lgal B100 } \\
\text { no incentives }\end{array}$ & $\begin{array}{c}\text { Estimatedccc } \\
\text { Incentive }\end{array}$ & $\begin{array}{c}\text { Net Biodiesel } \\
\text { Production } \\
\text { Cost, } \\
\text { \$lgal B100 }\end{array}$ & $\begin{array}{c}\text { Net Biodiesel } \\
\text { \$lgal B20 } \\
\text { with tax credit }\end{array}$ \\
\hline Soy & 0.238 & 2.29 & 1.43 & 0.86 & 0.66 \\
\hline Sunflower & 0.262 & 2.49 & 1.57 & 0.91 & 0.71 \\
\hline Corn & 0.263 & 2.49 & 1.58 & 0.92 & 0.72 \\
\hline Peanut & 0.436 & 3.9 & 2.62 & 1.28 & 1.08 \\
\hline Cottonseed & 0.279 & 2.62 & 1.67 & 0.95 & 0.75 \\
\hline Safflower & 0.735 & 6.32 & 4.41 & 1.91 & 1.71 \\
\hline Edible Tallow & 0.164 & 1.69 & 0.98 & 0.71 & 0.61 \\
\hline $\begin{array}{l}\text { Inedible } \\
\text { tallow }\end{array}$ & 0.151 & 1.59 & 0.91 & 0.68 & 0.58 \\
\hline Lard & 0.179 & 1.81 & 1.07 & 0.74 & 0.64 \\
\hline $\begin{array}{l}\text { Choice white } \\
\text { grease }\end{array}$ & 0.129 & 1.41 & 0.77 & 0.64 & 0.54 \\
\hline Yellow grease & 0.104 & 1.21 & 0.62 & 0.58 & 0.48 \\
\hline
\end{tabular}

\footnotetext{
${ }^{1}$ NREL. Presentation on Biodiesel Costs. July, 2003.
} 
Table 6 and Table 7 list the costs of pyrolysis oil and related assumptions.

Table 6. Pyrolysis oil costs.

\begin{tabular}{|c|c|c|c|c|c|c|c|}
\hline $\begin{array}{l}\text { Biomass } \\
\text { Federate }\end{array}$ & $\begin{array}{l}\text { Biomass } \\
\text { Feed Cost }\end{array}$ & Pyroly & Oil Prod & iced & Pyrolysis & il Cost & \\
\hline Tonne/day & \$/dry ton & t/day & bbl/day & \$/GJ (LHV) & \$/MMBtu & $\$ / B B L$ & $\$ / B B L$ of $F O E$ \\
\hline 500 & $\$ 30.00$ & 325 & 1705 & $\$ 6.77$ & $\$ 6.42$ & $\$ 21.10$ & $\$ 51.79$ \\
\hline 500 & $\$ 46.00$ & 325 & 1705 & $\$ 8.20$ & $\$ 7.77$ & $\$ 25.53$ & $\$ 62.67$ \\
\hline 2000 & $\$ 30.00$ & 1300 & 6820 & $\$ 5.10$ & $\$ 4.84$ & $\$ 15.89$ & $\$ 39.01$ \\
\hline 2000 & $\$ 46.00$ & 1300 & 6820 & $\$ 6.52$ & $\$ 6.18$ & $\$ 20.32$ & $\$ 49.88$ \\
\hline
\end{tabular}

Table 7. Additional assumptions.

\begin{tabular}{|l|r|l|}
\hline 1 GJ & 1.055 & MMBtu \\
\hline 1 Barrel & 42 & gallons \\
\hline Density of Pyrolysis Oil & 4.55 & $\mathrm{~kg} / \mathrm{gal}$ \\
\hline LHV of Pyrolysis Oil & 16,300 & $\mathrm{~kJ} / \mathrm{kg}$ \\
\hline $\begin{array}{l}\text { LHV of fuel oil } \\
\text { (No. 6 Fuel Oil from Phyllis) }\end{array}$ & 40,009 & $\mathrm{~kJ} / \mathrm{kg}$ \\
\hline
\end{tabular}


The properties of typical biofeedstocks are summarized in Table 8. The low heating value for pyrolysis oil is the result of the high oxygen content. The high alkali metals in vegetable oil, grease and pyrolysis oil are mostly potassium and calcium.

Table 8- Feedstock properties

\begin{tabular}{|l|c|c|c|c|c|}
\hline & Crude & Resid & Pyrolysis Oil & Soy Oil & $\begin{array}{c}\text { Yellow } \\
\text { Grease }\end{array}$ \\
\hline$\% \mathrm{C}$ & $83-86$ & 84.9 & 56.2 & $77 / 6$ & 76.4 \\
\hline$\% \mathrm{H}$ & $11-14$ & 10.6 & 6.6 & 11.7 & 11.6 \\
\hline$\% \mathrm{~S}$ & $0-4(1.8 \mathrm{avg})$ & 4.2 & - & 0.0006 & 0.04 \\
\hline$\% \mathrm{~N}$ & $0-1(0.1 \mathrm{avg})$ & .3 & 0.3 & 0.0011 & 0.03 \\
\hline$\% \mathrm{O}$ & - & - & 36.9 & 10.4 & 12.1 \\
\hline $\mathrm{H} / \mathrm{C}$ & $1.8-1.9$ & 1.5 & 1.4 & 1.8 & 1.8 \\
\hline Density & $.86(\mathrm{avg})$ & 1.05 & 1.23 & 0.92 & 0.89 \\
\hline TAN \# & $<1$ & $<1$ & 78 & 2 & 30 \\
\hline $\begin{array}{l}\text { Ppm alkali } \\
\text { metals }\end{array}$ & 60 & 6 & 100 & 100 & 100 \\
\hline $\begin{array}{l}\text { Heating value } \\
\text { BTU/lb }\end{array}$ & 18,000 & 17,500 & 6,560 & 16,000 & 16,000 \\
\hline
\end{tabular}


The relative locations of Biofeedstock sources and refineries in the U.S are shown in Figures 1 and 2.

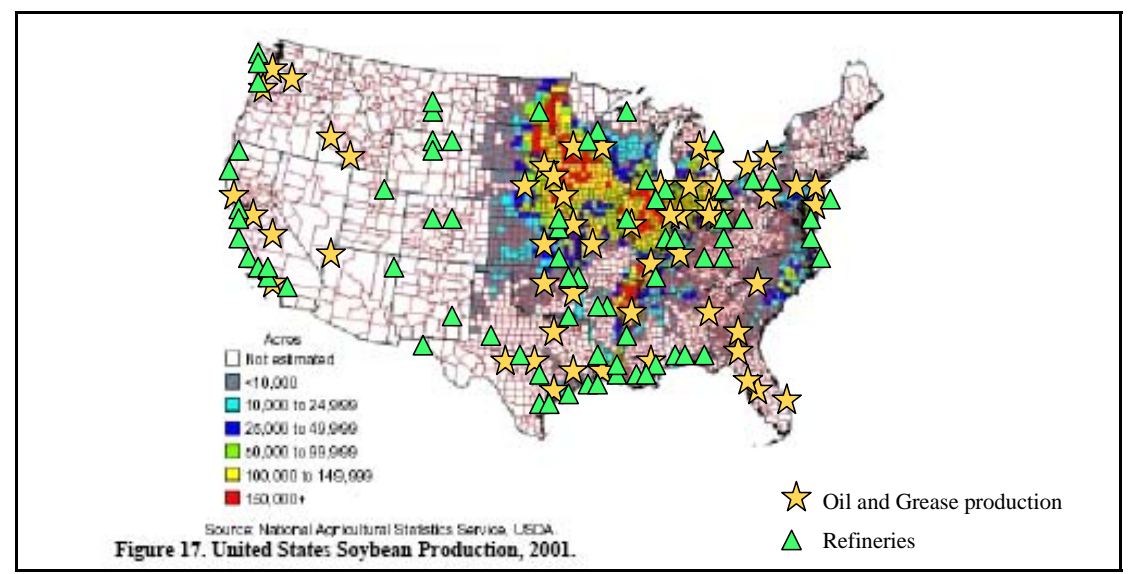

Figure 1. Locations of U.S oil, grease and refineries.

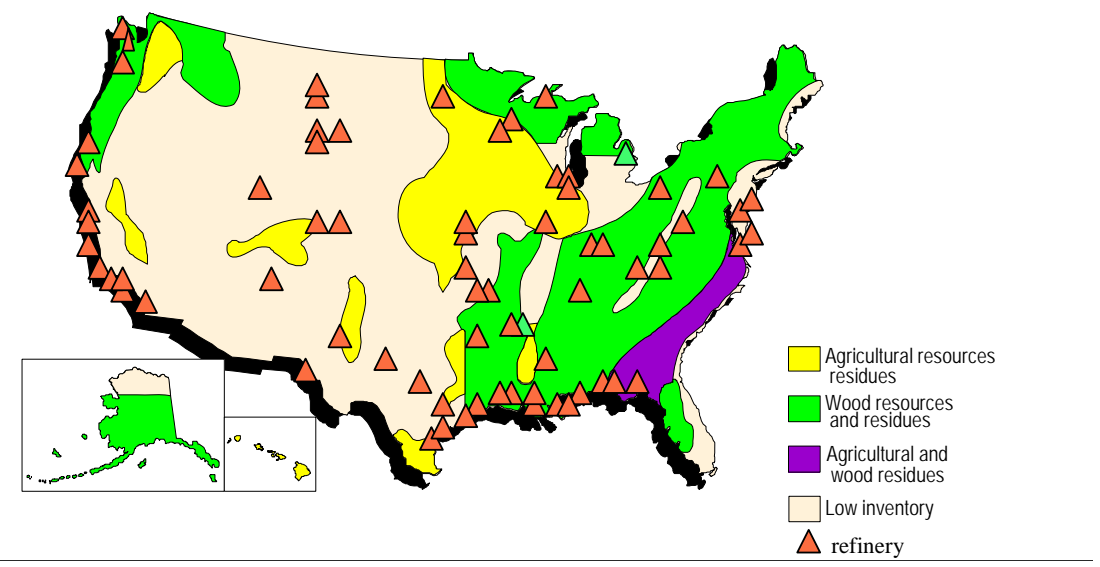

Figure 2. Locations of U.S. biomass and refineries. 